\title{
EFFECT OF CHEMICAL STRUCTURE AND CROSSLINKING DENSITY ON THE THERMO-MECHANICAL PROPERTIES AND TOUGHNESS OF (METH)ACRYLATE SHAPE-MEMORY POLYMER NETWORKS
}

\author{
A Thesis \\ Presented to \\ The Academic Faculty
}

By

David L. Safranski

\begin{abstract}
In Partial Fulfillment
Of the Requirements for the Degree

Master of Science in Materials Science and Engineering
\end{abstract}

Georgia Institute of Technology

May 2008 


\section{EFFECT OF CHEMICAL STRUCTURE AND CROSSLINKING DENSITY ON THE THERMO-MECHANICAL PROPERTIES AND TOUGHNESS OF (METH)ACRYLATE SHAPE-MEMORY POLYMER NETWORKS}

Approved by:

Dr. Kenneth A. Gall, Advisor

School of Materials Science and Engineering Woodruff School of Mechanical Engineering Georgia Institute of Technology

Dr. Karl Jacob

School of Polymer, Textile and Fiber Engineering Georgia Institute of Technology

Dr. David G. Bucknall

School of Polymer, Textile and Fiber Engineering School of Materials Science and Engineering Georgia Institute of Technology

Date Approved: March 24, 2008 
To Matthew Weaver, An exemplary man who taught me how to live and persevere. 


\section{ACKNOWLEDGEMENTS}

I would like to thank my advisor, Ken Gall, for his continued support and wisdom. His countless lessons have helped me to mature professionally. I would also like to thank my other committee members, Dr. Jacob and Dr. Bucknall, for their availability and fruitful discussions. Their insight has proven to be invaluable. I am grateful to Kurt Jacobus and MedShape Solutions for their donation to Tech.

Many lab members have contributed to this volume of research. Scott Kasprzak and Matthew DiPrima have given much guidance in experimental methods and as sources of daily office humor. The tremendous volume of material synthesized would not have been possible without the help of these undergraduate students: Paul Smith, Keith Hearon, Vivas Kaul, and Michelle Hyjek. Chrisopher Yakacki has given sound advice on a plethora of topics. I would like to thank Kathryn Smith for her immense encouragement, positive outlook on life, and time for many thought-provoking discussions.

My utmost thanks go to my family. My parents, Gerald and Judith, have given an infinite amount of support in both my academic and personal life. My sister, Laura, has been a source of advice for all the things in life that truly matter. 


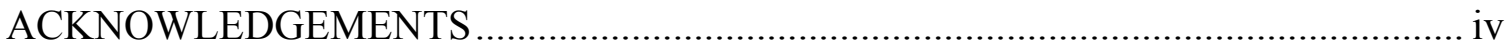

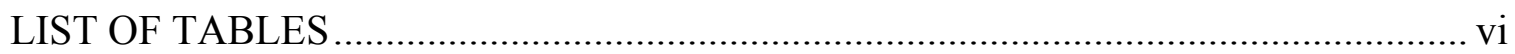

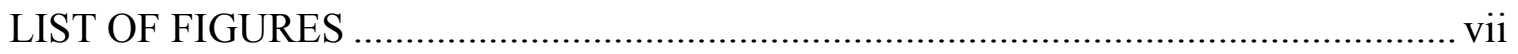

LIST OF SYMBOLS AND ABBREVIATIONS .................................................

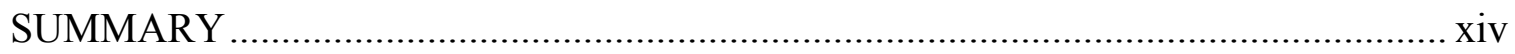

CHAPTER 1: INTRODUCTION ......................................................................... 1

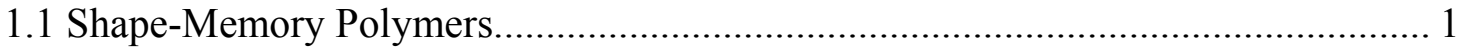

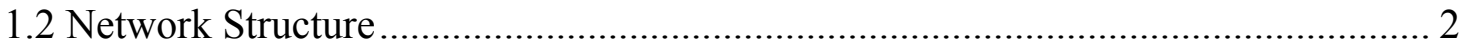

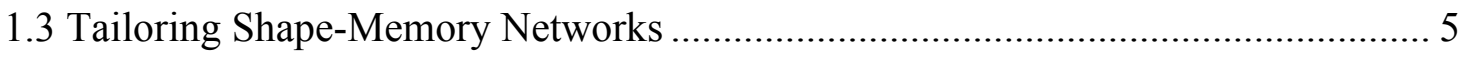

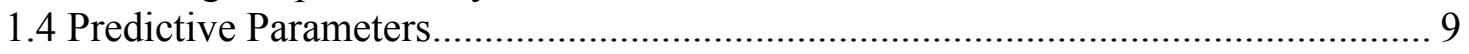

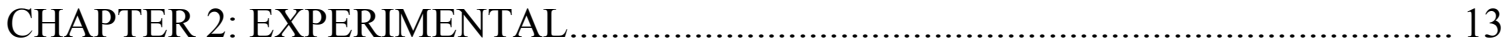

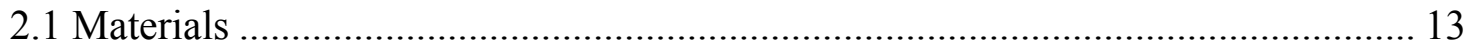

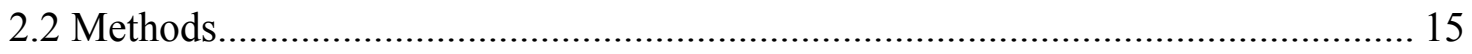

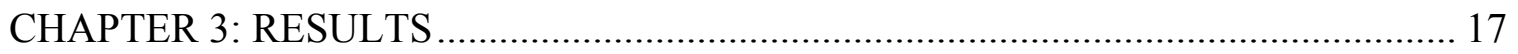

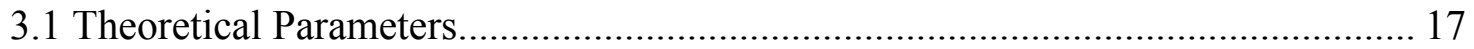

3.2 Thermo-mechanical properties of systematically varied networks ...................... 20

3.3 Thermo-mechanical properties and mechanical behavior of five select networks 24

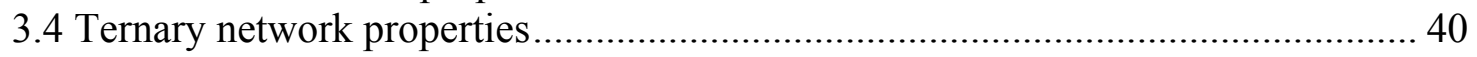

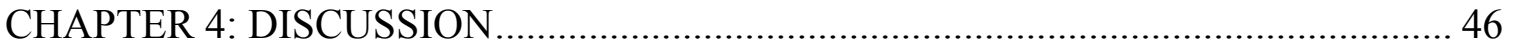

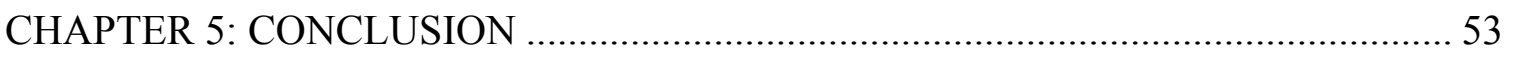

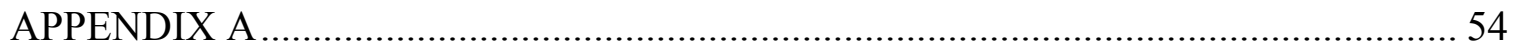

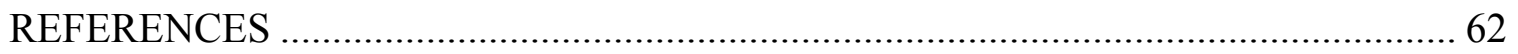




\section{LIST OF TABLES}

Table 1. Mole Percent to Weight Percent Conversions ............................................... 14

Table 2. Additional mol\% to wt $\%$ conversions for EGPEM and BZA ........................... 14

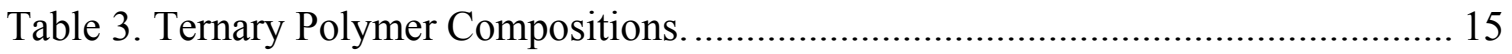

Table 4. Theoretical Characteristic Ratios for Mono-functional (meth)acrylates............ 17

Table 5. Group Contributions of Molar Stiffness Constant ........................................... 18

Table 6. Group Contribution Data to determine CED................................................. 19

Table 7. Calculated Cohesive Energy Densities of Select Monomers............................ 20

Table 8. Thermo-mechanical Properties of Networks Composed of $10 \mathrm{~mol} \%$ PEGDMA550 and 90 mol\% Mono-functional (meth)acrylate............................. 21

Table 9. Thermomechanical Properties of Networks Composed of $90 \mathrm{~mol} \%$ tBA and 10 mol\% Multi-functional (meth)acrylate............................................................. 22

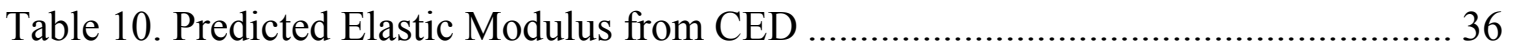

Table A1. Mono-functional Monomers .................................................................. 54

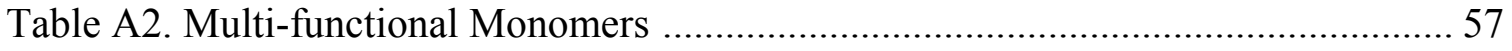

Table A3. Wt $\%$ Conversion of Ternary Networks of PEGDMA550-BMA-BZA .......... 61

Table A4. Wt\% Conversion of Ternary Networks of PEGDMA550-BMA-tBA............. 61

Table A5. Wt $\%$ Conversion of Ternary Networks of PEGDMA550-BMA-EGPEM...... 61 


\section{LIST OF FIGURES}

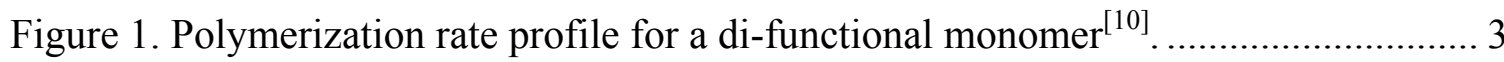

Figure 2. Conversion and Temperature Profiles as a function of Depth and Time for a Multi-functional acrylate network thick film ${ }^{[13]}$.................................................... 4

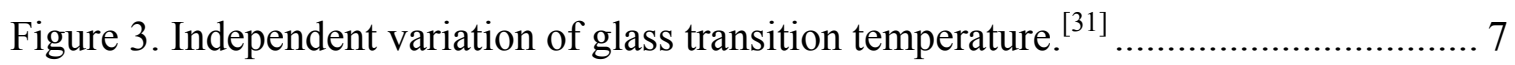

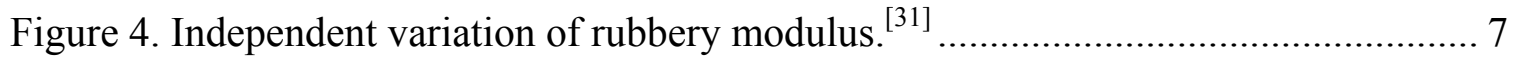

Figure 5. Effect of glass transition temperature on unconstrained recovery ${ }^{[31]}$................ 8

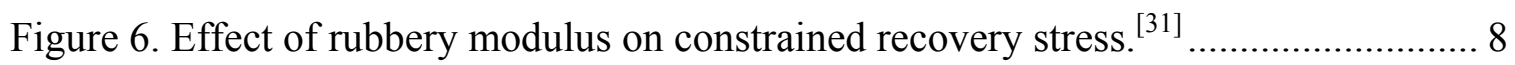

Figure 7. Cohesive energy density as a function of crosslinking density ${ }^{[50]}$................... 11

Figure 8. Spread of tan delta as a function of rubbery modulus of Networks from Table 9.

Figure 9. Failure Strain as a function of Rubbery Modulus of Networks in Table 9. ..... 23

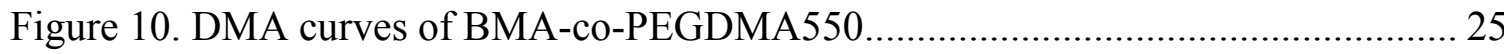

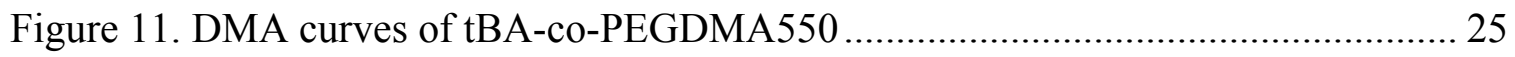

Figure 12. DMA curves of 2EEM-co-PEGDMA550 ……............................................. 26

Figure 13. DMA curves of BZA-co-PEGDMA550 .................................................. 26

Figure 14. DMA curves of EGPEM-co-PEGDMA550 …………………………....... 27

Figure 15. Glass Transition Temperature as a function of Crosslinker concentration for

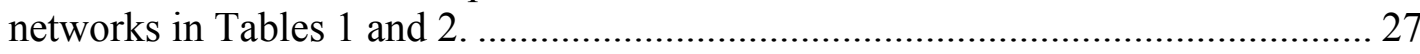

Figure 16. Glass Transiton Temperature as a function of wt $\%$ PEGDMA550-co-BMA 28

Figure 17. Rubbery Modulus as a function of Crosslinker concentration for networks in

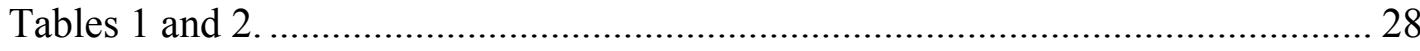

Figure 18. Stress-Strain curves of PEGDMA550-co-BMA ………………………........ 30

Figure 19. Stress-Strain curves of PEGDMA550-co-tBA .............................................. 30 


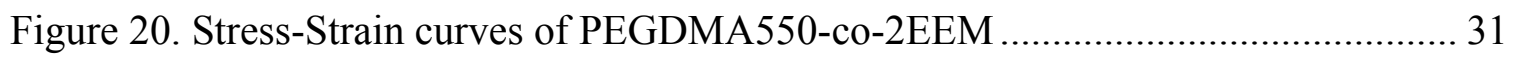

Figure 21. Stress-Strain curves of PEGDMA550-co-BZA......................................... 31

Figure 22. Stress-Strain curves of PEGDMA550-co-EGPEM ................................... 32

Figure 23. Failure strain as a function of mol\% crosslinker ....................................... 32

Figure 24. Failure Strain as a function of Rubbery Modulus for networks in Table 1 and

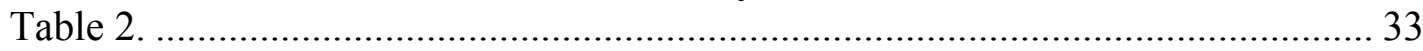

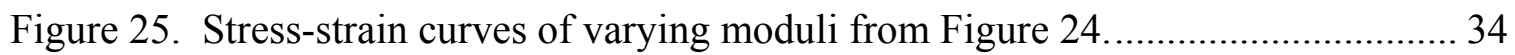

Figure 26. Toughness as a function of Rubbery Modulus for networks in Table 1 and 2. 35

Figure 27. Characteristic Ratio as a function of Toughness ...................................... 35

Figure 28. The relationship between Rubbery Modulus to Elastic Modulus .................. 36

Figure 29. Stress-Strain curves for PEGDMA550-co-BMA at varying temperatures. .... 38

Figure 30. Stress-Strain curves of PEGDMA550-co-tBA at varying temperatures. ........ 38

Figure 31. Failure Strain as a function of T- $\mathrm{T}_{\mathrm{g}}$ for $2.5 \mathrm{~mol} \%$ PEGDMA550-co-BMA or

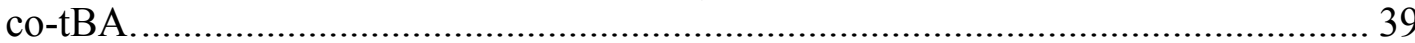

Figure 32. Toughness as a funciton of $\mathrm{T}_{-} \mathrm{T}_{\mathrm{g}}$ for $2.5 \mathrm{~mol} \%$ PEGDMA550-co-BMA or cotBA.

Figure 33. Representative DMA curves of PEGDMA-BMA-BZA............................... 41

Figure 34. Representative DMA curves of PEGDMA-BMA-EGPEM......................... 41

Figure 35. Representative DMA curves of PEGDMA-BMA-tBA ................................. 42

Figure 36. Representative Stress-Strain curves of PEGDMA-BMA-BZA networks...... 42

Figure 37. Representative Stress-Strain curves of PEGDMA-BMA-EGPEM networks. 43

Figure 38. Representative Stress-Strain curves of PEGDMA-BMA-tBA networks....... 43

Figure 39. Failure strain as a function of mol \% BMA-co-3rd monomer. .................... 44

Figure 40. Toughness as a function of mol\% BMA-co-3rd monomer. .......................... 44 
Figure 41. Glass Transition Temperature as a function of mol\% BMA-co-3rd monomer.

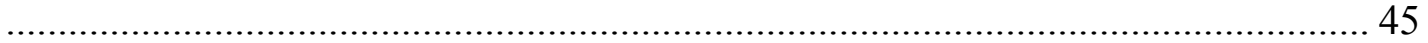

Figure 42. Rubbery Modulus as a function of mol\% BMA-co-3rd monomer................. 45 


\section{LIST OF SYMBOLS AND ABBREVIATIONS}

$\varphi_{\mathrm{o}}$

$\Omega$

$\rho$

$\rho_{\mathrm{c}}$

$\Delta \mathrm{H}_{\text {vap }}$

2EEM

$2 \mathrm{EHM}$

B

$\mathrm{B}_{\mathrm{t}}$

BA

BMA

BPA468

BPA512

BPA540

BPA688

BPA1700

BZA

$\mathrm{C}_{\infty}$

CED

DMA

DPPHA
$2.51 \times 10^{23} \mathrm{~cm}^{3} \mathrm{~mole}^{1 / 2} \mathrm{~g}^{-3 / 2}$

Total number of configurations

Density

Crosslink Density

Molar Enthalpy of Vaporization

2-Ethoxyethyl methacrylate

2-Ethylhexyl methacrylate

Bulk Modulus

Tacticity constant

Butyl acrylate

Benzyl methacrylate

Bisphenol A ethoxylate diacrylate $M_{n} 468$

Bisphenol A ethoxylate diacrylate $M_{n} 512$

Bisphenol A ethoxylate dimethacrylate $M_{n} 540$

Bisphenol A ethoxylate diacrylate $M_{n} 688$

Bisphenol A ethoxylate dimethacrylate $M_{n} 1700$

Benzyl acrylate

Characteristic Ratio

Cohesive Energy Density

Dynamic Mechanical Analysis

Dipentaerythritol penta-hexaacrylate 
DTTA

E

$\mathrm{E}_{\mathrm{coh}}$

$\mathrm{E}_{\mathrm{r}}$

EGPEM

F

G

GPTA

HEXDA

IA

IMA

$\mathrm{k}$

K

$\mathrm{K}^{\prime}$

K'

$\mathrm{K}_{\mathrm{B}}$

$\mathrm{K}_{\mathrm{i}}$

$\mathrm{K}_{\mathrm{x}}$

$<\mathrm{l}_{\mathrm{v}}{ }^{2}>$

$\mathrm{M}_{\mathrm{c}}$

$\mathrm{M}_{\mathrm{n}}$

$\mathrm{M}_{\mathrm{r}}$

$\mathrm{M}_{\mathrm{v}}$
Di(trimethylolpropane)tetraacrylate

Elastic Modulus

Cohesive Energy

Rubbery Modulus

Ethylene glycol phenyl ether methacrylate

Molar attraction constant

Shear Modulus

Glycerol propoxylate triacrylate

1,6-Hexanediol diacrylate

Isodecyl acrylate

Isobornyl methacrylate

Fitted constant

Fitted Constant

Fitted Constant

Fitted Constant

Boltzmann Constant

Molar stiffness constant for group i

Fitted Constant

Mean-square length of a statistical skeletal unit

Molecular weight between crosslinks

Number-average molecular weight

Molecular Weight of Repeat Unit

Average molecular weight per statistical skeletal unit 
MA

MMA

$\mathrm{mol} \%$

$\mathrm{n}_{\mathrm{r}}$

$\mathrm{n}_{\mathrm{v}}$

NGPDA

PEGDMA550

PEGPEA236

PEGPEA280

PEGPEA324

PETA

PPGA

$\mathrm{R}$

S

$\mathrm{T}$

$\mathrm{T}_{\mathrm{g}}$

$\mathrm{T}_{\mathrm{g} \infty}$

tBA

tBMA

TETA428

TETA604

TETA912
Methyl acrylate

Methyl methacrylate Mole Percent

Number of skeletal atoms in a repeat unit Number of real and imaginary bonds in a repeat unit Neopentyl glycol propoxylate diacrylate Poly(ethylene glycol) dimethacrylate $M_{n} 550$

Poly(ethylene glycol) phenyl ether acrylate $M_{n} 236$

Poly(ethylene glycol) phenyl ether acrylate $M_{n} 280$

Poly(ethylene glycol) phenyl ether acrylate $M_{n} 324$

Pentaerythritol triacrylate Poly(propylene glycol) acrylate

Gas Constant

Entropy

Temperature

Glass Transition Temperature

Glass Transition Temperature of fully extended polymer

tert-Butyl acrylate

tert-Butyl methacrylate

Trimethylolpropane ethoxylate triacrylate $M_{n} 428$

Trimethylolpropane ethoxylate triacrylate $M_{n} 604$

Trimethylolpropane ethoxylate triacrylate $M_{n} 912$ 
TPTA V

$\mathrm{W}_{\mathrm{i}}$

$w t \%$
Trimethylolpropane propoxylate triacrylate

Molar volume

Weight percent of polymer $\mathrm{i}$

Weight Percent 


\section{SUMMARY}

The objective of this work is to characterize and understand structure- mechanical property relationships in (meth)acrylate networks. The networks are synthesized from mono-functional (meth)acrylates with systematically varying sidegroup structure and multi-functional crosslinkers with varying mole fraction and functionality. Fundamental trends are established between the network chemical structure, crosslink density, glass transition temperature, rubbery modulus, failure strain, and toughness. The glass transition temperature of the networks ranged from -29 to $112{ }^{\circ} \mathrm{C}$, and the rubbery modulus ranged from 2.8 to $129.5 \mathrm{MPa}$. At low crosslink density $\left(\mathrm{E}_{\mathrm{r}}<10 \mathrm{MPa}\right)$ network chemistry has a profound effect on network toughness. At high crosslink densities $\left(E_{r}>\right.$ $10 \mathrm{MPa}$ ), network chemistry has little influence on material toughness. The characteristic ratio of the mono-functional (meth)acrylates components is unable to predict trends in thermoset toughness as a function of chemical structure, as is accomplished for thermoplastics. The cohesive energy density is a better tool for prediction of network mechanical properties. Due to superior mechanical properties, networks with phenyl ring sidegroups are further investigated to understand the effect of phenyl ring distance on toughness. This work provides a fundamental basis for designing (meth)acrylate shape memory polymer networks with specific failure strain, toughness, glass transition temperature, and rubbery modulus. 


\section{CHAPTER 1}

\section{INTRODUCTION}

\subsection{Shape-Memory Polymers}

Shape-memory polymers have been of practical use since the 1960's, when radiation crosslinked polyethylene was used for heat shrink tubing. More recently, researchers have focused on biomedical applications. Novel cardiac devices have been proposed as actuators for stroke victims and self-deploying stents for treatment of arterial disease $^{[1],[2]}$. Other shape-memory polymers have been used for neuronal probes ${ }^{[3]}$. The shape memory polymer cycle consists of programming and recovery. In programming, the material is heated to an elevated temperature, deformed to a new geometry, and cooled to store the new shape. The recovery process occurs when the material is heated near its transition temperature. This is a one-way shape-memory process. The thermodynamic basis for this process is rooted in the entropy of the system. From the Boltzmann equation, the entropy is determined by the conformation probability, where a highly coiled conformation gives the maximum entropy since that is the most probable state for a polymer chain ${ }^{[4]}$.

$$
\mathrm{S}=\mathrm{k}_{\mathrm{B}} \ln \Omega \quad \text { Equation } 1 .
$$

When above the transition temperature, these crosslinked networks display rubber elasticity, seen in Equation $2^{[5]}$.

$$
\mathrm{G}=\rho \mathrm{RT} / \mathrm{M}_{\mathrm{c}} \quad \text { Equation } 2 .
$$

An applied force or $G$ strains the network until $M_{c}$ is reached, then aligns the chains, while reducing the entropy of the system. The crosslinks behave as anchors points that 
hinder the chains from sliding past each other when under an applied load. Upon removal of the force, the networks springs back to its original shape in order to recover the lost entropy. An appropriate transition temperature must be chosen, typically at the glass transition temperature for the networks, in order for the shape memory process to work properly. The material is in an unfavorable entropic state in its programmed state, and returns to a more favorable state as it is heated above the transition temperature.

While the typical method of activation is direct thermal activation, indirect methods exist. Infrared light can be used to initiate the transition as seen in polyurethane medical devices ${ }^{[1]}$. Activation has also occurred by induction heating via magnetic nanoparticles embedded into the polymer ${ }^{[6]}$. A new method of great promise is activation by light. Distinct network have been formed where one wavelength of light forms covalent crosslinks, while a different wavelength cleaves these bonds ${ }^{[7]}$. While these polymers may vary in chemical composition and method of activation, their ability to change and maintain distinct shapes is pivotal. With such a broad possibility of applications, an equally diverse set of polymers must be formulated.

\subsection{Network Structure}

The structure of (meth)acrylate networks formed through free-radical polymerization has been defined by kinetic models and experimental research ${ }^{[8-12]}$. The network backbones are primarily carbon-carbon bonds formed by free radical polymerization with remaining backbones defined by the crosslinking monomers with finite length. The relationships between the reactivity of the double bond functional group and monomer size, fraction of monomer, conversion, free volume, and initiation have been studied as well ${ }^{[11]}$. It has been shown that there are three regions in the rate of 
polymerization for multi-functional (meth)acrylates, seen in Figure 1. The rate is initially very rapid, but starts to slow. The slower rate is referred to autoacceleration, where the radicals' mobility is reduced, thus lowering the termination rate. Since the termination rate drops, the number of radicals increases, thereby increasing the polymerization rate. Eventually, the polymerization rate obtains a maximum, and starts to decline. This is called autodeceleration, where the crosslinked network restricts the propagation reaction $^{[10]}$.

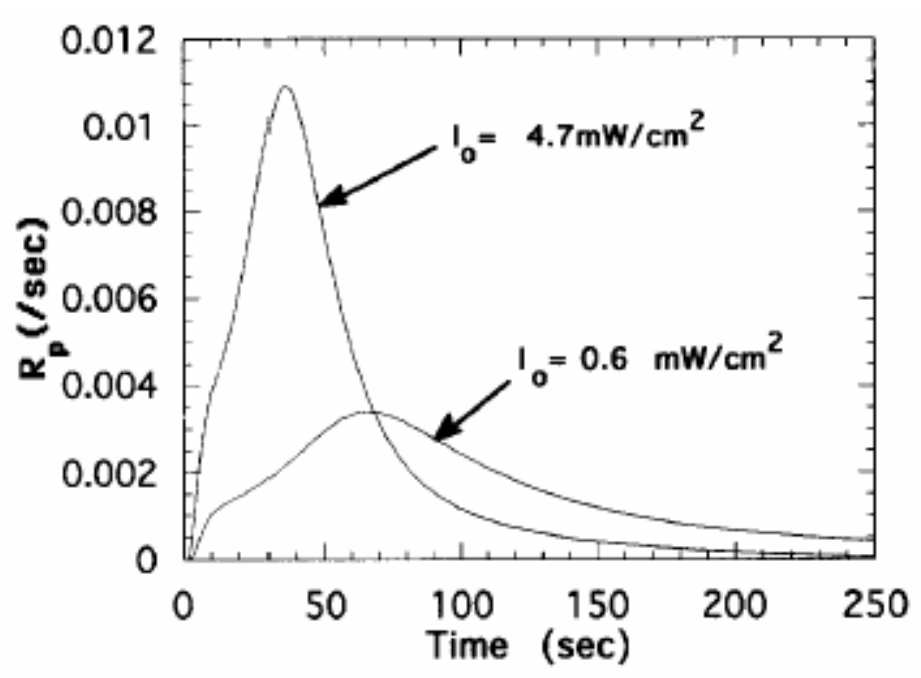

Figure 1. Polymerization rate profile for a di-functional monomer ${ }^{[10]}$.

There are polymerization differences between di-functional monomers and monomers of greater functionality in that di-functional monomers are more reactive due to lower viscosities driven by lower individual molecular weight ${ }^{[12]}$. Also for di-functional monomers, it has been found that the average number of double bonds reacted per monomer was one at maxiumum conversion ${ }^{[10]}$.

Effects of temperature, light intensity, and concentration have been studied in thicker films where heat and mass transfer were taken into account. Due to the thickness 
of the sample, the light intensity decreases into the film, thus a decrease in the polymerization rate. Due to the exothermic reaction and heat from light source, the polymerization reactions occurred faster in the first stage before autoacceleration starts. The larger size samples retained heat, thus allowing for greater conversion approaching unity because of the increased propagation kinetics and molecular mobility as seen in Figure $2^{[13]}$.
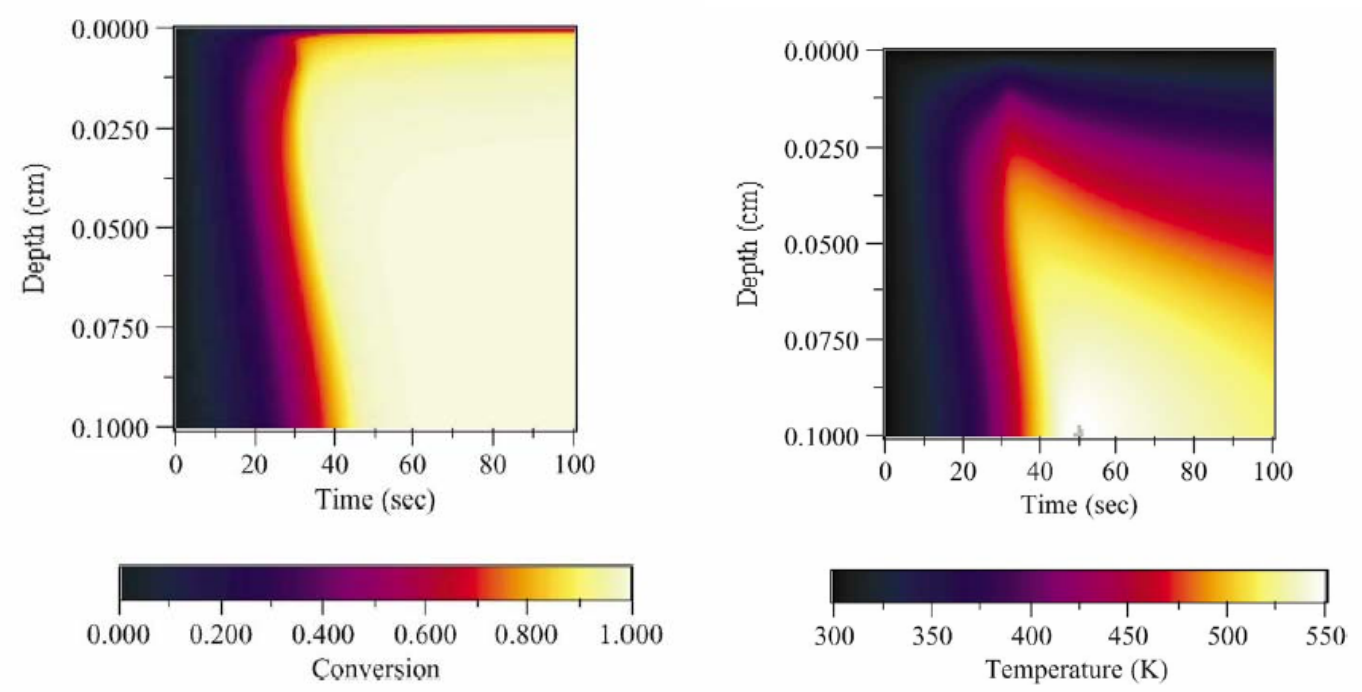

Figure 2. Conversion and Temperature Profiles as a function of Depth and Time for a Multi-functional acrylate network thick film ${ }^{[13]}$.

Lovell and Bowman have studied the effect of kinetic chain length on mutli-functional (meth)acrylate networks. Using a chain transfer agent to decrease the kinetic chain length, the radicals are more mobile and able to terminate quickly. The polymerization rate and thermo-mechanical properties decrease as the kinetic chain length decreases, but the effect diminishes as the crosslinking density increases ${ }^{[14]}$. 
The heterogeneity of these networks needs to be taken into consideration because multi-functional (meth)acrylates can create highly crosslinked regions which trap radicals. These highly crosslinked regions are called 'microgels', but unreacted monomer areas can occur as well, thus leading to a wide distribution of mobilities ${ }^{[15-17]}$. The distribution of mobilities or relaxation times can be revealed in dynamic mechanical behavior. A distribution parameter describing the heterogeneity of these networks was found from frequency domain experiments, where as the parameter approached 0 , the heterogeneity increased. From this, a relationship affecting structural heterogeneity has been observed where increasing the crosslink density increases the heterogeneity of the polymer for blends of mono-functional and multi-functional (meth)acrylates ${ }^{[9]}$. From these studies, the polymerization kinetics have provided the relationships between structure and processing conditions.

\subsection{Tailoring Shape-Memory Networks}

The topic of glass transition temperature for copolymers and networks has been explore ${ }^{[18-27]}$. The prediction of $\mathrm{T}_{\mathrm{g}}$ for a copolymer has come in several forms, where DiMarzio and Gibbs used a simple rule of mixtures seen in Equation 3. Other common equations are Equation 4 by Fox and Equation 5 by Gordon and Taylor.

$$
\begin{array}{ll}
\mathrm{T}_{\mathrm{g}}=\mathrm{w}_{1} \mathrm{~T}_{\mathrm{g} 1}+\mathrm{w}_{2} \mathrm{~T}_{\mathrm{g} 2} & \text { Equation } 3^{[28]} \\
1 / \mathrm{T}_{\mathrm{g}}=\left(\mathrm{w}_{1} / \mathrm{T}_{\mathrm{g} 1}\right)+\left(\mathrm{w}_{2} / \mathrm{T}_{\mathrm{g} 2}\right) & \text { Equation } 4^{[28]} \\
\mathrm{T}_{\mathrm{g}}=\left[\mathrm{w}_{1} \mathrm{~T}_{\mathrm{g} 1}+\mathrm{kw}_{2} \mathrm{~T}_{\mathrm{g} 2}\right] /\left[\mathrm{w}_{1}+\mathrm{kw}_{2}\right] & \text { Equation } 5^{[29]}
\end{array}
$$

Relationships have been developed to take into account the effect of molecular weight on $\mathrm{T}_{\mathrm{g}}$. The classic Fox-Flory relationship seen in Equation 6 has been modified by Fox and Loshaek to account for a broader range of $\mathrm{M}_{\mathrm{n}}$ in Equation 7. 


$$
\begin{array}{ll}
T_{g}=T_{g \infty}-K / M_{n} & \text { Equation } 6^{[30]} \\
T_{g}=T_{g \infty}-K^{\prime} /\left(K^{\prime \prime}+M_{n}\right) & \text { Equation } 7^{[26]}
\end{array}
$$

While these equations are often applied to linear polymers of large molecular weight $\mathrm{M}_{\mathrm{n}} \sim 10^{5}$, the effect of crosslinking also needs to be taken into account. By addition of another parameter to Equation 6, the increase in $T_{g}$ due to crosslinking is taken into account in Equation 8.

$$
\mathrm{T}_{\mathrm{g}}=\mathrm{T}_{\mathrm{g} \infty}-\mathrm{K} / \mathrm{M}_{\mathrm{n}}+\mathrm{K}_{\mathrm{x}} / \rho_{\mathrm{c}} \quad \text { Equation } 8^{[26]}
$$

More recently, the effect of crosslinking on $T_{g}$ has undergone further scrutiny. Equation 8 could not be applied to polyester crosslinks because the constants varied in an opposite way ${ }^{[19]}$. Relationships were formed that took into account the rotational degrees of freedom, a measure of chain flexibility, and the number of repeat units between crosslinks $^{[23]}$. Epoxy resins have proven useful by providing relationships between $T_{g}$, $\mathrm{M}_{\mathrm{w}}$, and crosslinking functionality ${ }^{[22]}$.

The tailor-ability of the thermo-mechanical properties of (meth)acrylate networks as shape memory polymers has been established. The glass transition temperature and rubbery modulus can be varied independently of each other by varying the amount and molecular weight of crosslinker and amount of mono-functional monomer seen in Figure 3 and 4 , respectively. The $T_{g}$ primarily controls the free strain recovery time and $E_{r}$ primarily controls the constrained recovery force. Despite what the rubbery modulus may be, the polymer will not fully recover unless the environmental temperature is close to the glass transition temperature as seen in Figure 5. The recovery force is approximately one third of the rubbery modulus of the network as seen in Figure 6, thus allowing for further tailoring of mechanical properties ${ }^{[31]}$. Also, the effect of crosslinker concentration on $E_{r}$ 
has been determined in (meth)acrylate networks, where increasing the amount of crosslinker increases the $\mathrm{E}_{\mathrm{r}}^{[32]}$. These qualities allow for the wide variety of applications mentioned previously.

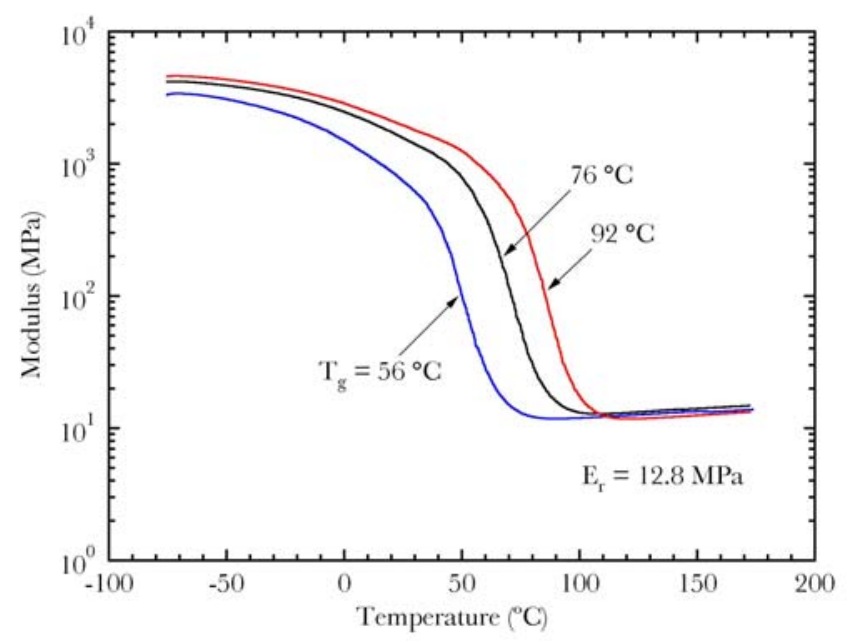

Figure 3. Independent variation of glass transition temperature. ${ }^{[31]}$

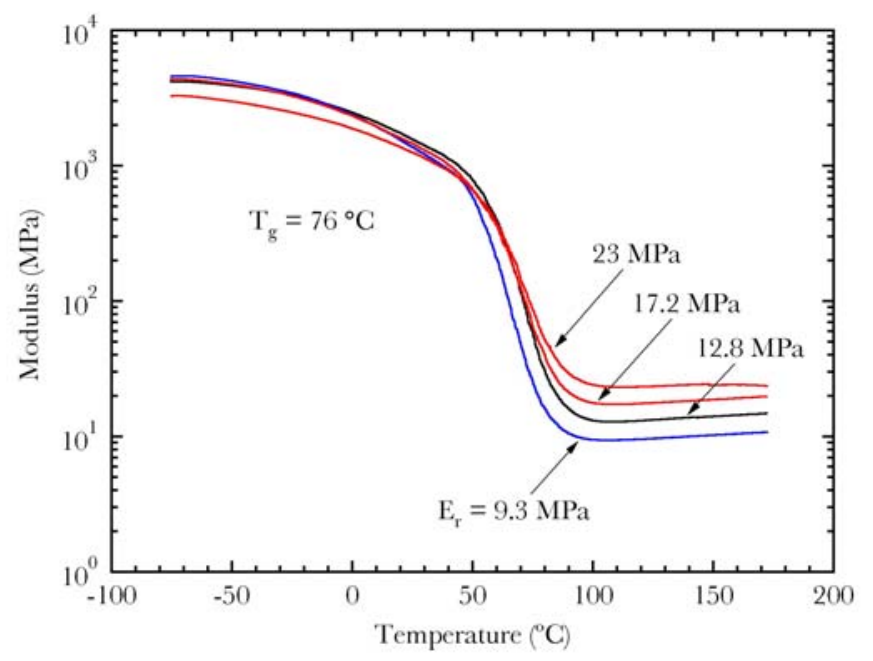

Figure 4. Independent variation of rubbery modulus. ${ }^{[31]}$ 


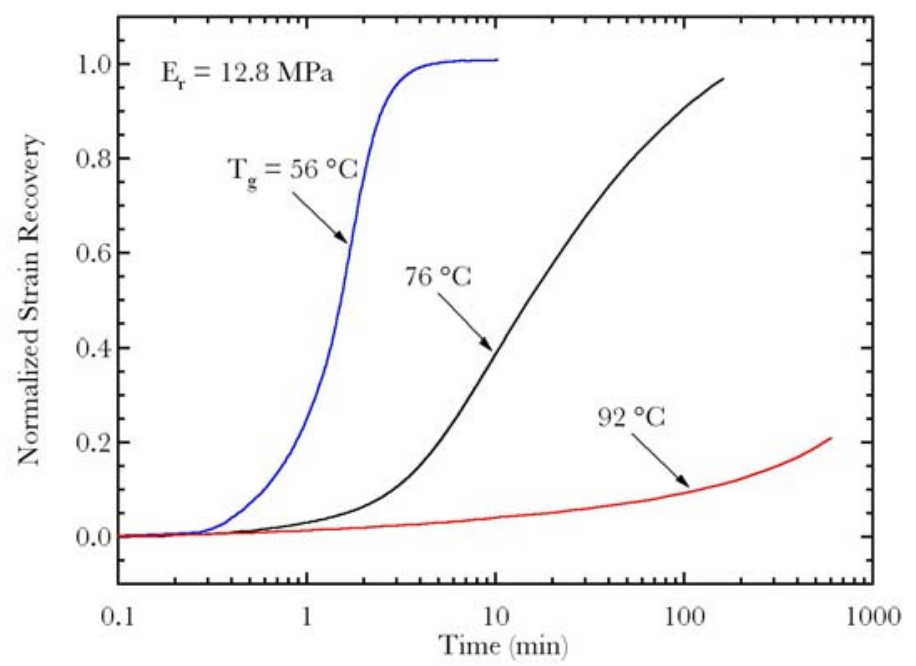

Figure 5. Effect of glass transition temperature on unconstrained recovery. ${ }^{[31]}$

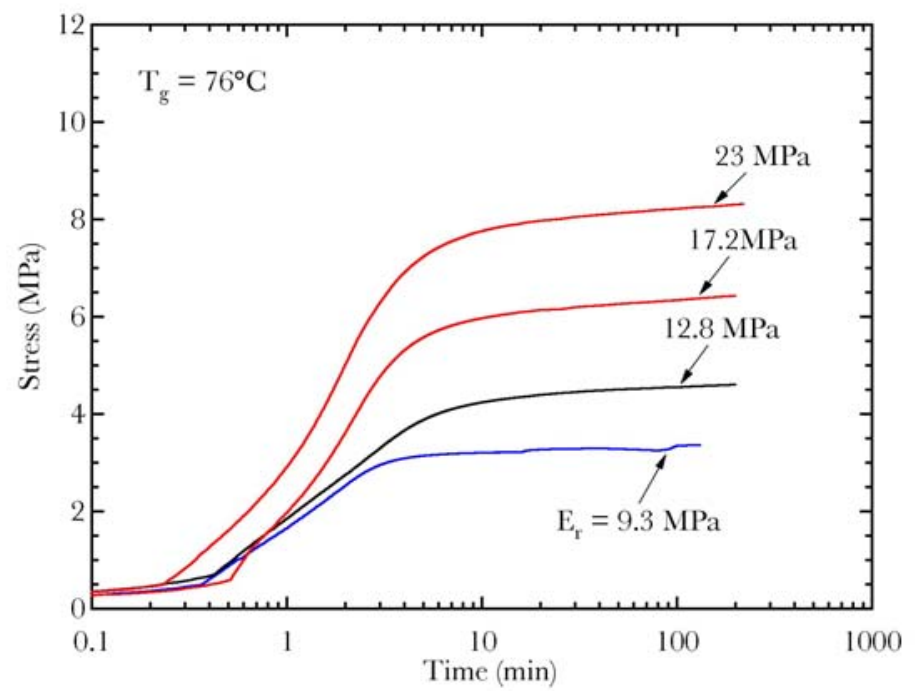

Figure 6. Effect of rubbery modulus on constrained recovery stress. ${ }^{[31]}$

Yet, the total shape change (strain) possible in these systems has not been fully explored. It is known that if heated above the composition's $\mathrm{T}_{\mathrm{g}}$, (meth)acrylate networks will fully recover strains up to their failure strain due to the chemical crosslinking ${ }^{[33]}$. Many thermosets have a strain recovery ratio of $100 \%$, but this does not often occur in thermoplastics. Thus, the failure strain of these systems is a property of significant importance. It has been found that as the crosslink density increases, the ultimate strength 
increases and the failure strain decreases. A region of insensitivity to failure strain was found at high crosslink densities for an acrylate system, where the failure mechanisms differed in regions of low and high crosslink densities ${ }^{[34]}$. After accounting for crosslinking effectiveness through rubbery modulus, the choice of crosslinker does not drastically change the failure strain in networks formed from mono-functional and difunctional (meth)acrylates ${ }^{[35]}$. In summary, although failure strain and rubbery modulus will be naturally traded off in a network as a function of changing crosslink density, the role of network chemistry on toughness (large strain capacity at equivalent rubbery modulus) in (meth)acrylates is relatively unexplored.

\subsection{Predictive Parameters}

The large strain capacity and toughness of polymers has been studied extensively in thermoplastic materials. For example, the characteristic ratio, first suggested by Flory ${ }^{[36]}$, describes the ability of a polymer chain to coil. A series of studies has described the theoretical prediction of $\mathrm{C}_{\infty}$ based upon chemical structure and trends between $\mathrm{C}_{\infty}$ and mechanical properties ${ }^{[37-40]} \cdot C_{\infty}$ is calculated by using group contributions from the intrinsic viscosity of the polymer, which falls within $7 \%$ of the experimental outcomes. $\mathrm{C}_{\infty}$ can be used to define the brittle-ductile transition temperature in many thermoplastics, where polymers with $\mathrm{C}_{\infty}$ values less than 7.5 typically fail by yielding, and polymers with $\mathrm{C}_{\infty}$ values above 7.5 fail by crazing. When $\mathrm{C}_{\infty}=1$, the polymer has a random walk structure, and ideal tetrahedral skeletal bonds along the backbone chain have a $\mathrm{C}_{\infty}=2$. Thus, as the $\mathrm{C}_{\infty}$ of the polymer approaches 2 , the polymer becomes intrinsically more ductile, such as polycarbonate, which has $\mathrm{C}_{\infty}=2.4$. The lowest (meth)acrylate is methyl acrylate at 7.5 , which falls on the border of yielding and crazing for a thermoplastic 
material. The craze-yield behavior is determined by the ratio of craze strength to yield strength. If the craze strength is higher, then the polymer will yield and vice versa. The characteristic ratio does not take into account the effect of crosslinking, and the limit of applying this parameter to networks has yet to be determined.

Another parameter used to predict chemical and mechanical properties of polymers is the cohesive energy density, which characterizes the intermolecular interactions in polymers. Originally, the cohesive energy was defined for liquids as the energy necessary to break all intermolecular bonds per mole, thus related to the molar heat of evaporation by Equation 9. The CED can be defined in one manner by Equation 10. An alternative route to calculating CED is found by using the molar attraction constant seen in Equation 11 via the relationship of Equation 12.

$$
\begin{array}{ll}
\mathrm{E}_{\mathrm{coh}}=\Delta \mathrm{H}_{\text {vap }}-\mathrm{RT} & \text { Equation } 9^{[41]} \\
\mathrm{CED}=\mathrm{E}_{\mathrm{coh}} / \mathrm{V} & \text { Equation } 10^{[41]} \\
\mathrm{CED}=(\mathrm{F} / \mathrm{V})^{2} & \text { Equation 11 } 1^{[42]} \\
\mathrm{E}_{\mathrm{coh}}=\mathrm{F}^{2} / \mathrm{V} & \text { Equation } 12^{[41]}
\end{array}
$$

The CED can be determined by calculation through group contributions, swelling experiments, bulk modulus measurements, and modeling methods ${ }^{[30],[41-47]}$. The preferred methods of determination are the characterization of bulk modulus at low temperatures and high frequencies and calculation by group contributions. Tobolsky proposed the relationship between CED and B seen in Equation 13, but has been further modified to Equation 14 to correlate closer to literature values. This method of measurement is most likely the simplest and most accurate $\mathrm{e}^{[48]}$.

$$
\mathrm{B}=\text { 8.04CED } \quad \text { Equation } 13^{[49]}
$$




$$
\mathrm{B}=11 \mathrm{CED} \quad \text { Equation } 14^{[46]}
$$

The group contribution method relies upon the assumption that $\mathrm{E}_{\mathrm{coh}}$ or $\mathrm{F}$ can be treated as additive molar functions where each are summed over their respective groups. Fedors calculation method provides the molar volumes, but is often found to give higher $\mathrm{E}_{\text {coh }}$ results. The tables available from Van Krevelen are often accurate, but may be skewed if a group is very $\operatorname{polar}^{[30,41,47]}$.

Swelling techniques are not preferred for characterization because of the ambiguity associated with the methodology ${ }^{[48]}$. However, recent studies have shown marked improvement in the methodology and determination for lightly crosslinked networks ${ }^{[44,45]}$. The CED has become a widely used parameter to predict properties such as elastic modulus, surface tension, and yield stress ${ }^{[30,41,49]}$. Recent modeling has shown that as the crosslink density of an epoxy network decreases, the CED increases as seen in Figure $7 .{ }^{[50]}$. Thus as the crosslinking density decreases, the linear monomer backbone structures exert increasing influence. At present, the role of CED between linear (meth)acrylate chains, crosslinked to different degrees, is relatively unexplored.

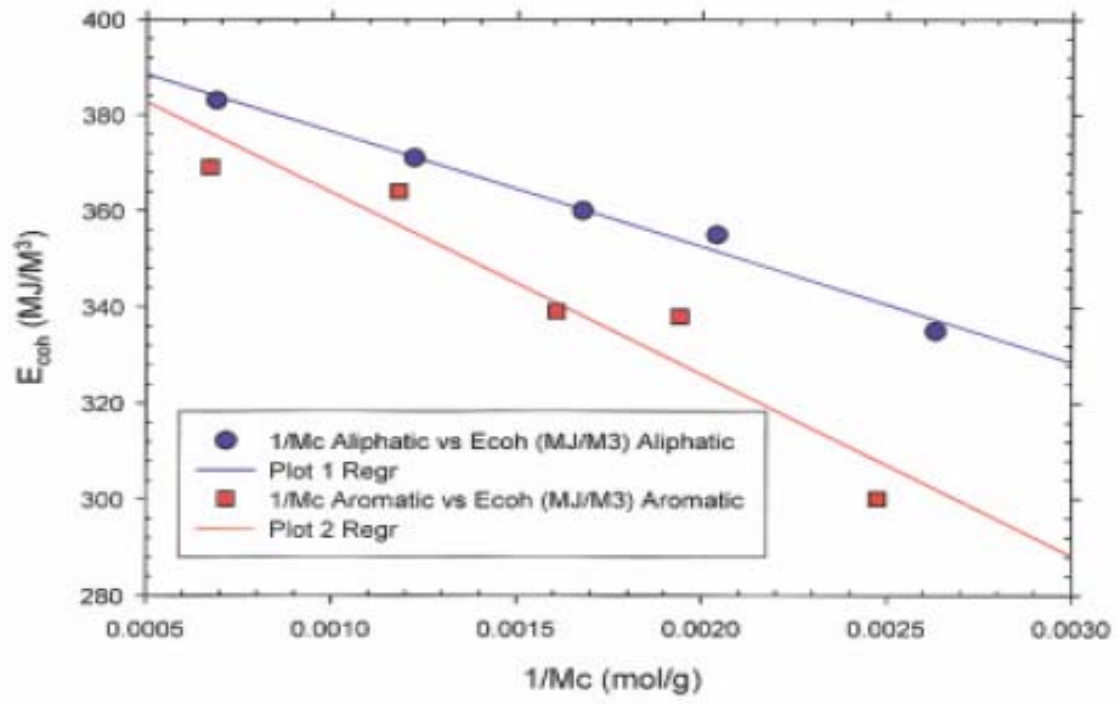

Figure 7 . Cohesive energy density as a function of crosslinking density. ${ }^{[50]}$ 
The purpose of this study will be to determine the effect of chemical structure and crosslinking density on both the thermal and mechanical properties of (meth)acrylate networks. The effect of chemical structure on thermal properties will be revealed through systematic variation in diverse sets of monomers. A series of networks with the same crosslinker and varying mono-functional monomer will be studied in order to assess the influence of the mono-functional monomer on the networks' properties. Emphasis will be placed on failure strain and material toughness due to the importance of these properties in shape memory polymers. The parameters, $\mathrm{C}_{\infty}$ and $\mathrm{CED}$, will be calculated for varying mono-functional monomers to probe possible correlation with the mechanical properties of the networks. 


\section{CHAPTER 2}

\section{EXPERIMENTAL}

\subsection{Materials}

Sixteen mono-functional (meth)acrylates were used as the linear chain builders and sixteeen multi-functional (meth)acrylates were used as the crosslinkers to form the polymer networks. The names, chemical structures, and molecular weights can be found in Table A1 and A2 of Appendix A. A set of networks comprised of $10 \mathrm{~mol} \%$ PEGDMA550 were copolymerized with each mono-functional acrylate from Table A1. A set of networks comprised of $10 \mathrm{~mol} \%$ of each crosslinker from Table A2 were copolymerized with $90 \mathrm{~mol} \%$ tBA. These sets were calculated using the molecular weights given in Tables A1 and A2 and Equation 15.

$$
\operatorname{mol} \%=\left(\mathrm{w}_{1} / \mathrm{M}_{\mathrm{w} 1}\right) /\left[\left(\mathrm{w}_{1} / \mathrm{M}_{\mathrm{w} 1}\right)+\left(\mathrm{w}_{2} / \mathrm{M}_{\mathrm{w} 2}\right)\right] \quad \text { Equation } 15 .
$$

- In addition, equivalent molar amounts of BMA, tBA, and 2EEM were copolymerized in varying degrees with PEGDMA550. The mol\% and corresponding $\mathrm{wt} \%$ ratios of these three sets of materials can be found in Table 1 . The photoinitiator, 2,2-dimethoxy-2-phenylacetophenone, was added to each material in an amount of 0.5 $\mathrm{wt} \%$. Further equivalent molar amounts of EGPEM and BZA were copolymerized with PEGDMA550, which can be found in Table 2. Ternary polymer networks with a fixed $2.5 \mathrm{~mol} \%$ PEGDMA550 are described in Table 3 . The exact wt $\%$ for the ternary polymer networks can be found in Tables A3, A4, and A5 in Appendix A. All materials were purchased from Sigma Aldrich or Polysciences and used as received. 
Table 1. Mole Percent to Weight Percent Conversions

\begin{tabular}{|l|l|l|l|}
\hline \multirow{2}{*}{$\begin{array}{l}\text { Mole Percent } \\
\text { PEGDMA550 }\end{array}$} & \multicolumn{3}{|c|}{ Weight Percent PEGDMA550 } \\
\cline { 2 - 4 } & co-BMA & co-tBA & co-2EEM \\
\hline 0.08 & 0 & 0 & 0 \\
\hline 0.16 & 0.33 & 0.45 & 0.37 \\
\hline 0.32 & 0.65 & 0.9 & 0.71 \\
\hline 0.64 & 1.25 & 1.75 & 1.41 \\
\hline 1.25 & 2.45 & 3.45 & 2.8 \\
\hline 2.5 & 4.85 & 6.5 & 5.45 \\
\hline 5.0 & 9.37 & 12.5 & 10.5 \\
\hline 10.0 & 17.6 & 22.5 & 19.4 \\
\hline 21.0 & 31.4 & 40 & 33.7 \\
\hline 43.0 & 51.8 & 60 & 53.4 \\
\hline 100.0 & 75.7 & 81 & 75.5 \\
\hline
\end{tabular}

Table 2. Additional mol $\%$ to $\mathrm{wt} \%$ conversions for EGPEM and BZA

\begin{tabular}{|r|r|r|}
\hline \multicolumn{1}{|l|}{ Mole Percent PEGDMA550 } & \multicolumn{2}{|c|}{ Weight Percent PEGDMA550 } \\
\cline { 2 - 4 } & co-EGPEM & \multicolumn{2}{c|}{ Co-BZA } \\
\hline 1.25 & 4.15 & 5.2 \\
\hline 2.5 & 8.1 & 10 \\
\hline 5 & 15.3 & 31 \\
\hline 10 & 27.7 & 54 \\
\hline 21 & 57 & 100 \\
\hline 100 & 100 & \\
\hline
\end{tabular}


Table 3. Ternary Polymer Compositions.

\begin{tabular}{|c|c|}
\hline \multicolumn{2}{|c|}{ Fixed Mol Percent of 2.5\% PEGDMA550 for Ternary Polymers } \\
\hline Mol Percent BMA & Mol Percent BZA, EGPEM, or tBA \\
\hline 87.75 & 9.75 \\
\hline 78 & 19.5 \\
\hline 68.25 & 29.25 \\
\hline 58.5 & 39 \\
\hline 48.75 & 48.75 \\
\hline 39 & 58.5 \\
\hline 29.25 & 68.25 \\
\hline 19.5 & 78 \\
\hline 9.75 & 87.75 \\
\hline
\end{tabular}

\subsection{Methods}

The copolymer solutions were injected into a mold composed of two glass slides separated by $1 \mathrm{~mm}$ glass spacers. Glass slides were cleaned with Alconox then coated with Rain-X as a mold release agent. The injected molds were polymerized under a 365 nm UV lamp for an average of 20 minutes, while materials with low concentrations of crosslinker could take over 30 minutes. For each material set in Tables 1, 2, and 3, two batches of each composition were created separately.

Samples for Dynamic Mechanical Analysis were prepared by laser cutting specimens to $20 \mathrm{~mm} \times 5 \mathrm{~mm} \times 1 \mathrm{~mm}$ from bulk material. A TA Q800 was used in tensile loading with strain of $.2 \%$, preload of $0.001 \mathrm{~N}$, force track of $150 \%$, and frequency of 1 Hz. The samples were equilibrated at $-50^{\circ} \mathrm{C}$ for 2 minutes then raised to $200^{\circ} \mathrm{C}$ at a rate of $5^{\circ} \mathrm{C} / \min (\mathrm{n} \geq 2)$. The glass transition temperature was defined as the peak of the $\tan \delta$ curve from the DMA testing ${ }^{[25]}$. The rubbery modulus was determined from the storage 
modulus, when it had reached a steady state above the $T_{g}$ as indicated by the unchanging $\tan \delta$ curve.

Mechanical tensile testing was performed on half-sized ASTM D 638 type IV dog-bone samples, which were laser cut from $1 \mathrm{~mm}$ thick samples. For each material set in Tables 1, 2, 3, and 9, each composition was tested at least twice $(n=2)$, one being from each batch. The testing apparatus was a MTS Insight 2 mechanical tester with $100 \mathrm{~N}$ load cell. A thermal chamber (Thermcraft, Inc., model LBO-14-8-5.25-1X-J8249_1A) was used to isothermally test either at the glass transition temperature of each material or at another specified temperature. Once the chamber reached the set temperature, ten minutes were given to insure equilibrium. A displacement rate of one $\mathrm{mm} / \mathrm{min}$ was used, and the displacement was measured by the crosshead. Toughness was calculated by integrating the area under each stress-strain curve using the trapezoidal rule. 


\section{CHAPTER 3}

\section{RESULTS}

\subsection{Theoretical Parameters}

The characteristic ratios are presented in Table 4 and were calculated using the method according to $\mathrm{Wu}^{[37]}$ by the following equations:

$$
\begin{array}{ll}
\mathrm{C}_{\infty}=\left(1 / \varphi_{\mathrm{o}}\right)^{2 / 3}\left[\left(\Sigma \mathrm{K}_{\mathrm{i}}+\mathrm{Bn}_{\mathrm{r}}\right) / \mathrm{M}_{\mathrm{r}}\right]^{4 / 3}\left(\mathrm{M}_{\mathrm{v}} /<\mathrm{l}_{\mathrm{v}}{ }^{2}>\right) & \text { Equation } 16 \\
\mathrm{M}_{\mathrm{v}}=\mathrm{M}_{\mathrm{r}} / \mathrm{n}_{\mathrm{v}} & \text { Equation } 17
\end{array}
$$

Table 4. Theoretical Characteristic Ratios for Mono-functional (meth)acrylates.

\begin{tabular}{|l|l|}
\hline Monofunctional Monomer & $\mathrm{C}_{\infty}$ \\
\hline MA & 7.49 \\
\hline MMA & 8.12 \\
\hline BA & 9.45 \\
\hline tBA & 9.47 \\
\hline tBMA & 10.17 \\
\hline 2EEM & 11.98 \\
\hline IMA & 12.64 \\
\hline 2EHM & 12.89 \\
\hline BZA & 12.97 \\
\hline IA & 13.56 \\
\hline BMA & 13.67 \\
\hline EGPEMA & 16.19 \\
\hline PPGA & 34.63 \\
\hline PEGPEA236 & 47.58 \\
\hline PEGPEA280 & 50.21 \\
\hline PEGPEA324 & 52.97 \\
\hline
\end{tabular}


$\left[\left(\Sigma \mathrm{K}_{\mathrm{i}}+\mathrm{B}_{\mathrm{t}} \mathrm{n}_{\mathrm{r}}\right) / \mathrm{M}_{\mathrm{r}}\right]^{4 / 3}$ takes into account the intrinsic viscosity of the chain, where the numerator sums the molar stiffness of each group. $\mathrm{n}_{\mathrm{r}}$ was taken to be 2 as the number of statistical skeletal units, consequently also equivalent to $n_{v}$ for the case of acrylates. $<1_{v}^{2}>$ was taken to be $2.34 * 10^{-16} \mathrm{~m}$ since carbon-carbon bonds have a length of $0.153 \mathrm{~nm}$. The molar stiffness constants for each group such as acrylic group or phenyl rings are reproduced in Table 5. B takes into account the tacticity of the chain, where for poly(methyl methacrylate) polymerized by free radical polymerization, $\mathrm{B}_{\mathrm{t}} \sim 4.12$. Methyl methacrylate was first calculated to be 8.12 , a difference of 0.02 from $\mathrm{Wu}^{[37]}$.

Table 5. Group Contributions of Molar Stiffness Constant

\begin{tabular}{|l|l|}
\hline Group & $\mathrm{K}_{\mathrm{i}}\left(\mathrm{g}^{1 / 4} \mathrm{~cm}^{3 / 2} \mathrm{~mol}^{-3 / 4}\right)$ \\
\hline$-\mathrm{CH}_{3}$ & 3.55 \\
\hline$-\mathrm{CH}_{2}-$ & 2.35 \\
\hline$>\mathrm{CH}-$ & 1.15 \\
\hline$>\mathrm{C}<$ & 0 \\
\hline Phenyl & 18.25 \\
\hline$-\mathrm{CH}$ & 5 \\
\hline$-\mathrm{O}-$ & 5.1 \\
\hline$-\mathrm{C}(=\mathrm{O}) \mathrm{O}-$ & 6.4 \\
\hline
\end{tabular}

The CED for five mono-functional meth(acrylates) was calculated using the group contribution method outlined by Van Krevelen and Fedors ${ }^{[41,47]}$. Likewise, the molar volume values used were for glassy amorphous polymers were also calculated from each respective source ${ }^{[41,47]}$. The cohesive energy density was calculated from the molar 
attraction values using Equation 11 and the $E_{\text {coh }}$ of Equation 10. Table 6 contains the group contribution data for $\mathrm{V}, \mathrm{F}$, and $\mathrm{E}_{\text {coh. }}$. Table 7 contains the calculated CED values. The CED values calculated using Fedors method were higher than those using Van Krevelen's data, which was expected. Regardless of the method, the monomers with aromatic sidegroups had higher CED values than the monomers with aliphatic side groups. These values are acceptable by comparing to the $\mathrm{E}_{\mathrm{coh}}$ found by Lesser in epoxies $^{[50]}$.

Table 6. Group Contribution Data to determine CED.

\begin{tabular}{|l|l|l|l|l|l|}
\hline Group & $\begin{array}{l}\mathrm{V}_{\mathrm{g}}^{[41]} \\
\left(\mathrm{cm}^{3} / \mathrm{mol}\right)\end{array}$ & $\begin{array}{l}\mathrm{V}^{[47]} \\
\left(\mathrm{cm}^{3} / \mathrm{mol}\right)\end{array}$ & $\left(\mathrm{cal}^{[41]} \mathrm{cm}^{3}\right)^{1 / 2} / \mathrm{mol}$ & $\begin{array}{l}\mathrm{E}_{\mathrm{coh}}{ }^{[41]} \\
(\mathrm{cal} / \mathrm{mol})\end{array}$ & $\begin{array}{l}\mathrm{E}_{\mathrm{coh}}{ }^{[4]} \\
(\mathrm{cal} / \mathrm{mol})\end{array}$ \\
\hline$-\mathrm{CH}_{3}$ & 23.9 & 33.5 & 205.5 & 2300 & 1125 \\
\hline$-\mathrm{CH}_{2-}$ & 15.85 & 16.1 & 137 & 1000 & 1180 \\
\hline$>\mathrm{CH}-$ & 9.85 & -1 & 68.5 & 100 & 820 \\
\hline$>\mathrm{C}<$ & 4.6 & -19.2 & 0 & -1600 & 350 \\
\hline Phenyl & 72.7 & 71.4 & 741.5 & 6800 & 7630 \\
\hline$-\mathrm{O}-$ & 10 & 3.8 & 125 & 1500 & 800 \\
\hline$-\mathrm{C}(=\mathrm{O}) \mathrm{O}-$ & 18.25 & 14.6 & 250 & 3200 & 4950 \\
\hline
\end{tabular}


Table 7. Calculated Cohesive Energy Densities of Select Monomers.

\begin{tabular}{|l|c|c|c|}
\hline \multirow{2}{*}{ Monomer } & \multicolumn{3}{|c|}{ Cohesive Energy Density (MPa) } \\
\cline { 2 - 4 } & $\begin{array}{l}\text { Via F from Van } \\
\text { Krevelen }\end{array}$ & $\begin{array}{l}\text { Via } \mathrm{E}_{\text {coh }} \text { from } \\
\text { Van Krevelen }\end{array}$ & Via $\mathrm{E}_{\text {coh }}$ from Fedors \\
\hline BMA & 396 & 351 & 488 \\
\hline BZA & 424 & 382 & 526 \\
\hline EGPEM & 401 & 359 & 479 \\
\hline 2EEM & 358 & 339 & 394 \\
\hline tBA & 332 & 334 & 375 \\
\hline
\end{tabular}

\subsection{Thermo-mechanical properties of systematically varied networks}

The 16 networks in Table 8 were produced by polymerizing $10 \mathrm{~mol} \%$ of PEGDMA500 and $90 \mathrm{~mol} \%$ of the mono-functional monomers individually. $10 \mathrm{~mol} \%$ crosslinker was chosen because it would insure a measurable rubbery modulus. The $\mathrm{T}_{\mathrm{g}}$ and $\mathrm{E}_{\mathrm{r}}$ measured through DMA and showed no trend relative to each other. The $\mathrm{T}_{\mathrm{g}}$ of the networks ranged from -29 to $112{ }^{\circ} \mathrm{C}$, and the $\mathrm{E}_{\mathrm{r}}$ ranged from 2.75 to $17.5 \mathrm{MPa}$. Generally, the $\mathrm{T}_{\mathrm{g}}$ increased as the pendant length decreased or by the addition of a $\alpha$ methyl group. The 16 networks in Table 9 were produced from $90 \mathrm{~mol} \%$ tBA and 10 mol\% of each crosslinker. The $\mathrm{T}_{\mathrm{g}}$ and the $\mathrm{E}_{\mathrm{r}}$ showed no clear dependence on each other. The $\mathrm{T}_{\mathrm{g}}$ ranged from -2 to $98{ }^{\circ} \mathrm{C}$, and the $\mathrm{E}_{\mathrm{r}}$ ranged from 6.48 to $129.5 \mathrm{MPa}$. As the functionality of the crosslinker increased, the $\mathrm{E}_{\mathrm{r}}$ increased for equivalent mole fraction of crosslinking molecule. The increase in rubbery modulus is driven by the relative increase in mole fraction of crosslinking "bonds" for a crosslinker with higher functionality. The full width at half maximum of the $\tan \delta$ curves of these networks were measured and found to increase as the $\mathrm{E}_{\mathrm{r}}$ increased as seen in Figure 8. 
Table 8. Thermo-mechanical Properties of Networks Composed of $10 \mathrm{~mol} \%$ PEGDMA550 and 90 mol\% Mono-functional (meth)acrylate.

\begin{tabular}{|l|l|l|}
\hline $\begin{array}{l}\text { Mono-functional } \\
\text { (meth)acrylate }\end{array}$ & $\mathrm{T}_{\mathrm{g}}\left({ }^{\circ} \mathrm{C}\right)$ & $\mathrm{E}_{\mathrm{r}}(\mathrm{MPa})$ \\
\hline MMA & 91.3 & 17.5 \\
\hline MA & 23.5 & 11.75 \\
\hline BA & -15 & 7.3 \\
\hline tBA & 40.5 & 10.7 \\
\hline tBMA & 89.5 & 8.9 \\
\hline 2EEM & 19.5 & 11.25 \\
\hline IMA & 112 & 6.45 \\
\hline 2EHM & 20.5 & 7.7 \\
\hline BZA & 23 & 10.51 \\
\hline IA & -23.5 & 6.5 \\
\hline BMA & 68 & 9.4 \\
\hline EGPEMA & 40.5 & 12.75 \\
\hline PPGA & -29 & 2.75 \\
\hline PEGPEA236 & 10.5 & 6.1 \\
\hline PEGPEA280 & -3.5 & 6.05 \\
\hline PEGPEA324 & -9.5 & 4.45 \\
\hline
\end{tabular}

The 16 networks from Table 9 were tensile tested until failure to characterize their large strain mechanical properties including failure strain and toughness. The failure strain of each network is plotted against its corresponding $E_{r}$ from DMA in Figure 9. The failure strain ranged from less than $10 \%$ to over a $100 \%$. The numbers $2,3,4,5$, in the figure are noting the functionality of the crosslinkers. It can be seen that as the $\mathrm{E}_{\mathrm{r}}$ of the network decreases as the failure strain increases by Equation 18. For most crosslinkers, as the functionality of the crosslinker decreases, the failure strain increases. Consistent with 
previous results a significant effect of the crosslinker was not observed aside from that predicted by a change in crosslinking effectiveness measured through rubbery modulus. Failure Strain $=-0.00162+290.704 \mathrm{E}_{\mathrm{r}}^{-0.999486} \quad$ Equation 18

Table 9. Thermomechanical Properties of Networks Composed of $90 \mathrm{~mol} \%$ tBA and 10 mol\% Multi-functional (meth)acrylate.

\begin{tabular}{|l|l|l|l|}
\hline Multi-functional (meth)acrylate & $\mathrm{T}_{\mathrm{g}}\left({ }^{\circ} \mathrm{C}\right)$ & $\mathrm{E}_{\mathrm{r}}(\mathrm{MPa})$ & FWHM $\tan \delta\left({ }^{\circ} \mathrm{C}\right)$ \\
\hline BPA1700 & -2.75 & 7.35 & 27.5 \\
\hline BPA540 & 70.5 & 8.15 & 28.5 \\
\hline BPA688 & 43.5 & 8.25 & 14.5 \\
\hline BPA512 & 64.5 & 9.0 & 10.5 \\
\hline BPA468 & 59.5 & 8.8 & 13.5 \\
\hline NGPDA & 62.5 & 6.48 & 15.5 \\
\hline HEXDA & 68.5 & 10.85 & 15.5 \\
\hline PEGDMA550 & 40.5 & 10.7 & 16 \\
\hline PETA & 98 & 42.5 & 53 \\
\hline TETA428 & 83 & 25 & 18.75 \\
\hline TETA604 & 55 & 16.65 & 14.5 \\
\hline TETA912 & 24.5 & 15.95 & 17.25 \\
\hline TPTA & 58 & 23 & 16.5 \\
\hline GPTA & 69.5 & 15.5 & 16.25 \\
\hline DTTA & 92 & 49.5 & 48 \\
\hline DPPHA & 74 & 129.5 & 75 \\
\hline
\end{tabular}




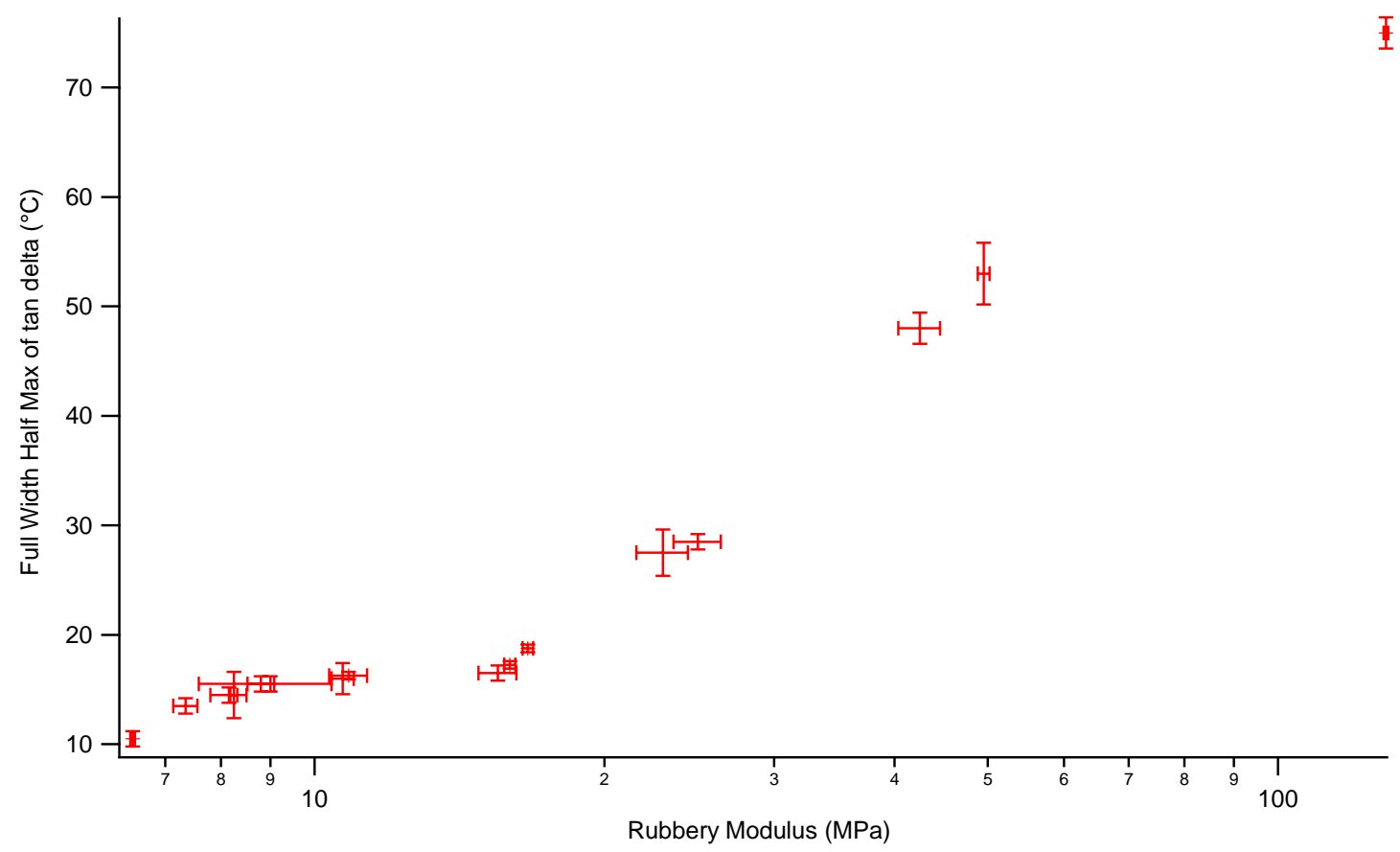

Figure 8. Spread of tan delta as a function of rubbery modulus of Networks from Table 9.

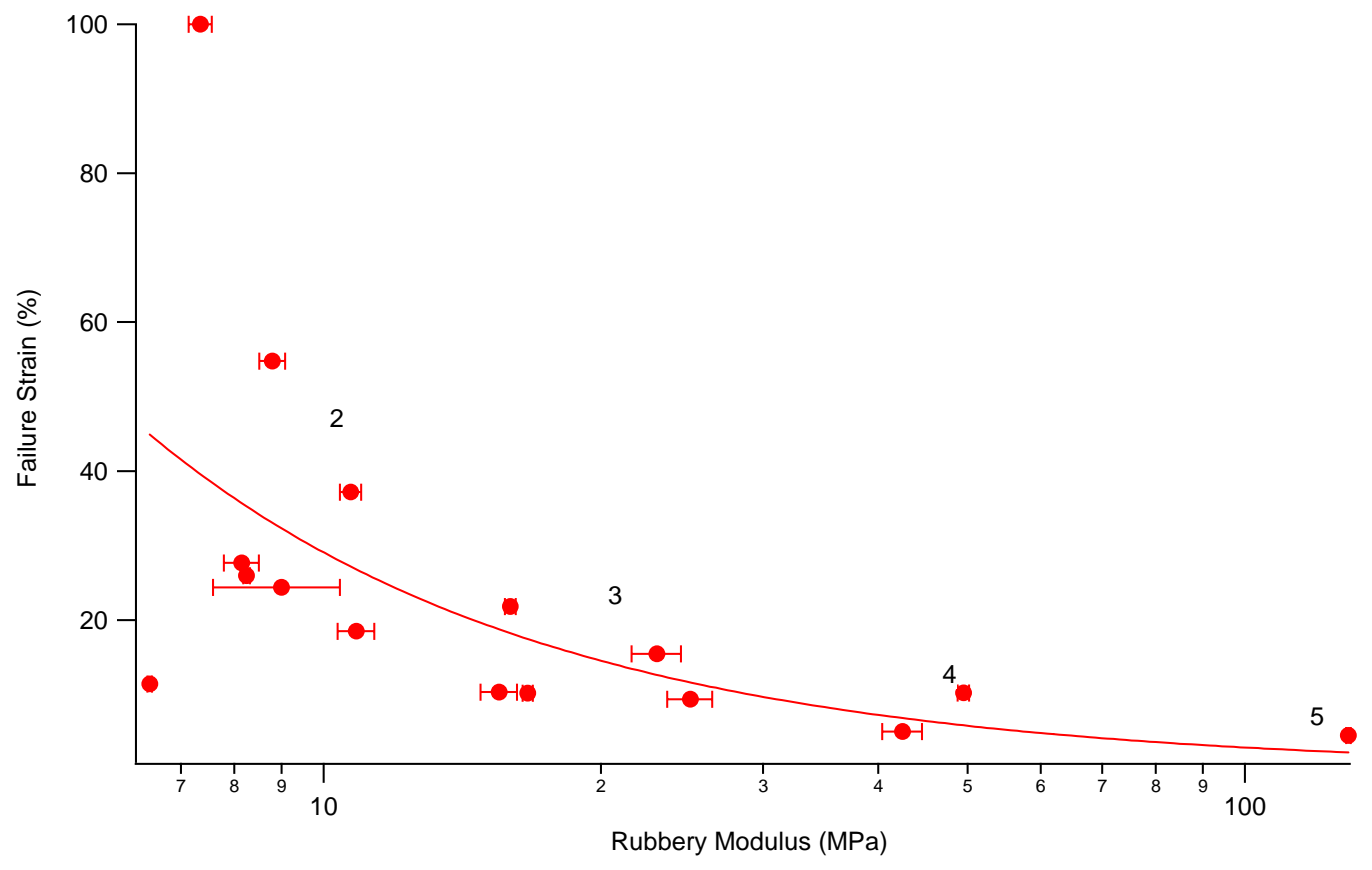

Figure 9. Failure Strain as a function of Rubbery Modulus of Networks in Table 9. 


\subsection{Thermo-mechanical properties and mechanical behavior of five select networks}

DMA curves showing the change in crosslinker concentration with five different mono-functional (meth)acrylates are found in Figures 10, 11, 12, 13, and 14. The five linear (meth)acrylates were selected based on their difference in chemical structure and initial thermo-mechanical testing data. In all of these figures, the curve with the highest $E_{r}$ is the pure PEGDMA550 curve. As the crosslinker concentration was decreased, the $E_{r}$ decreased. As the concentration of crosslinker approaches zero, the $\mathrm{E}_{\mathrm{r}}$ plateau disappears and $E_{\mathrm{r}}$ steadily decreases with increasing temperature. The $T_{\mathrm{g}}$ of each network increased as the concentration of crosslinker decreased. A non-linear trend is observed in Figure 15, which shows the $\mathrm{T}_{\mathrm{g}}$ of each composition from Tables 1 and 2 . If $\mathrm{wt} \%$ is used instead of mol\%, a linear trend between $\mathrm{T}_{\mathrm{g}}$ and composition is found in Figure 16. Equation 3 and Equation 4 were plotted as well, where Equation 3 provided a better fit to the experimental data. Figure 17 displays the trend of the decreasing $\mathrm{E}_{\mathrm{r}}$ as the crosslinker concentration decreased for the five systems. Systems start at the same point since each was originally composed of $100 \%$ PEGDMA550. Systems approach $0 \mathrm{MPa}$ as the crosslinker concentration approaches $0 \%$. 


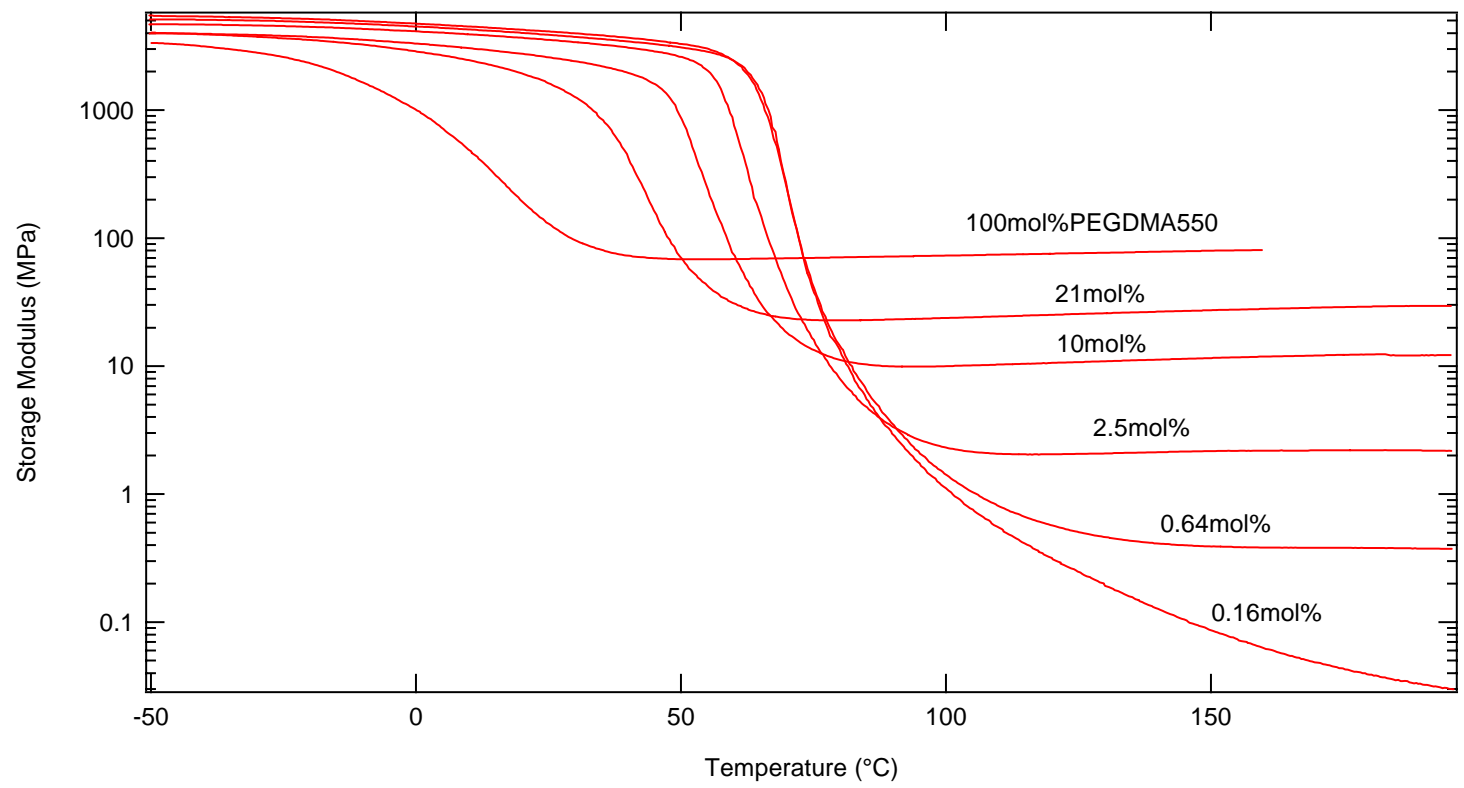

Figure 10. DMA curves of BMA-co-PEGDMA550

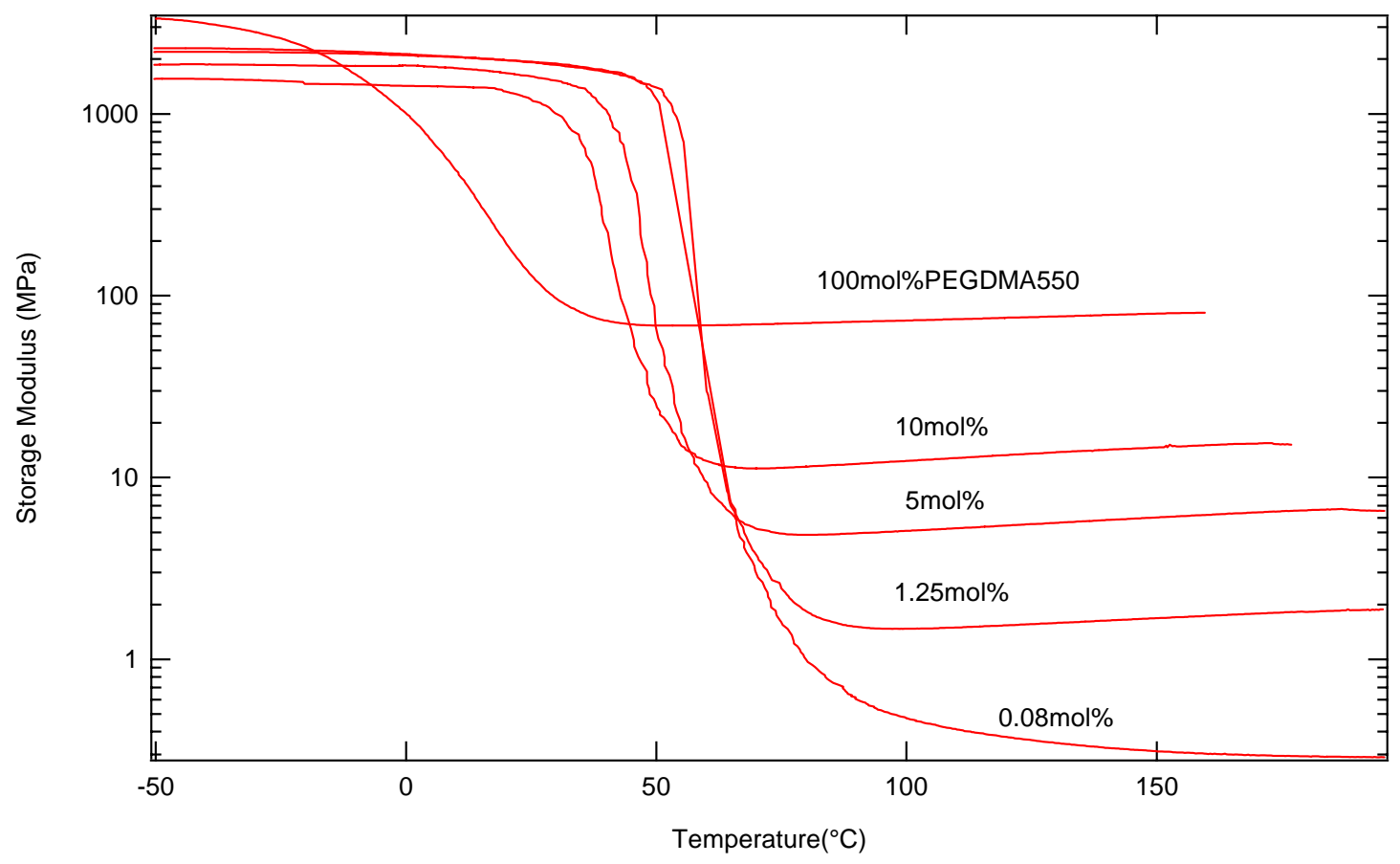

Figure 11. DMA curves of tBA-co-PEGDMA550 


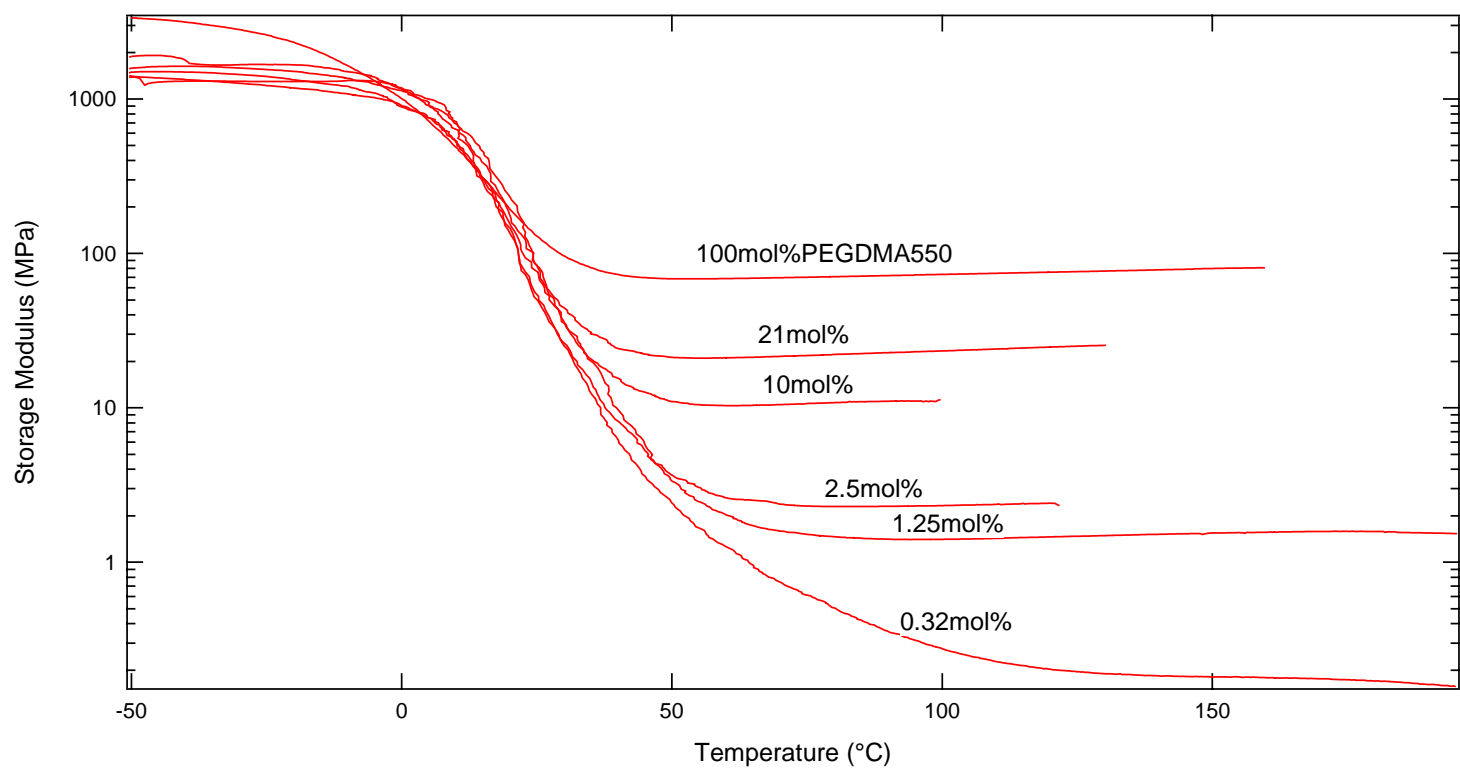

Figure 12. DMA curves of 2EEM-co-PEGDMA550

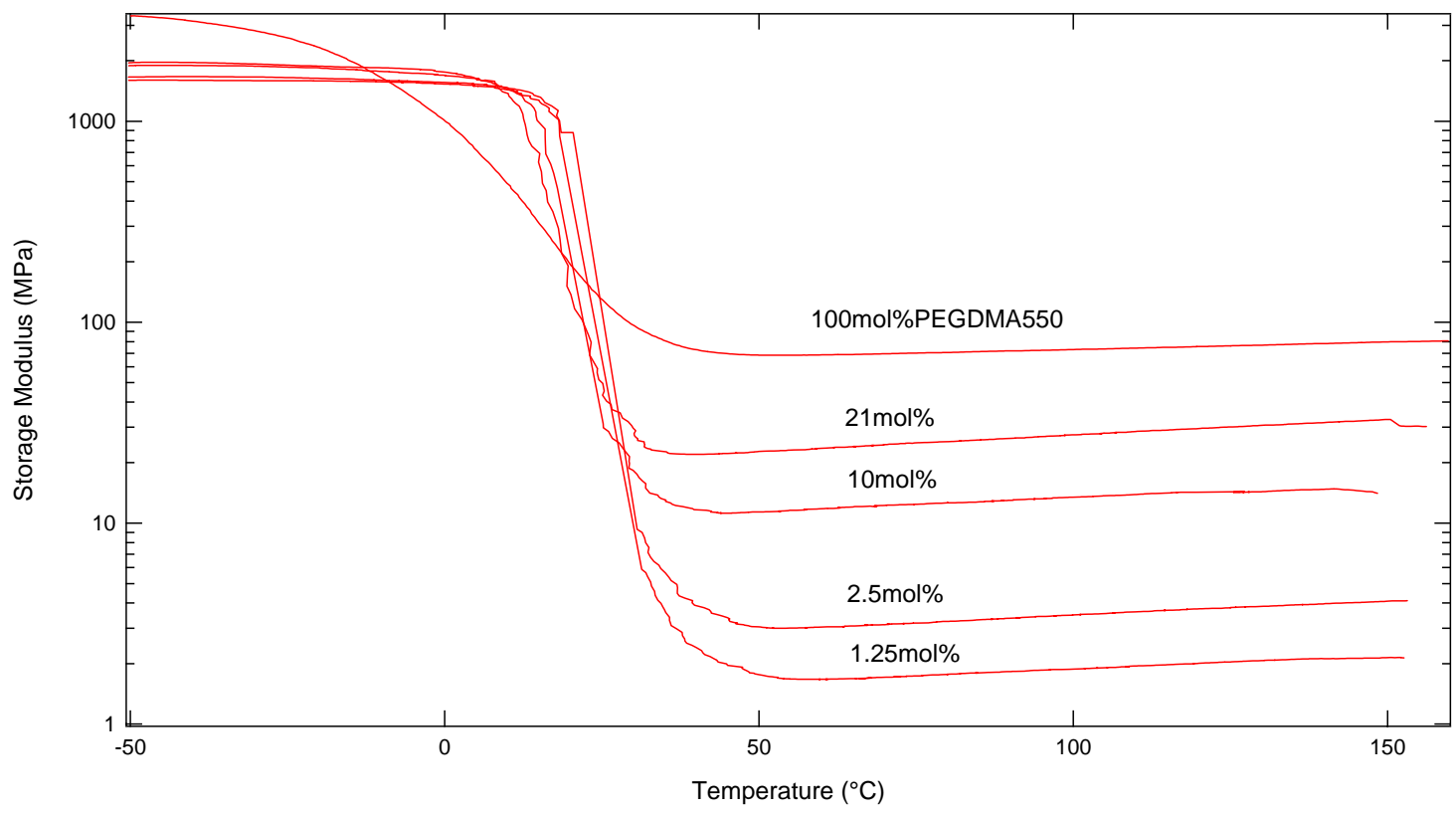

Figure 13. DMA curves of BZA-co-PEGDMA550. 


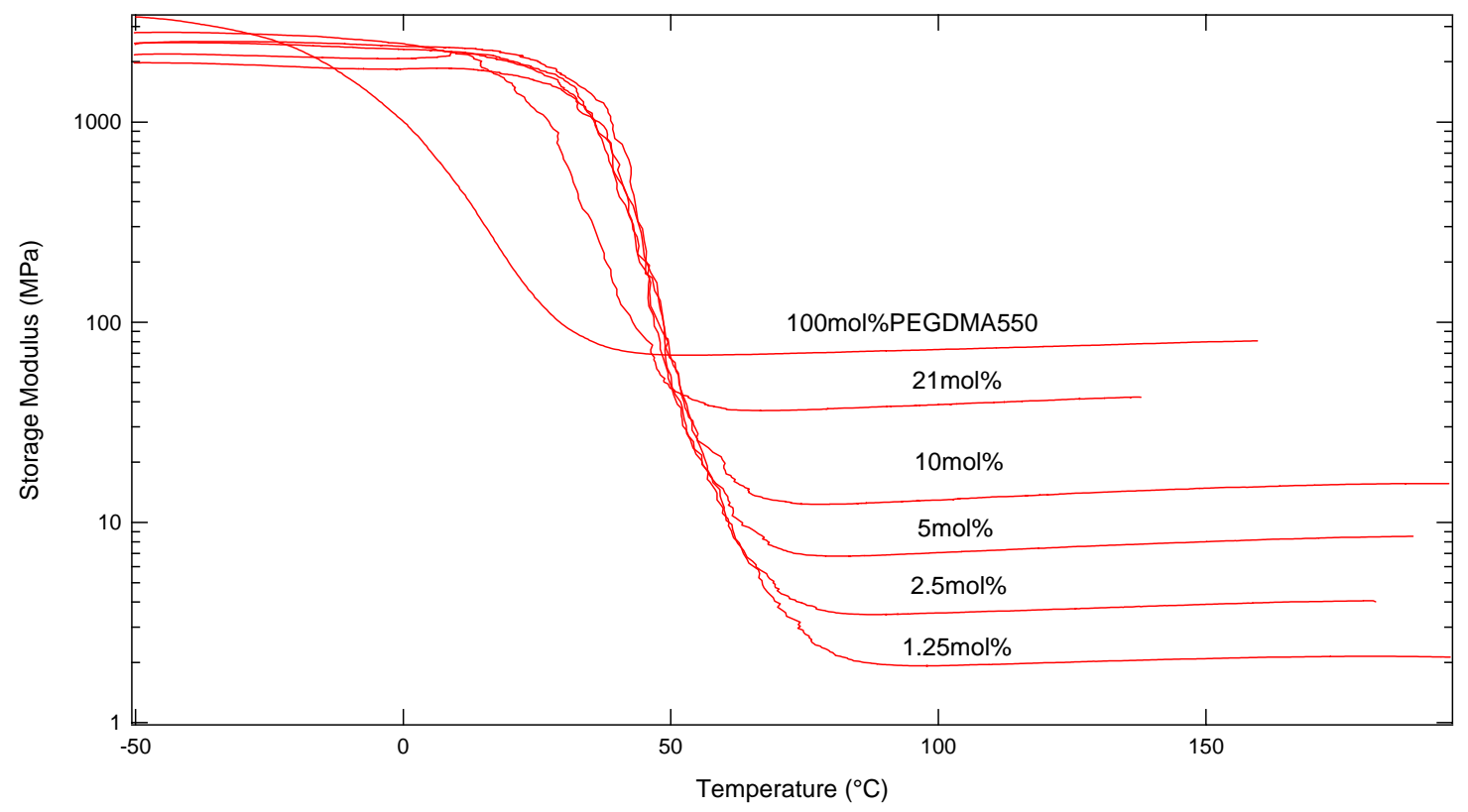

Figure 14. DMA curves of EGPEM-co-PEGDMA550.

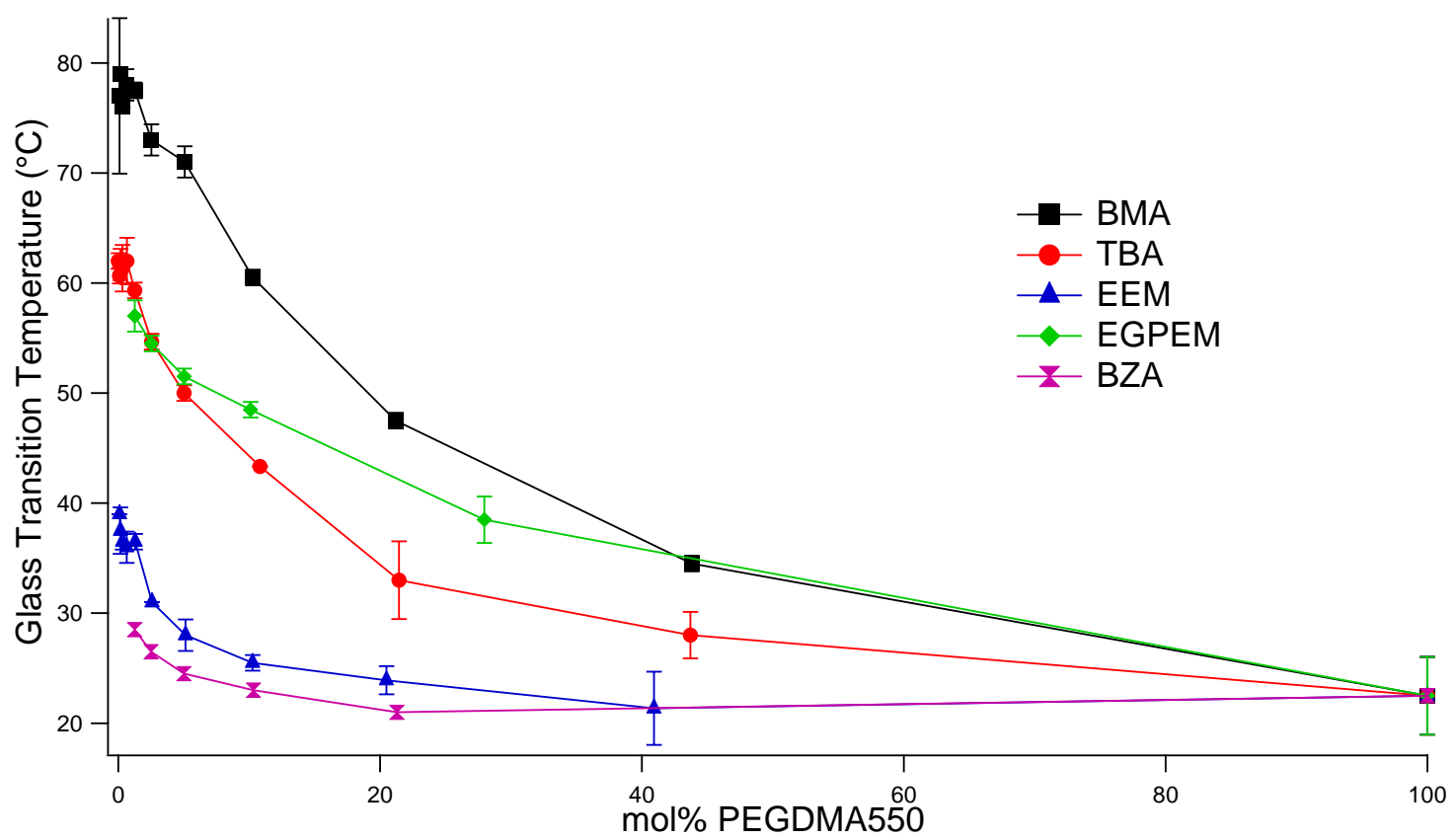

Figure 15. Glass Transition Temperature as a function of Crosslinker concentration for networks in Tables 1 and 2 . 


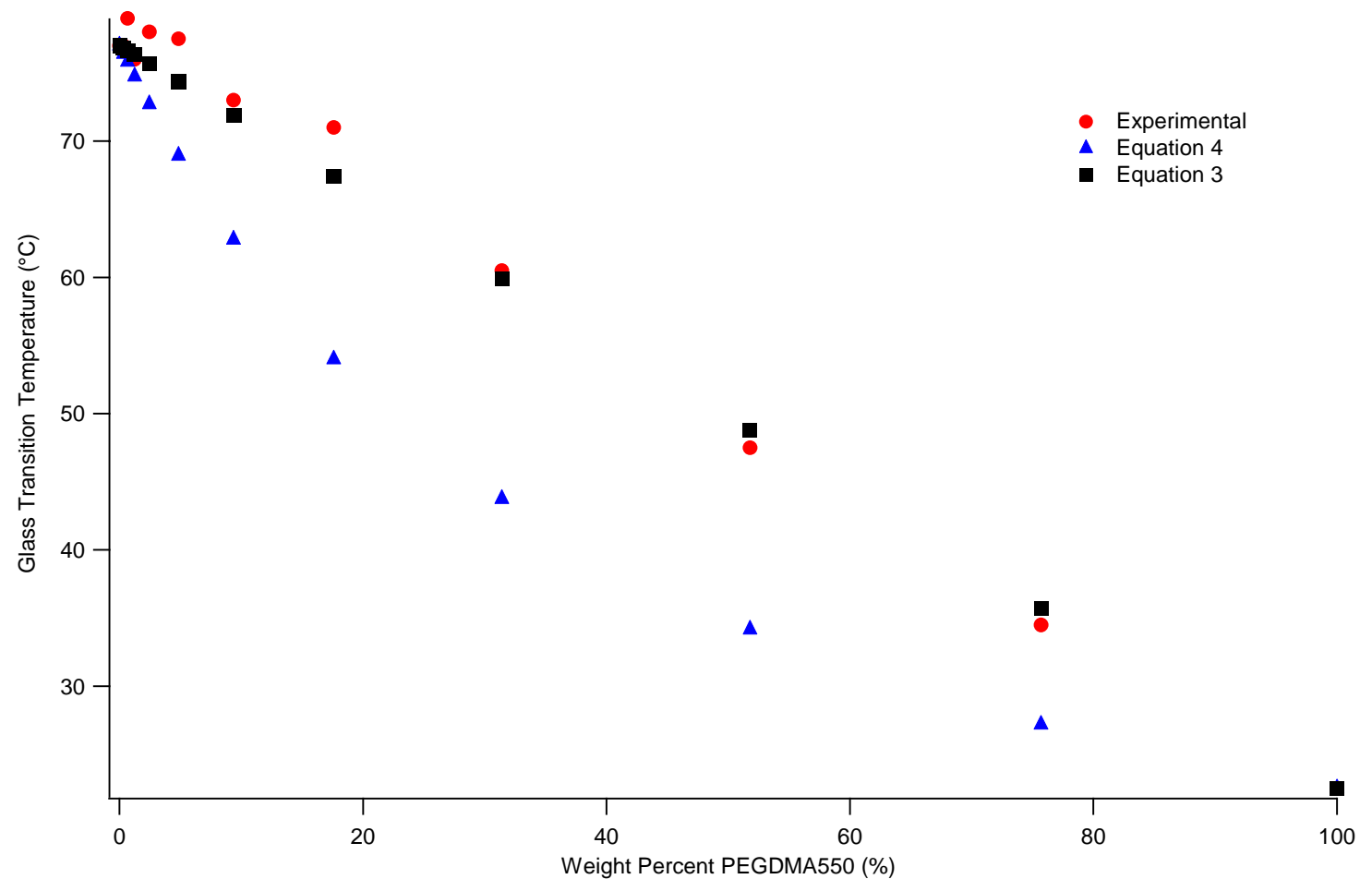

Figure 16. Glass Transiton Temperature as a function of wt $\%$ PEGDMA550-co-BMA

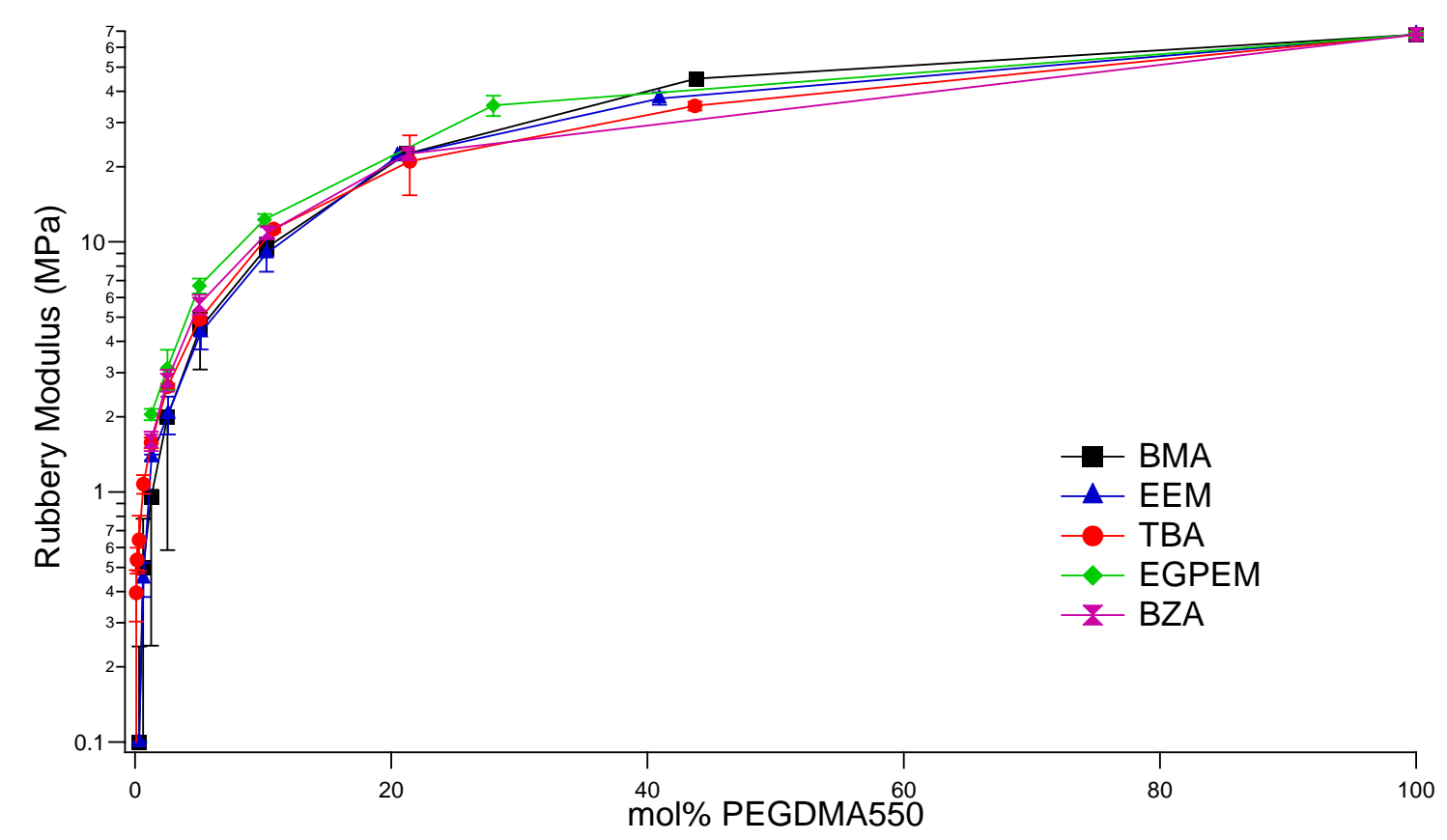

Figure 17. Rubbery Modulus as a function of Crosslinker concentration for networks in Tables 1 and 2. 
The compositions from Tables 1 and 2 were tensile tested to understand the effect of structure on the large strain behavior of the networks. The stress-strain curves of each system can be found in Figures 18, 19, 20,21, and 22. The failure strain of each network was plotted against its respective mol\% crosslinker, which shows the tradeoff between failure strain and mol\% crosslinker in Figure 23. The failure strain of each composition from the tensile test was plotted against its respective $\mathrm{E}_{\mathrm{r}}$ from DMA in Figure 24. The results were plotted against $\mathrm{E}_{\mathrm{r}}$ to eliminate any differences that may be a result of different "effective" crosslink density in the networks and thus isolate the effects of the linear monomer chemistry as a function of increasing crosslinker concentration. In addition, all tests in Figure 24 were conducted at the $T_{g}$ of the respective polymer to assure all networks were in an equivalent state of macromolecular motion. At $\mathrm{E}_{\mathrm{r}}$ greater than $10 \mathrm{MPa}$ (high crosslink density) the five systems had similar failure strains for all compositions. At $\mathrm{E}_{\mathrm{r}}$ lower than $10 \mathrm{MPa}$ the network failure strains diverged. As the $\mathrm{E}_{\mathrm{r}}$ further decreased below $1 \mathrm{MPa}$, the networks did not display reliable rubbery plateaus, thus the data were excluded. 


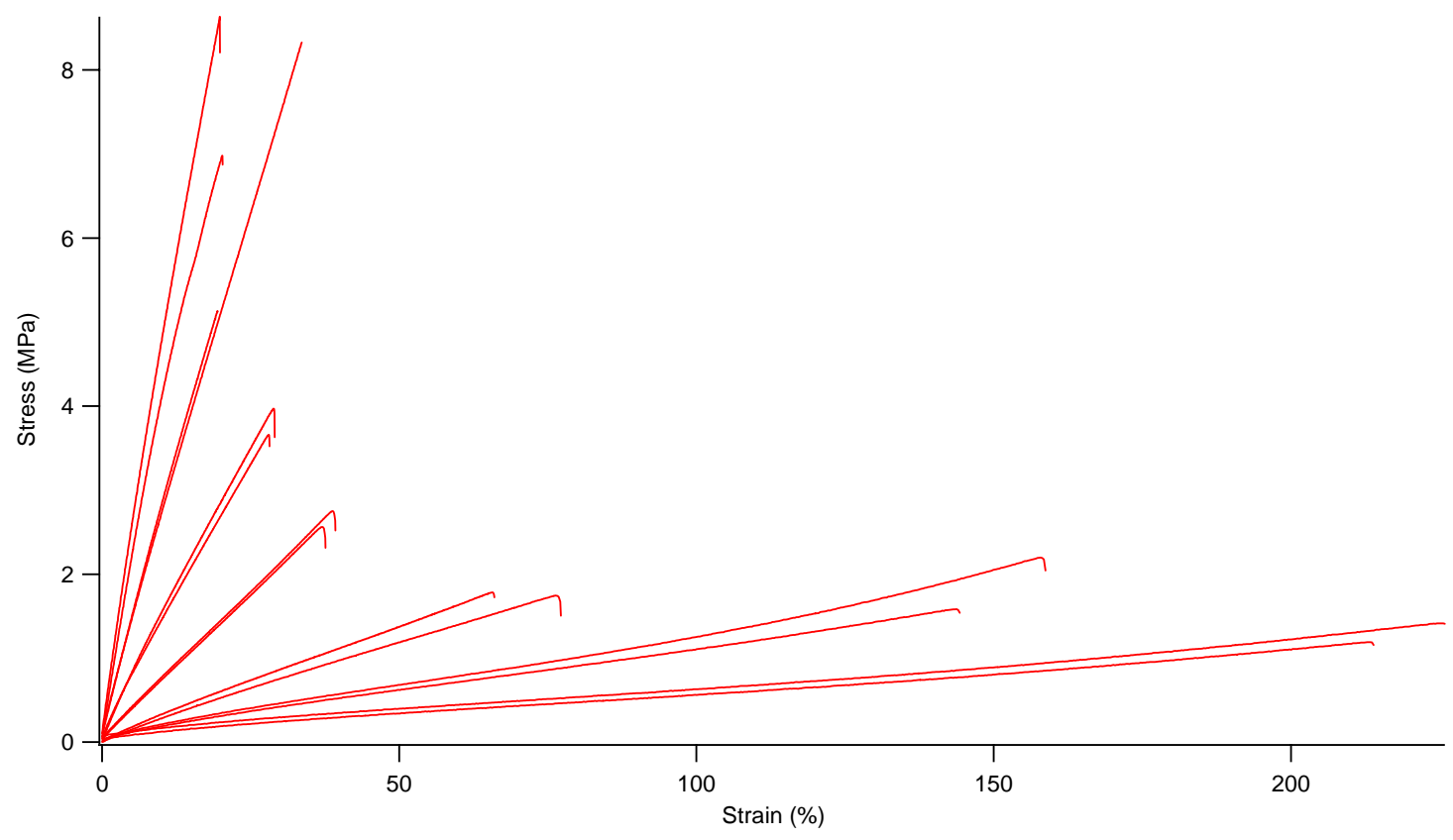

Figure 18. Stress-Strain curves of PEGDMA550-co-BMA

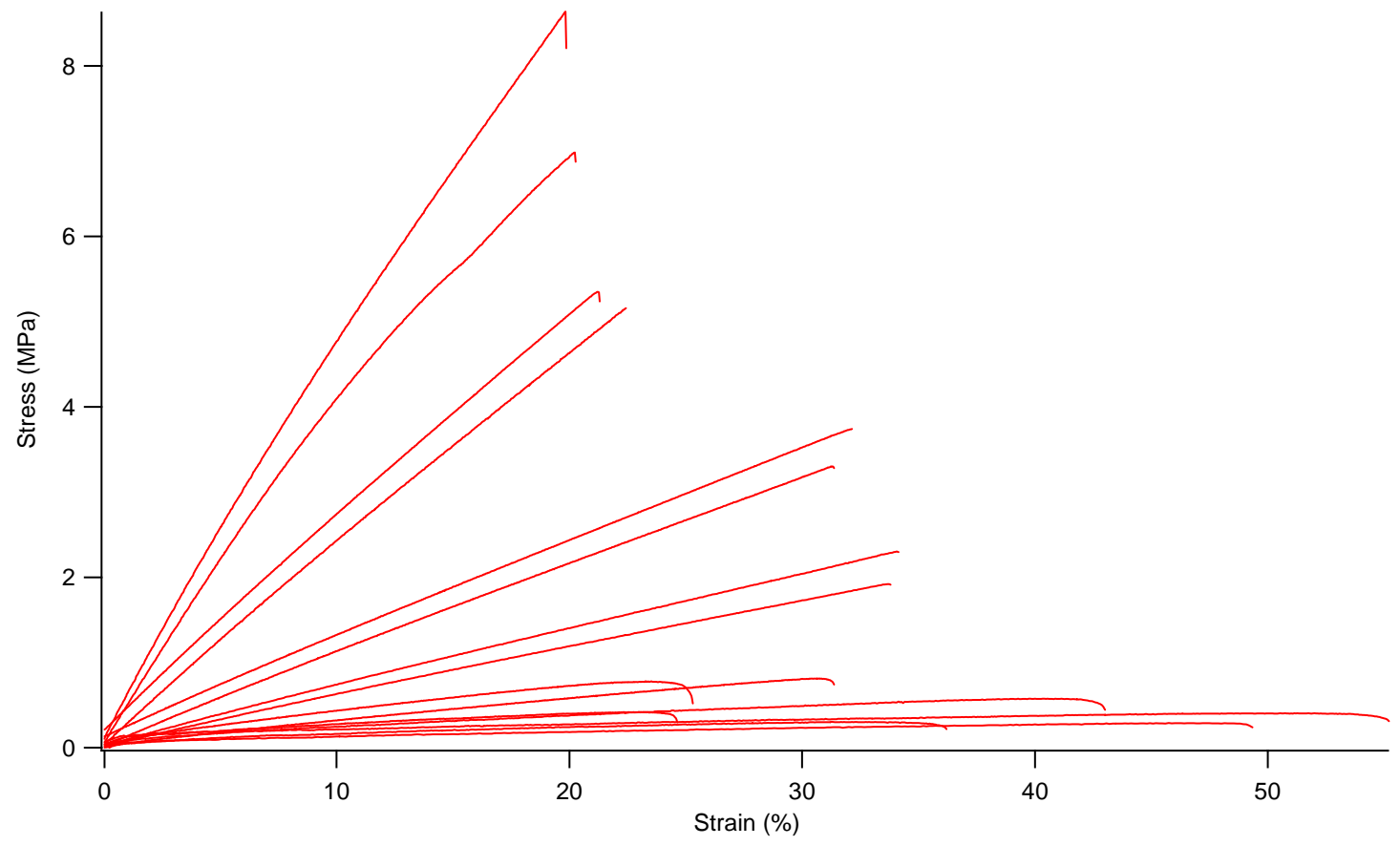

Figure 19. Stress-Strain curves of PEGDMA550-co-tBA 


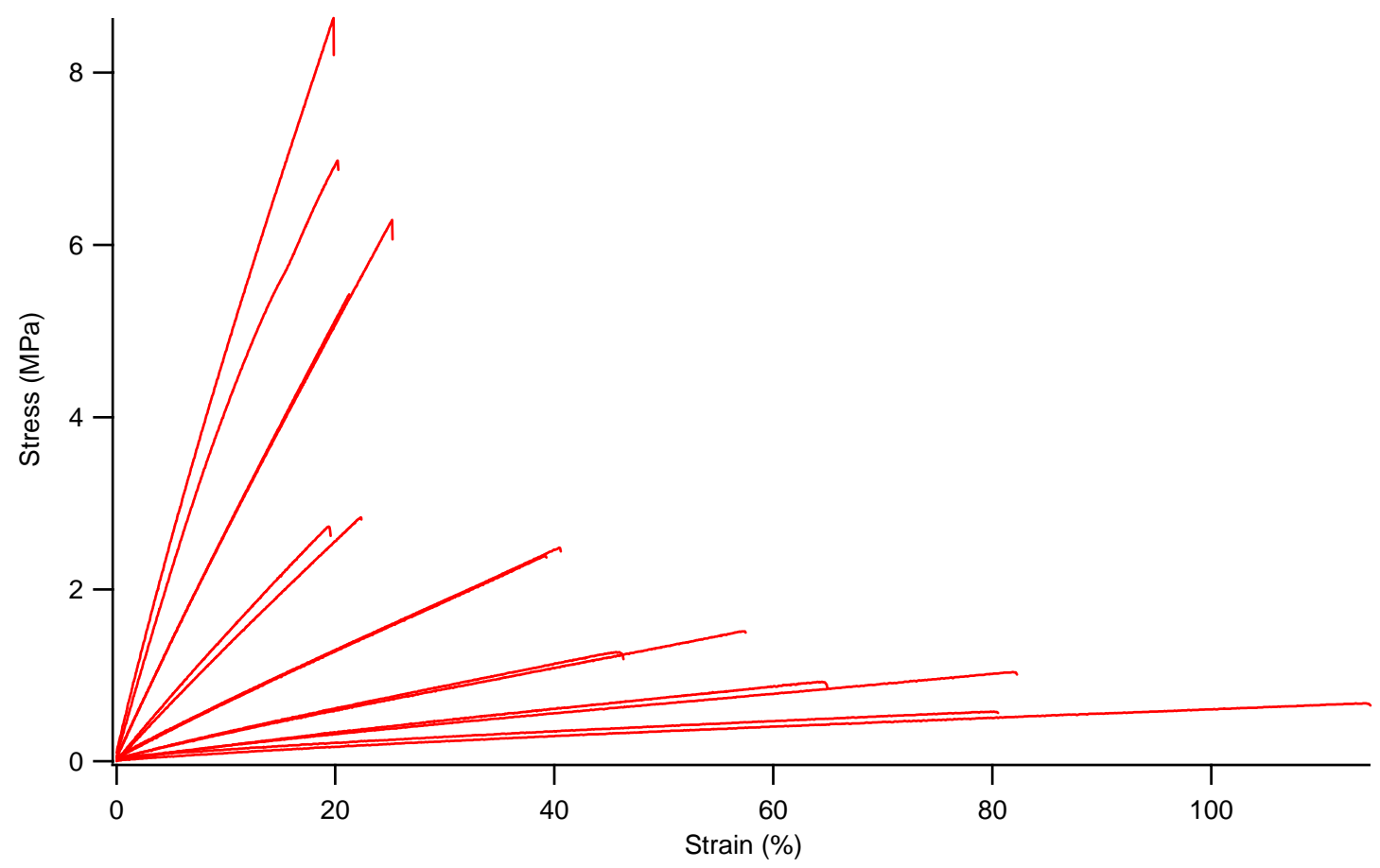

Figure 20. Stress-Strain curves of PEGDMA550-co-2EEM

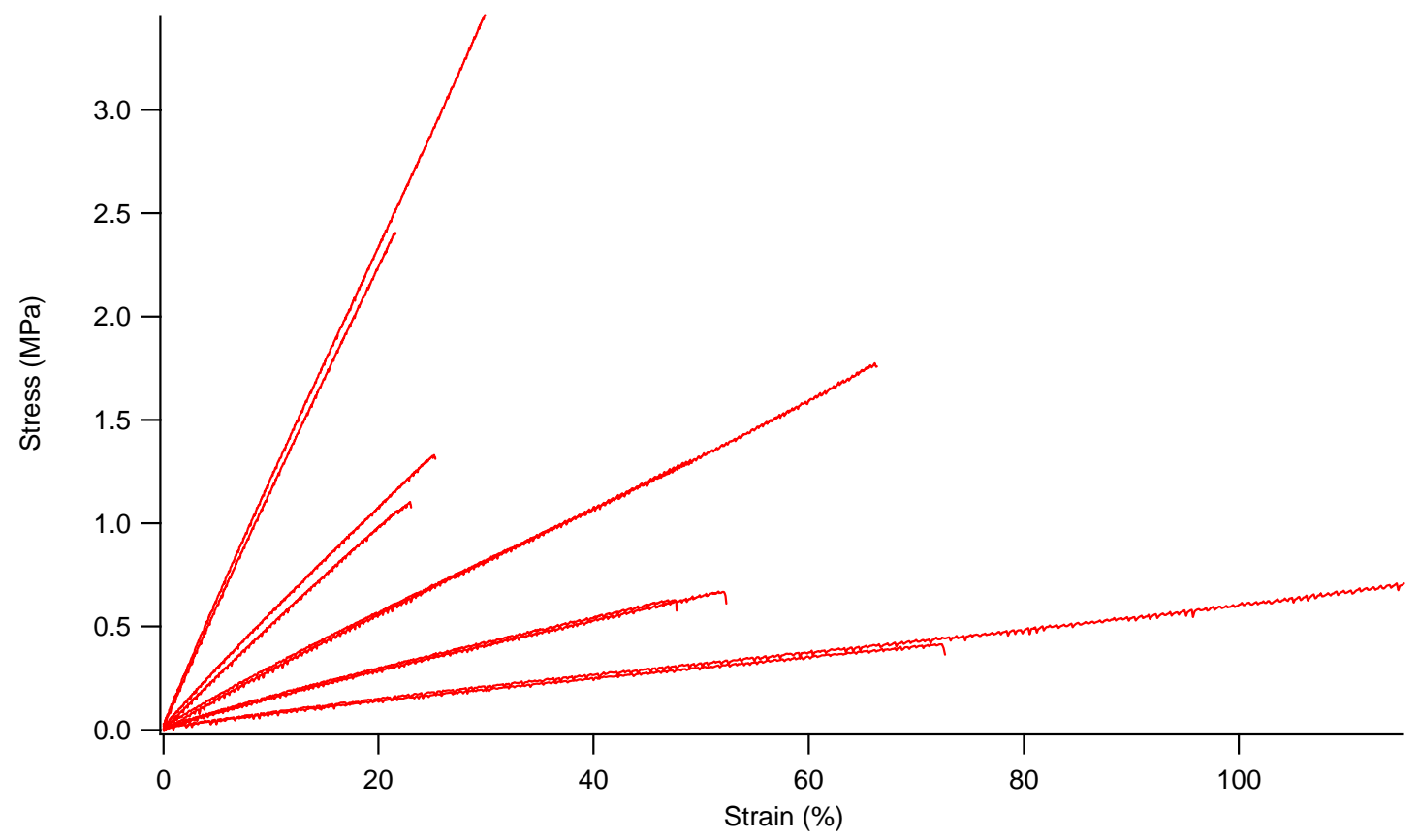

Figure 21. Stress-Strain curves of PEGDMA550-co-BZA 


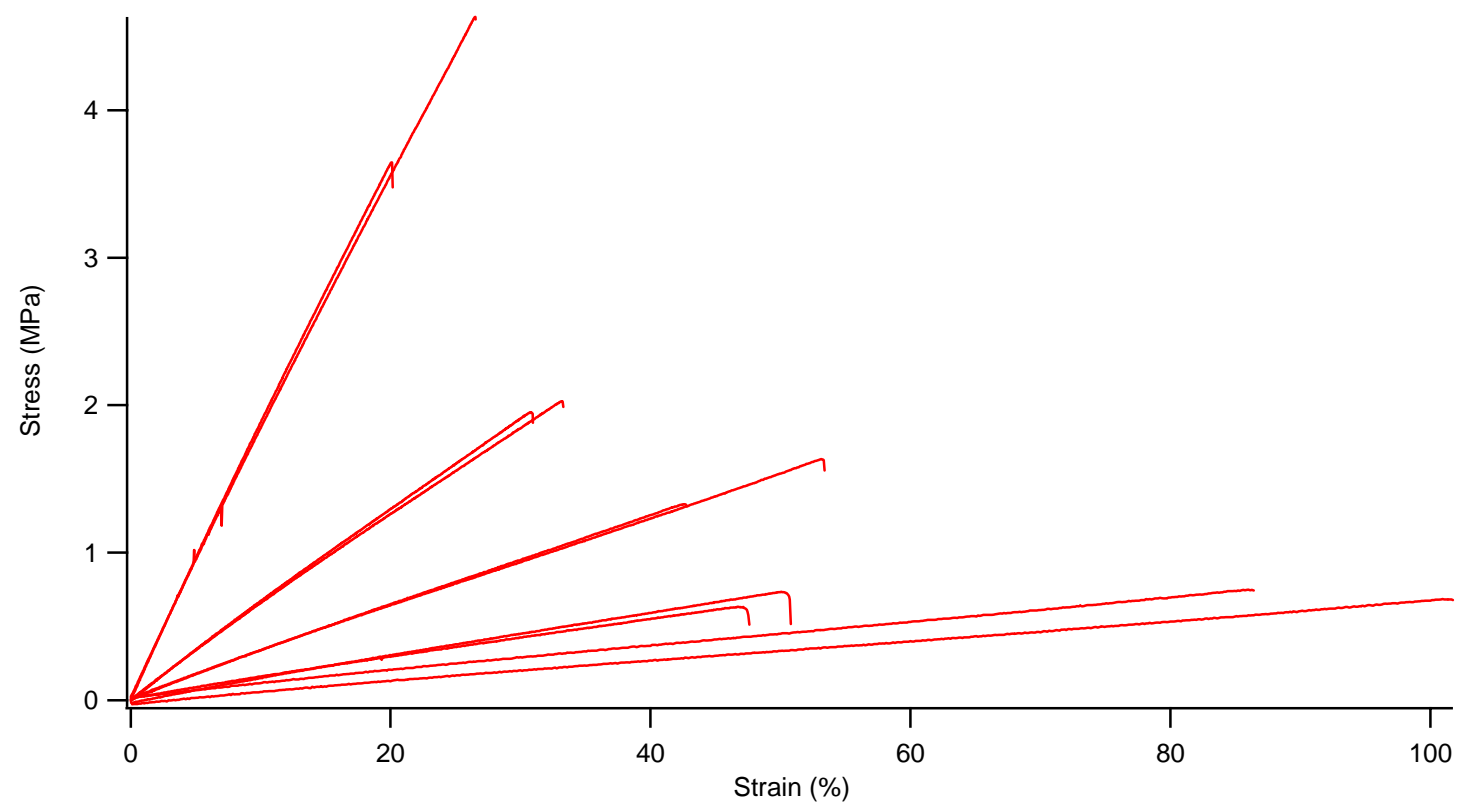

Figure 22. Stress-Strain curves of PEGDMA550-co-EGPEM

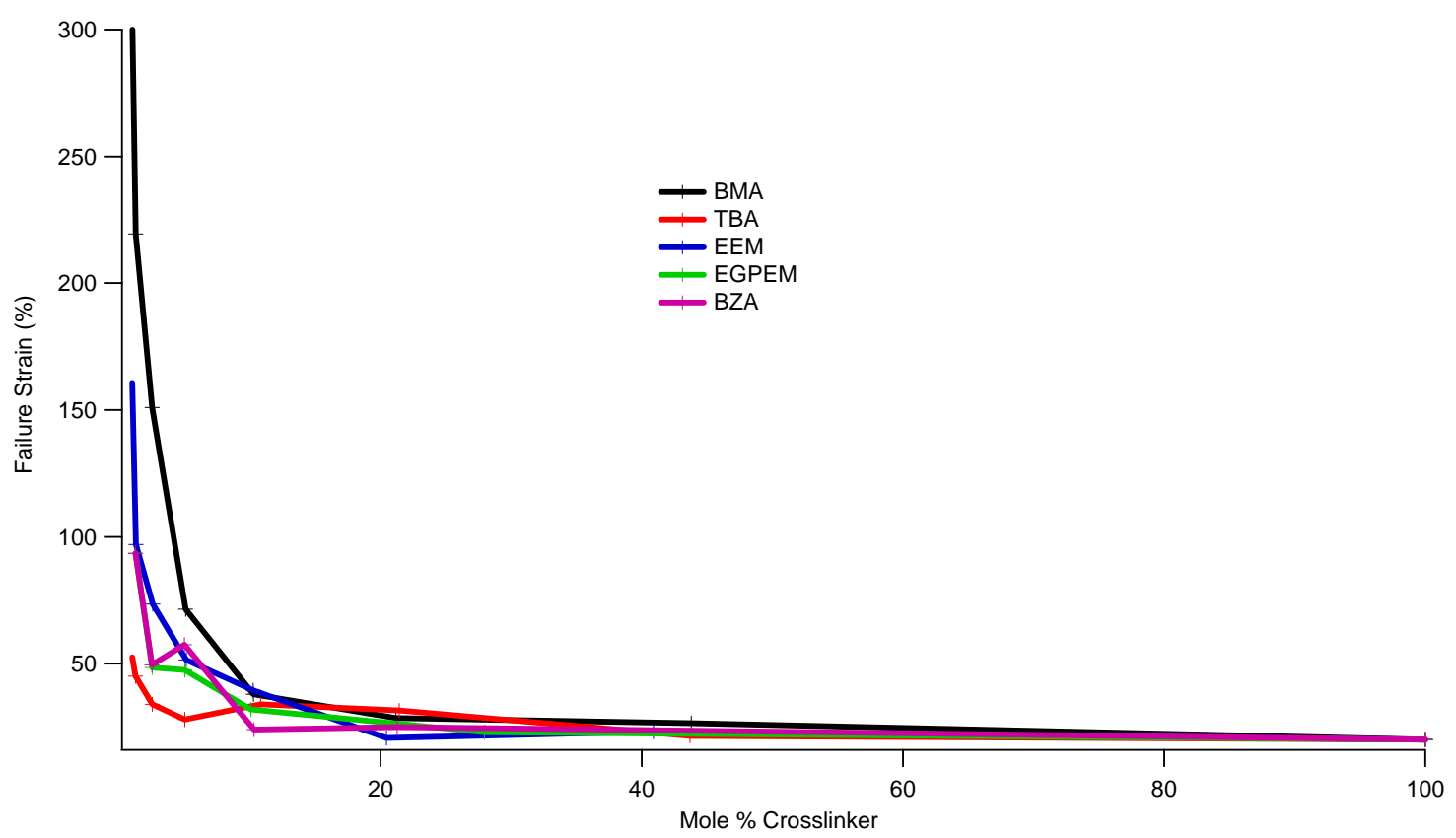

Figure 23. Failure strain as a function of mol $\%$ crosslinker 


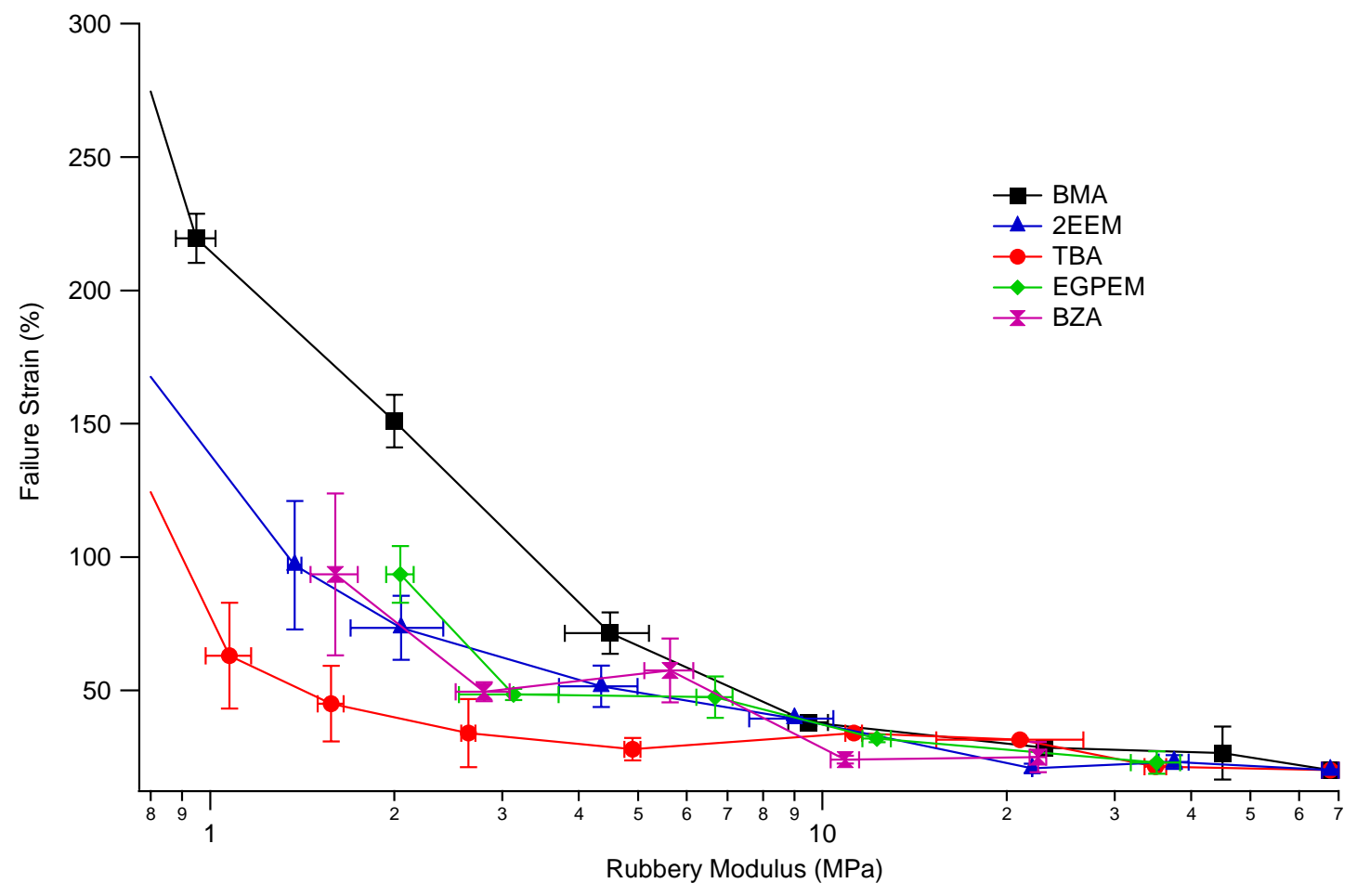

Figure 24. Failure Strain as a function of Rubbery Modulus for networks in Table 1 and Table 2.

Figure 25 displays representative stress-strain curves of the five systems with increasing rubbery moduli. For all five materials, as the $\mathrm{E}_{\mathrm{r}}$ drops, the failure strain increases. The tBA, 2EEM, BZA, and EGPEM also show a decrease in strength as $\mathrm{E}_{\mathrm{r}}$ decreases. Unlike the other systems, the BMA system does not show a steady decrease in strength as the $\mathrm{E}_{\mathrm{r}}$ decreases. The BMA has relatively higher failure strains and failure strengths as compared to the other materials even for nearly equivalent rubbery modulus.

Figure 26 displays toughness, calculated as the area under stress-strain curves of the systems, as a function of the $\mathrm{E}_{\mathrm{r}}$. The systems have similar toughness at relatively higher $E_{r}$ values, and the systems diverge at $E_{r}$ values below $10 \mathrm{MPa}$. The tBA, 2EEM, BZA, and EGPEM systems have toughness values nearly a third of BMA. The point of divergence, the shape of the BMA stress-strain curves, and the increased toughness are 
points of interest to be further studied. Figure 27 displays the characteristic ratio as a function of toughness for the five networks. The toughness is the average toughness of the networks below the divergence point. Three systems, EGPEM, 2EEM, and BZA, have similar average toughness values near 0.3 , but have different characteristic ratios. Figure 28 displays the relationship between the rubbery modulus and the elastic modulus of the five networks at and below the divergence point. Equation 19 gives the average relationship between $\mathrm{E}_{\mathrm{r}}$ and $\mathrm{E}$.

$$
\mathrm{E}_{\mathrm{r}}=1.677 \mathrm{E} \quad \text { Equation } 19
$$

By applying Equation 13 and Equation 14 to the average of CED values from Table 7, the predicted values for $\mathrm{E}$, assuming $\mathrm{E}=\mathrm{B}$, are found in Table 10 . These values are $10^{3}$ larger than the values of $\mathrm{E}$ and $\mathrm{E}_{\mathrm{r}}$ from Figure 28.

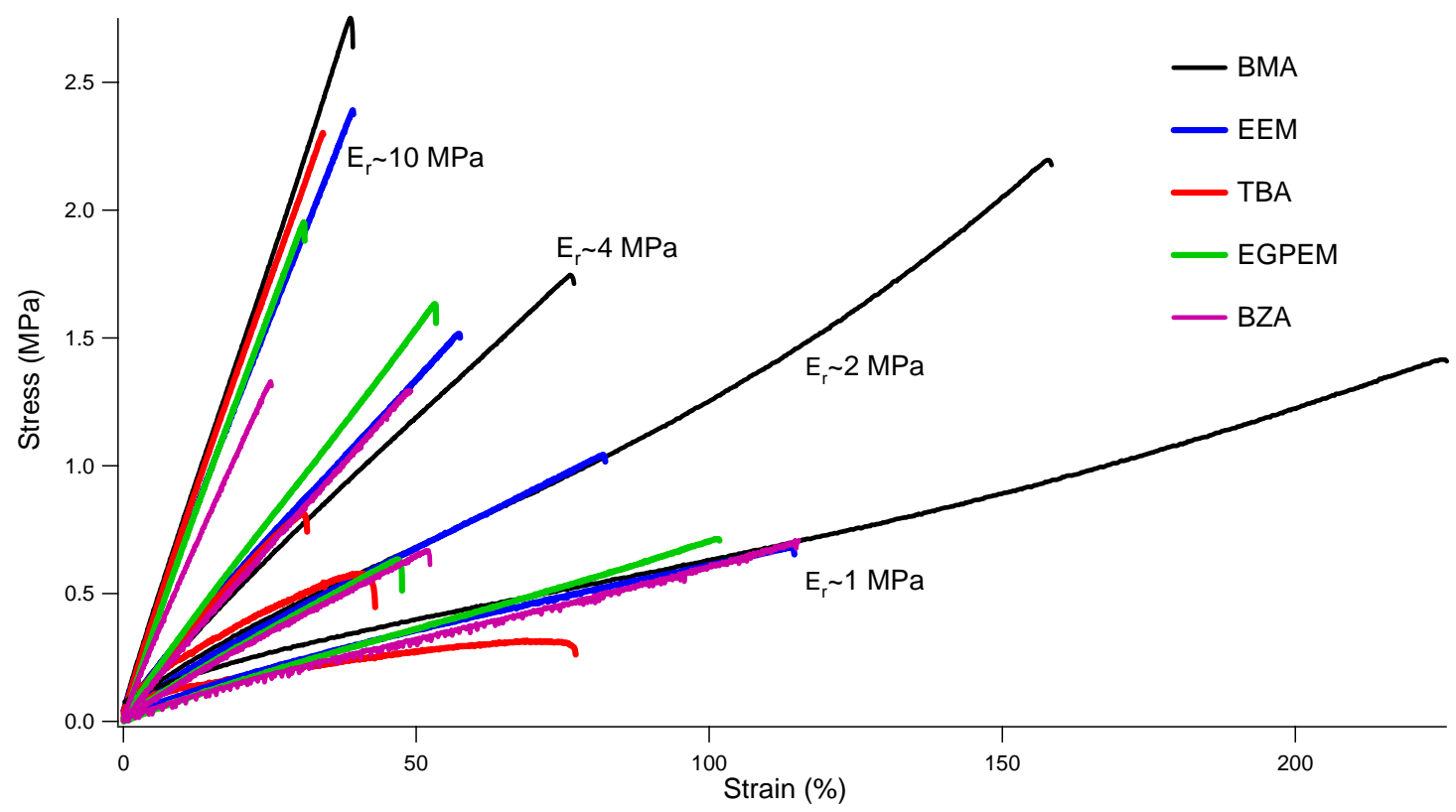

Figure 25. Stress-strain curves of varying moduli from Figure 24. 


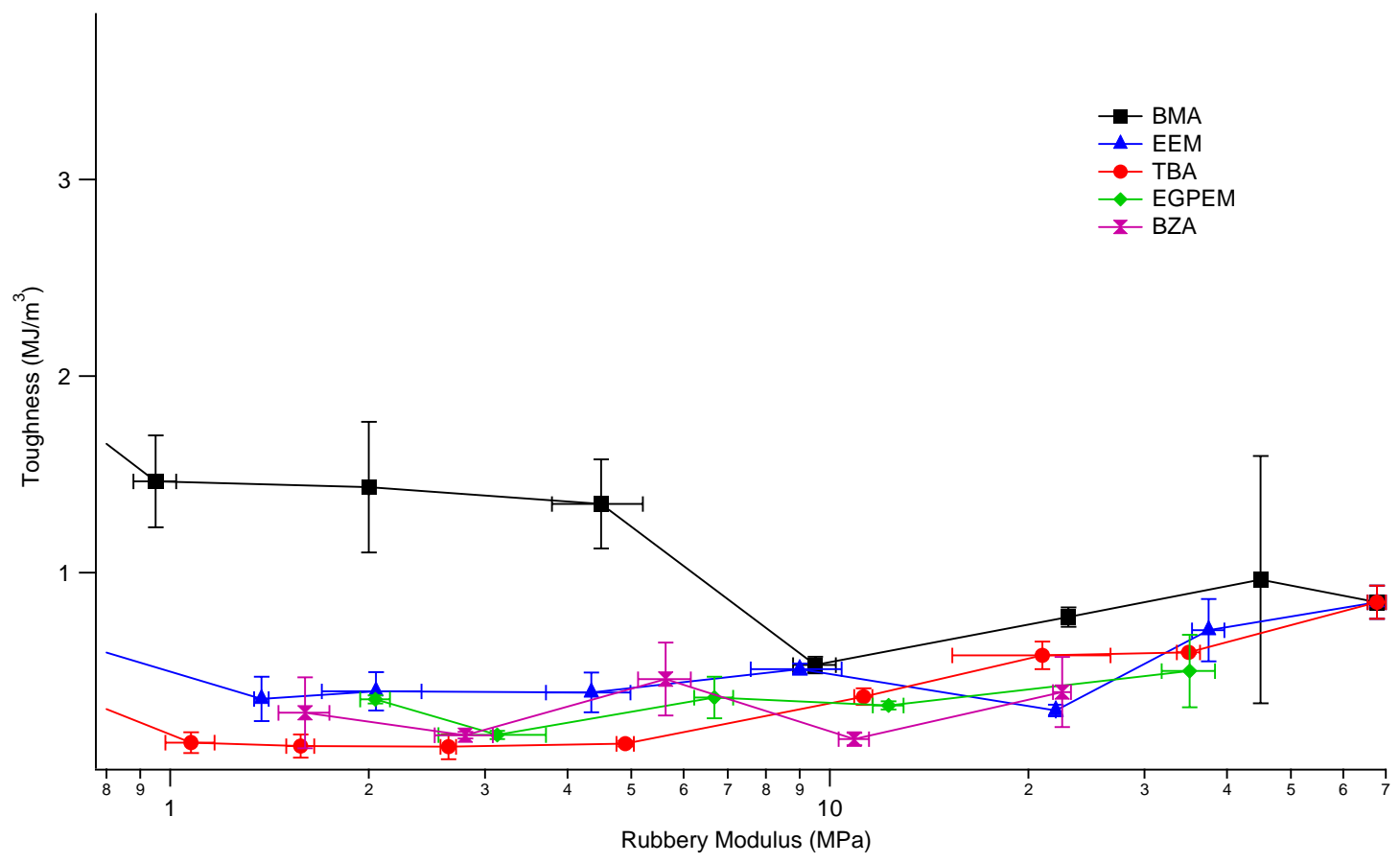

Figure 26. Toughness as a function of Rubbery Modulus for networks in Table 1 and 2.

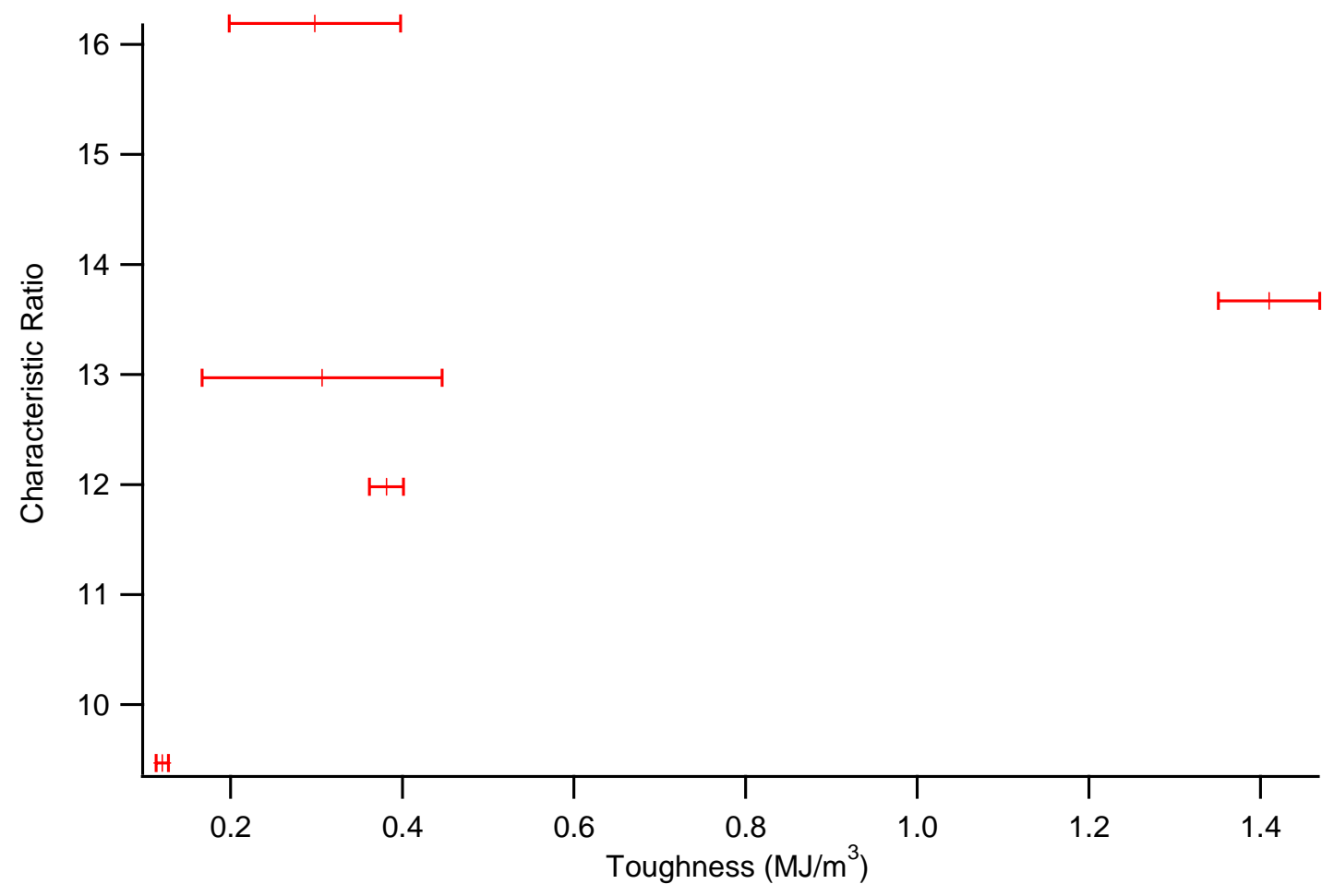

Figure 27. Characteristic Ratio as a function of Toughness 


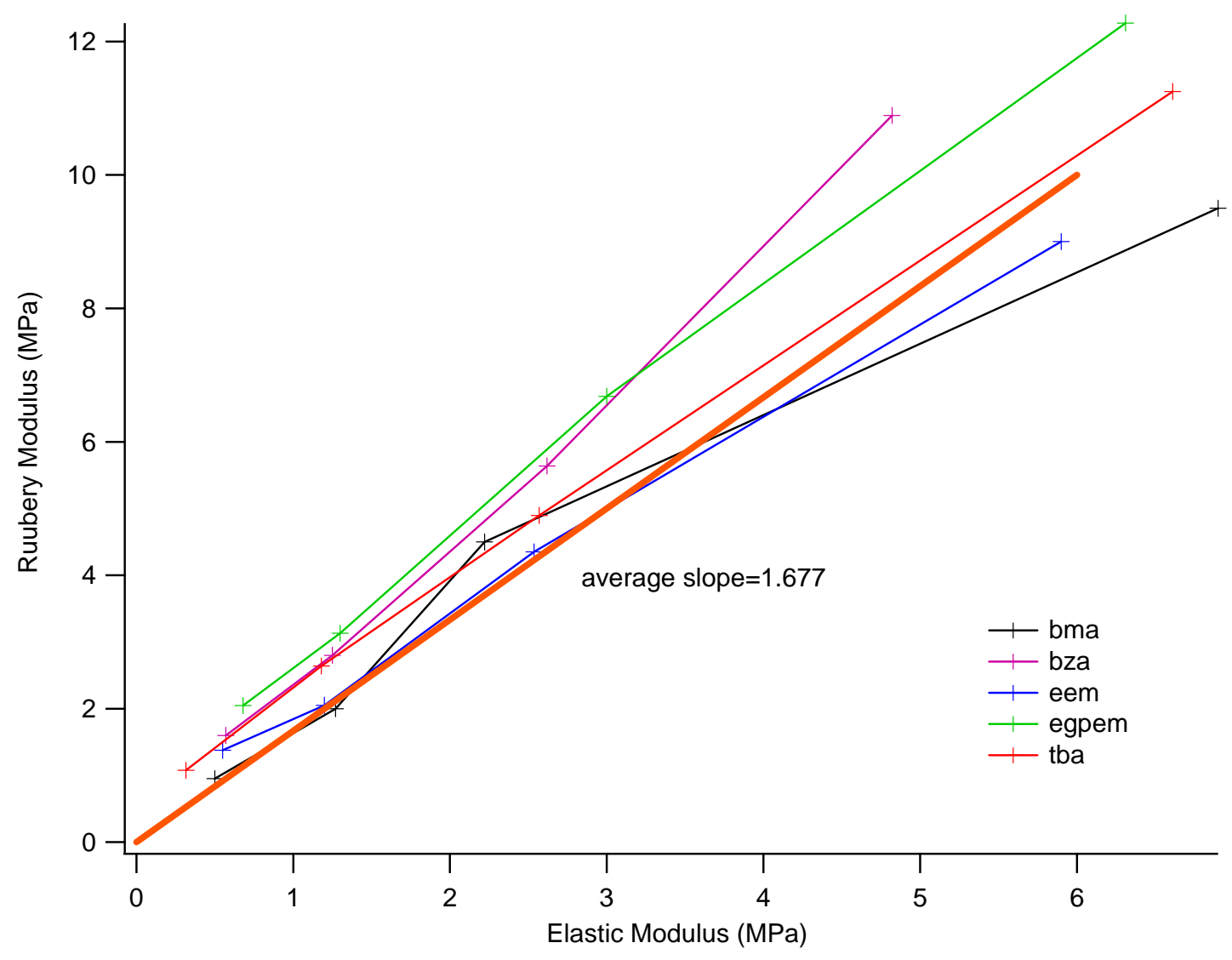

Figure 28. The relationship between Rubbery Modulus to Elastic Modulus

Table 10. Predicted Elastic Modulus from CED

\begin{tabular}{|c|c|}
\hline$E^{[49]}(\mathrm{MPa})$ & $E^{[46]}(\mathrm{MPa})$ \\
\hline 3310 & 4528 \\
\hline 3570 & 4884 \\
\hline 3321 & 4543 \\
\hline 2924 & 4000 \\
\hline 2790 & 3817 \\
\hline
\end{tabular}

Networks composed of 2.5 mol\% PEGDMA550-co-BMA or PEGDMA550-cotBA from Table 1 were tensile tested across a range of temperatures, represented in 
Figures 29 and 30. Brittle behavior was present at temperatures below $\mathrm{T}_{\mathrm{g}}$, marked as low temperature. Ductile behavior was present at temperatures above $T_{g}$, marked as high temperature. The scatter in the stress-strain curves of Figure 30 at low temperature were due to repeated flushing of liquid nitrogen. The objective of this testing was to verify that the relatively high toughness of the BMA material compared to tBA was not merely an artifact of a relative test temperature difference. The strain to failure in Figure 31 is plotted at temperatures relative to each composition's respective $T_{g}, T-T_{g}$. A peak in failure strain is seen 15 to $20^{\circ} \mathrm{C}$ before the $\mathrm{T}_{\mathrm{g}}$, then the curves level off when well into their respective rubbery region. The toughness in Figure 32 is plotted also plotted at temperatures relative to each composition's respective $\mathrm{T}_{\mathrm{g}}$. It can be seen that at temperatures leave the glassy region and approach the $T_{g}, T_{g}-20$, the toughness of BMA is greater than that of tBA. Well below the $T_{g}$ in the glassy region, the error in measuring the toughness occurs do the differences in failure strain, where some materials fail early, while others can undergo extended amounts of deformation. tBA may have a higher average toughness in the glassy region due to a lower glassy modulus. The PEGDMA550-BMA failure strain curve reaches a higher peak and is broader than the PEGDMA550-tBA curve, highlighting the inherent toughness difference in the two materials that is not driven by a difference in effective crosslink density or temperature relative to $T_{g}$. 


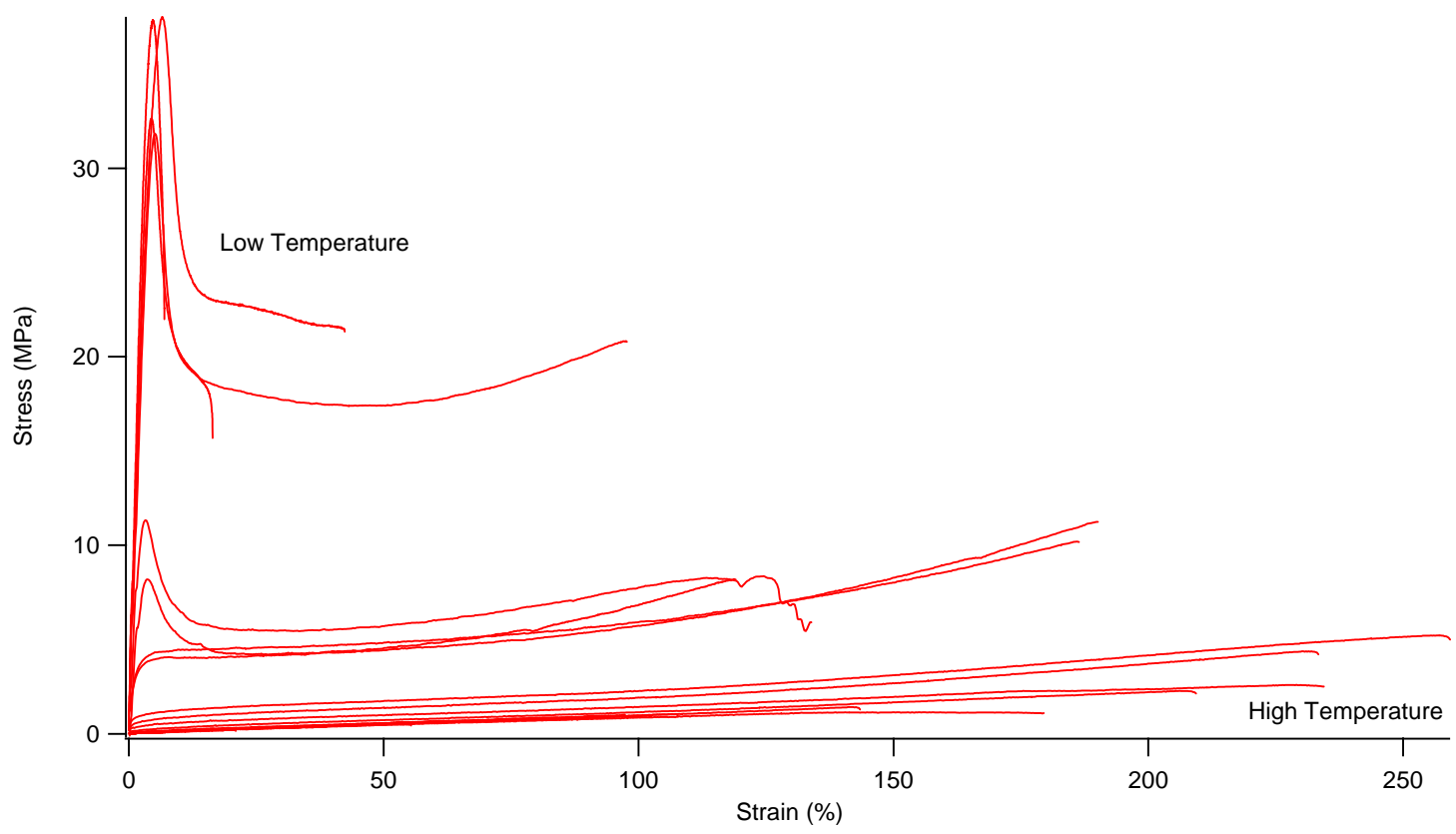

Figure 29. Stress-Strain curves for PEGDMA550-co-BMA at varying temperatures.

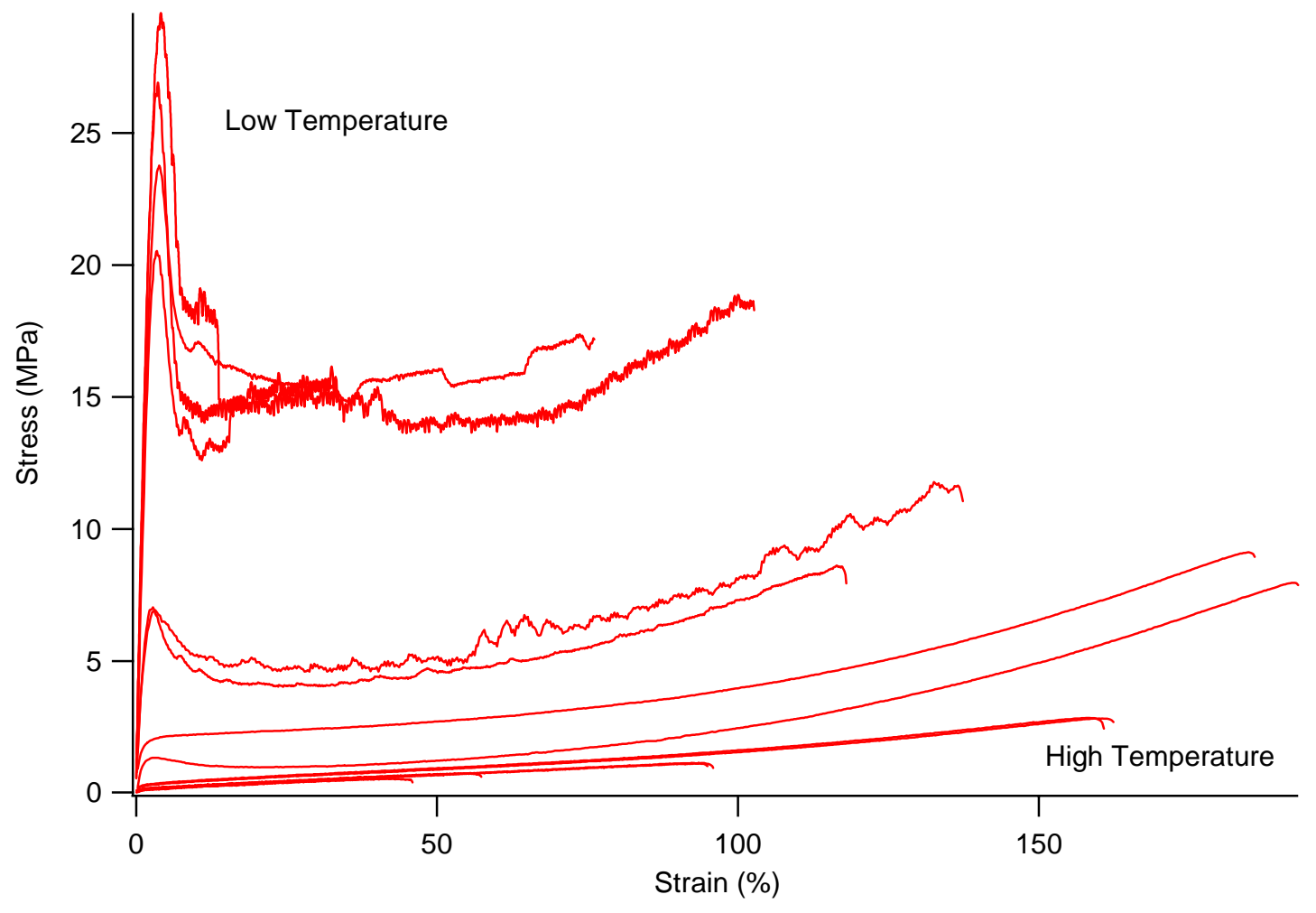

Figure 30. Stress-Strain curves of PEGDMA550-co-tBA at varying temperatures. 


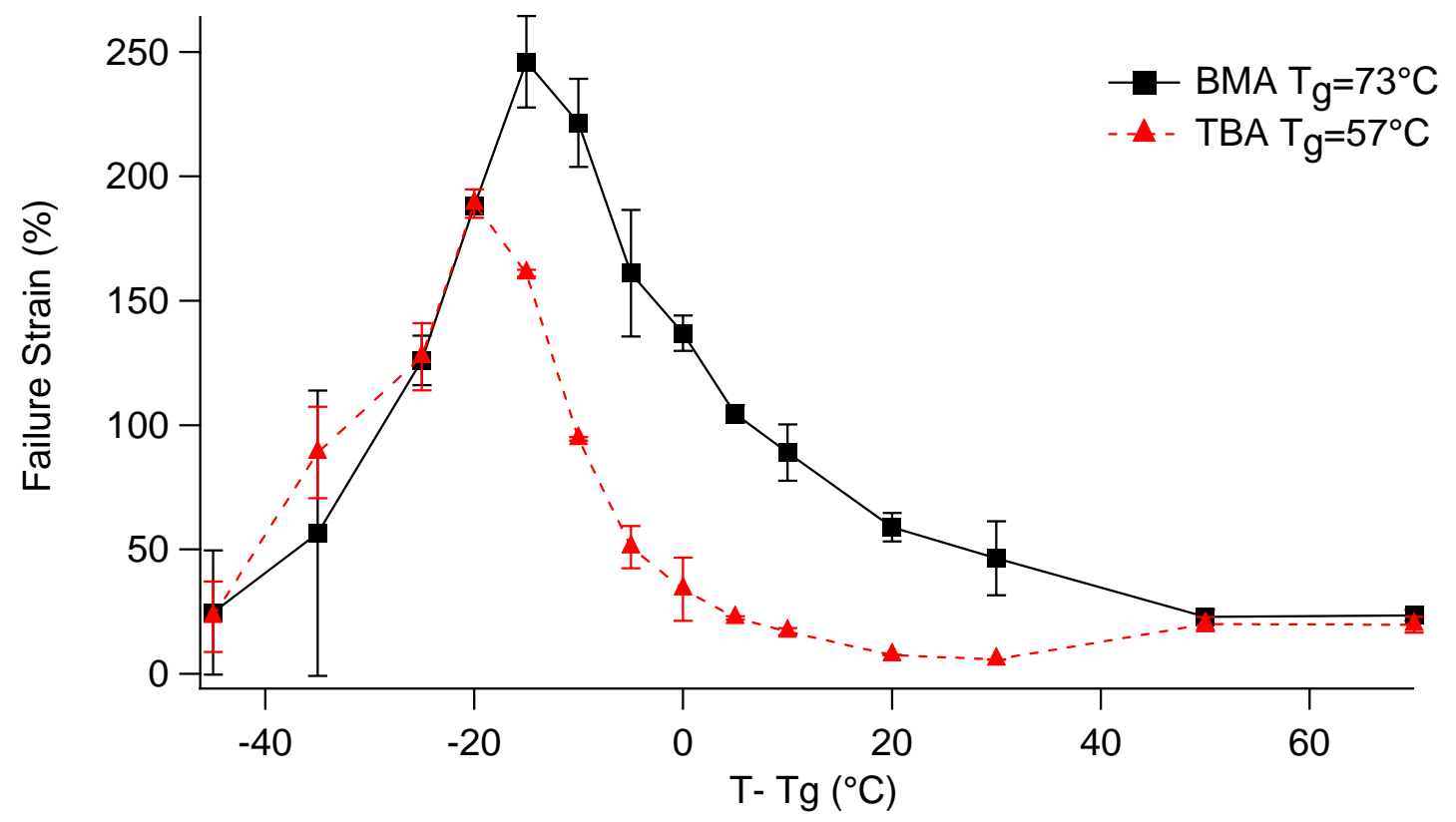

Figure 31. Failure Strain as a function of $\mathrm{T}-\mathrm{T}_{\mathrm{g}}$ for $2.5 \mathrm{~mol} \%$ PEGDMA550-co-BMA or co-tBA.

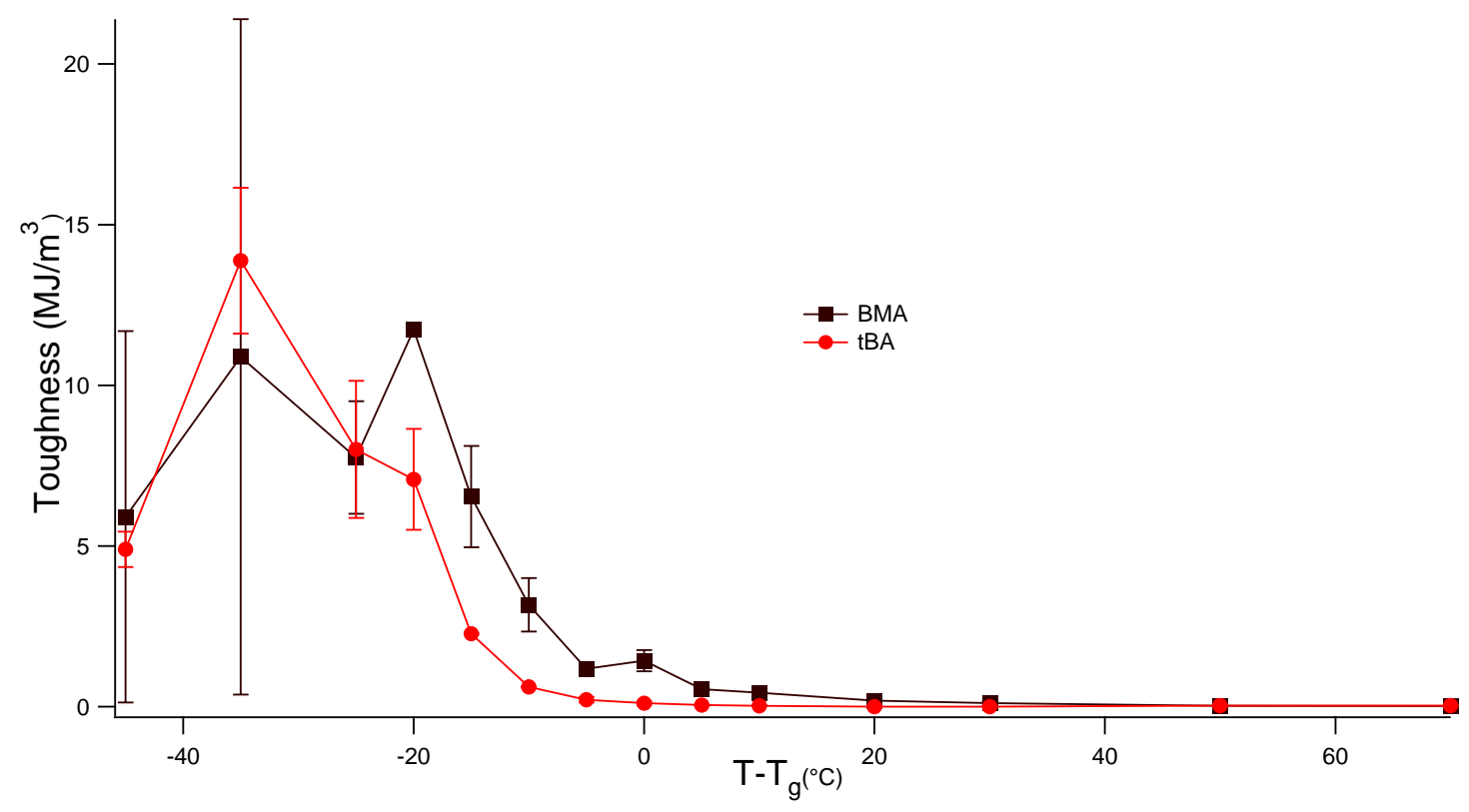

Figure 32. Toughness as a funciton of $\mathrm{T}-\mathrm{T}_{\mathrm{g}}$ for $2.5 \mathrm{~mol} \%$ PEGDMA550-co-BMA or cotBA. 


\subsection{Ternary network properties}

Mixtures of the various linear monomers were created with equivalent crosslinker concentration to determine how mechanical properties evolved from one network to another. From the ternary systems in Table 3, representative DMA curves for each of the three network systems can be found in Figures 33, 34, and 35. Representative stressstrain curves of the three networks can be found in Figures 36, 37, and 38. These networks have similar modulus, as expected since they contain the same concentration of crosslinker. Figure 39 shows the failure strain as a function of mol\% BMA in three other linear monomers (all materials contain $2.5 \mathrm{~mol} \%$ crosslinker). As the concentration of BMA increases, the failure strain increases. This trend is also seen in Figure 40, which describes the effect of increasing the concentration of BMA on the toughness of the networks. By increasing the concentration of BMA, the $\mathrm{T}_{\mathrm{g}}$ rose for all three systems, which is displayed in Figure 41. The EGPEM and tBA had similar $\mathrm{T}_{\mathrm{g}}$ values across all concentrations of BMA. Since 2.5 mol\% PEGDMA550 was used in all mixtures, it would be expected that the $\mathrm{E}_{\mathrm{r}}$ would be nearly constant across the range of compositions, which is seen in Figure 42. 


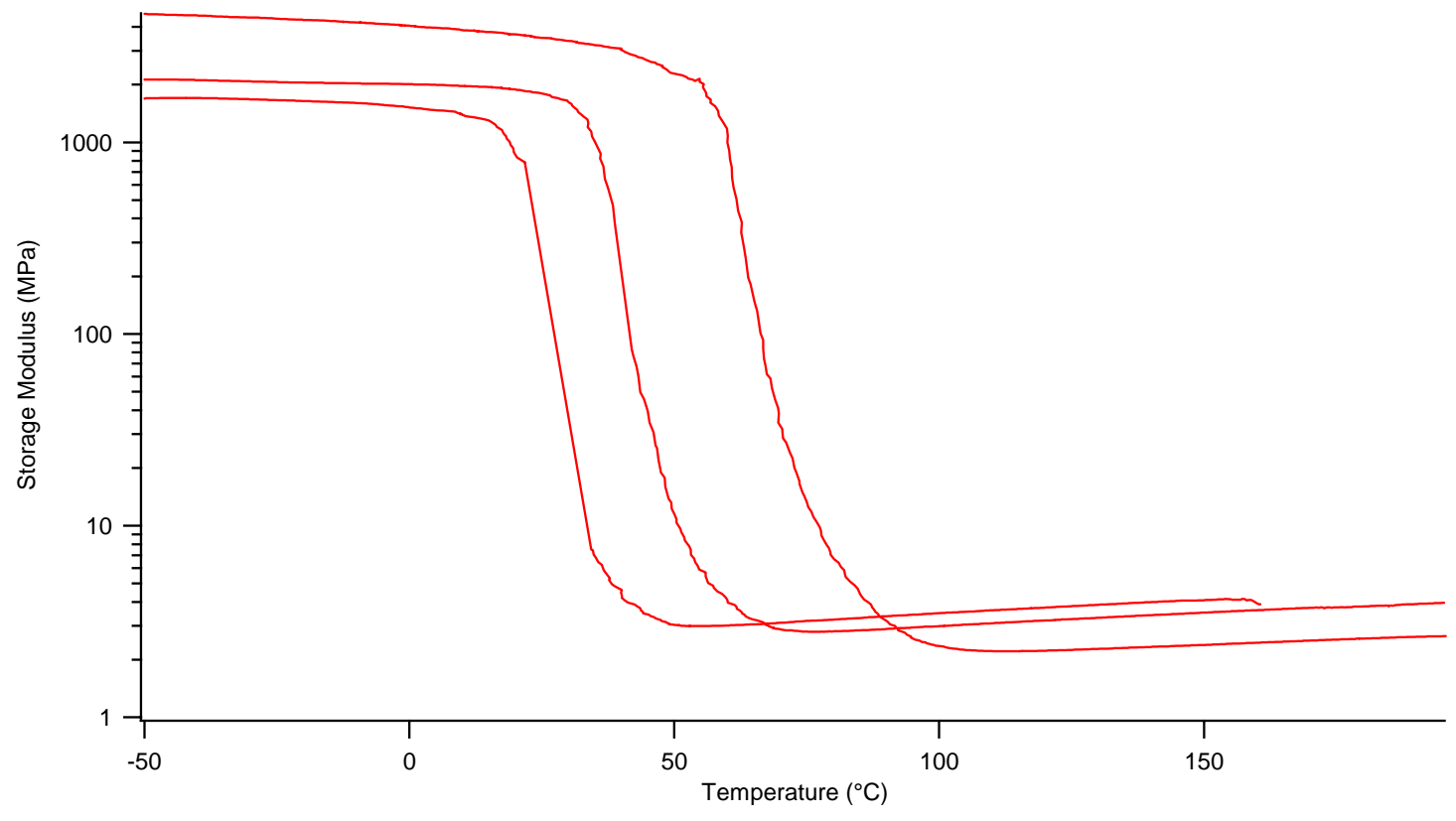

Figure 33. Representative DMA curves of PEGDMA-BMA-BZA.

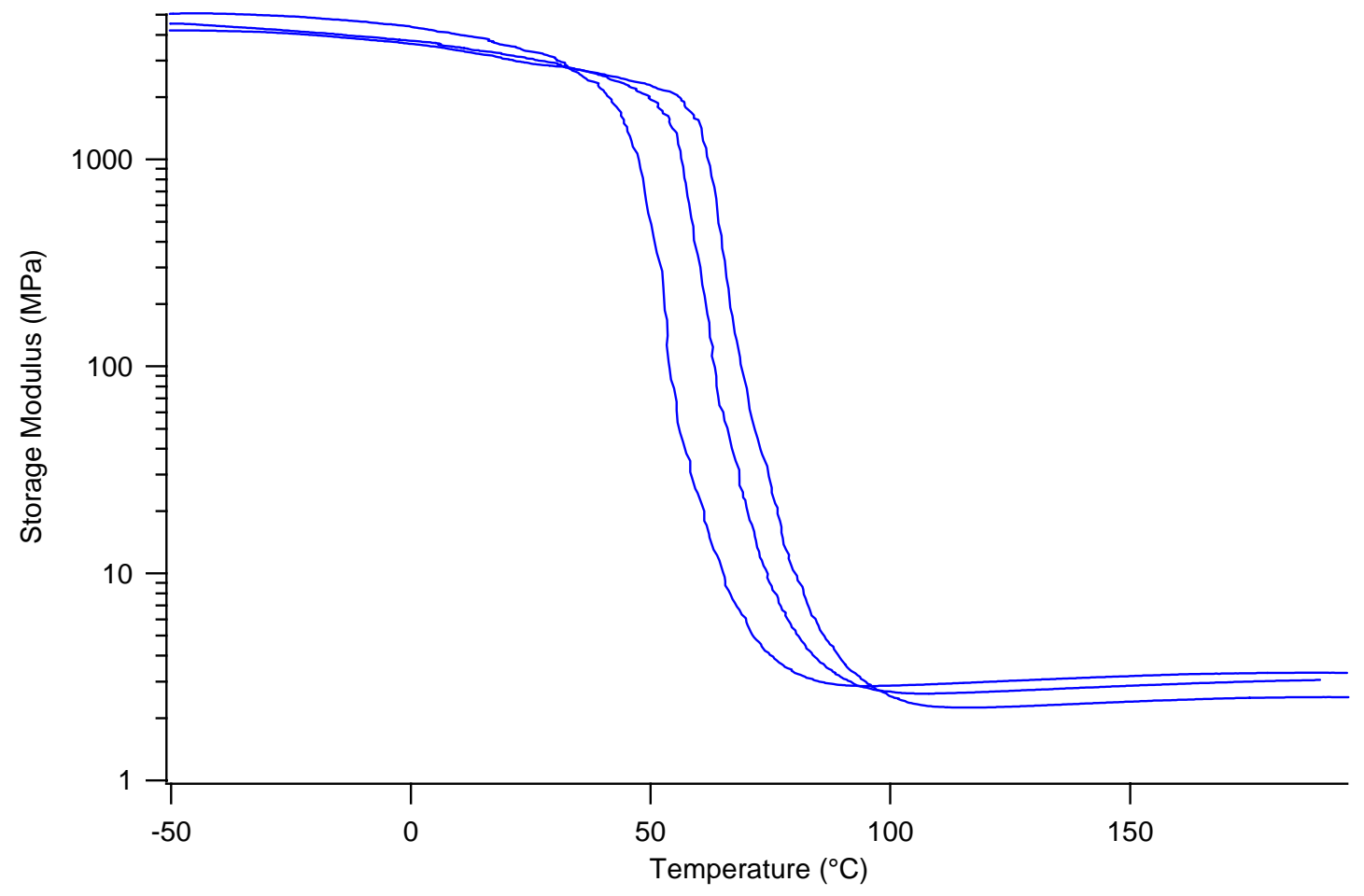

Figure 34. Representative DMA curves of PEGDMA-BMA-EGPEM. 


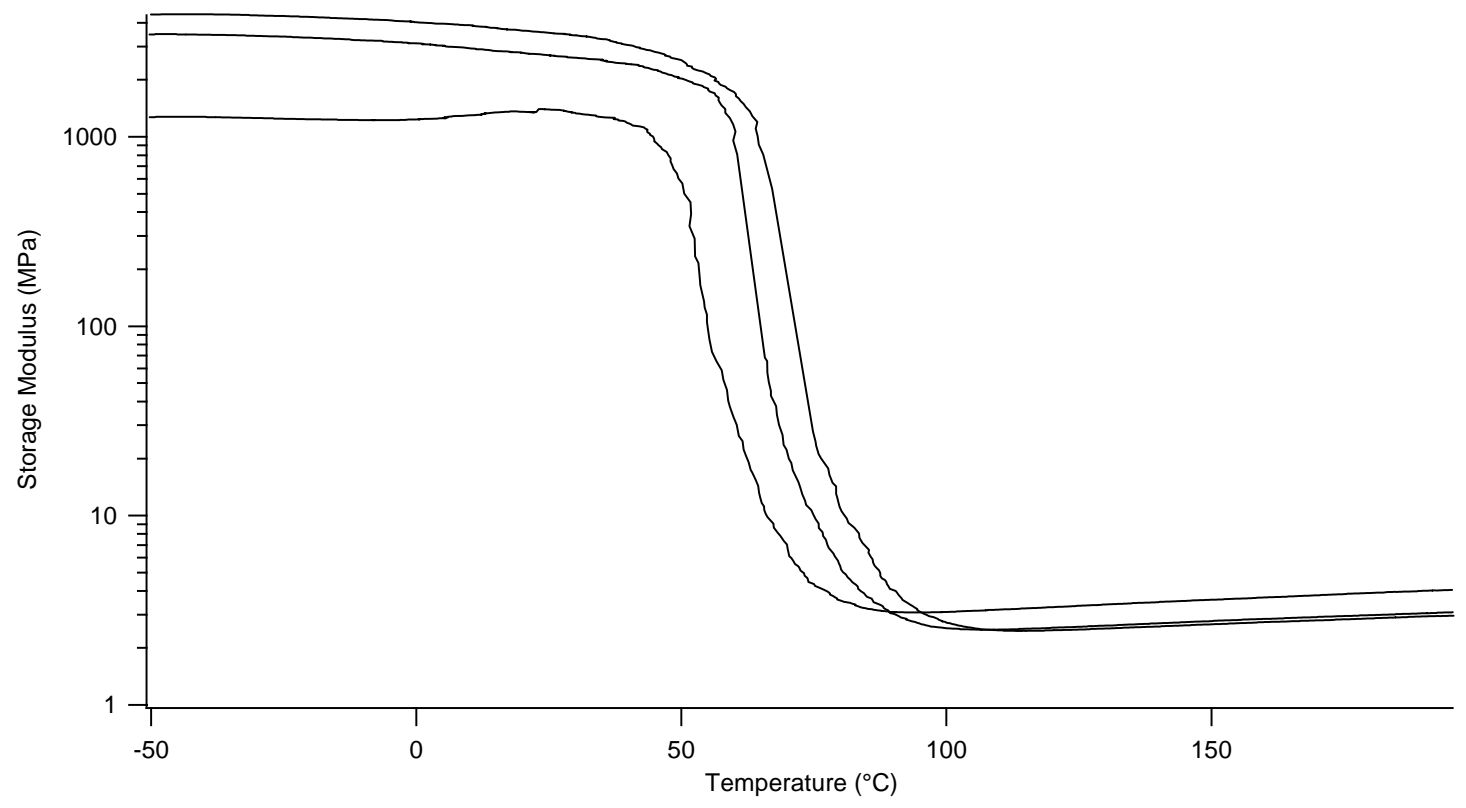

Figure 35. Representative DMA curves of PEGDMA-BMA-tBA.

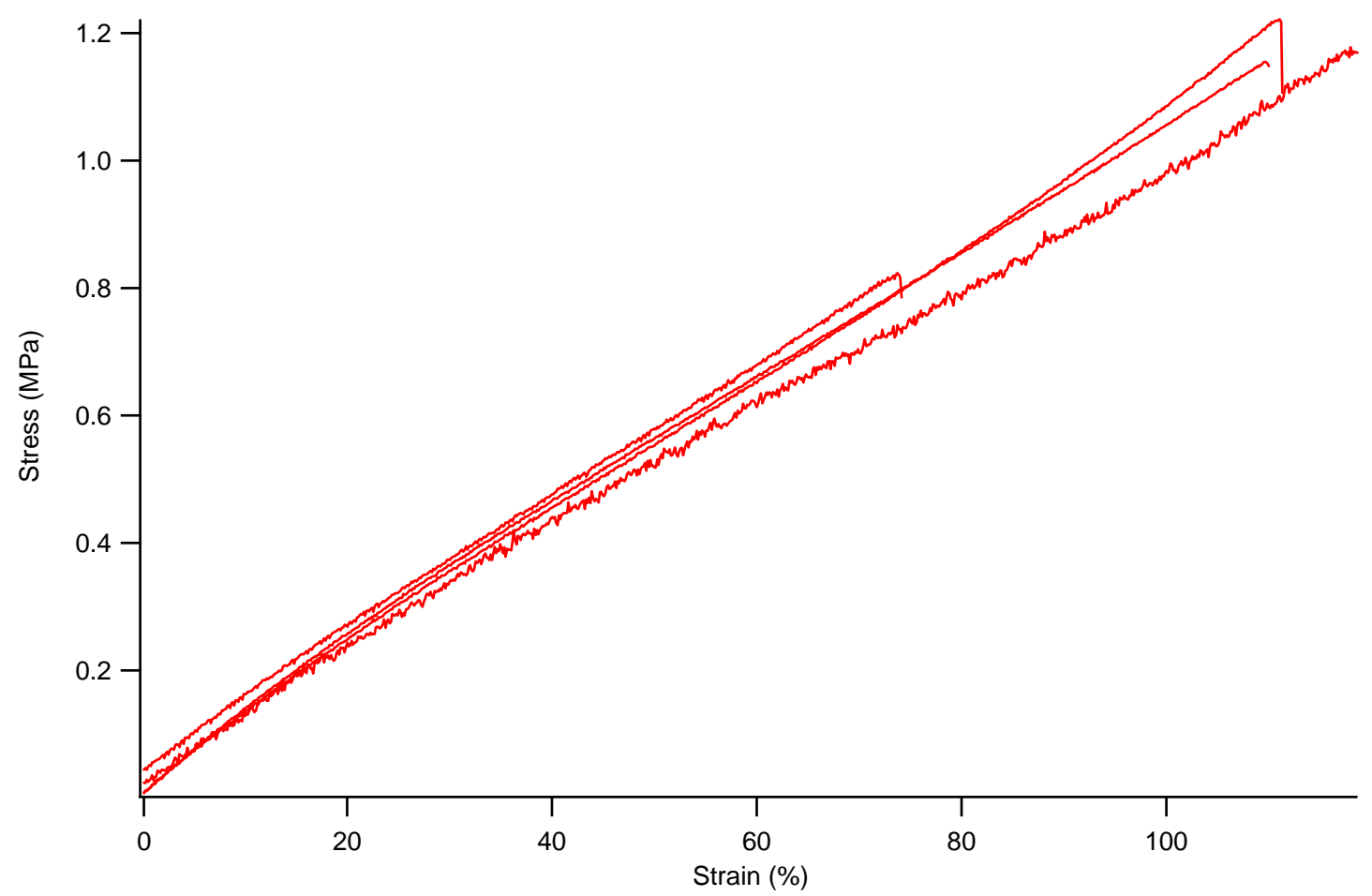

Figure 36. Representative Stress-Strain curves of PEGDMA-BMA-BZA networks. 


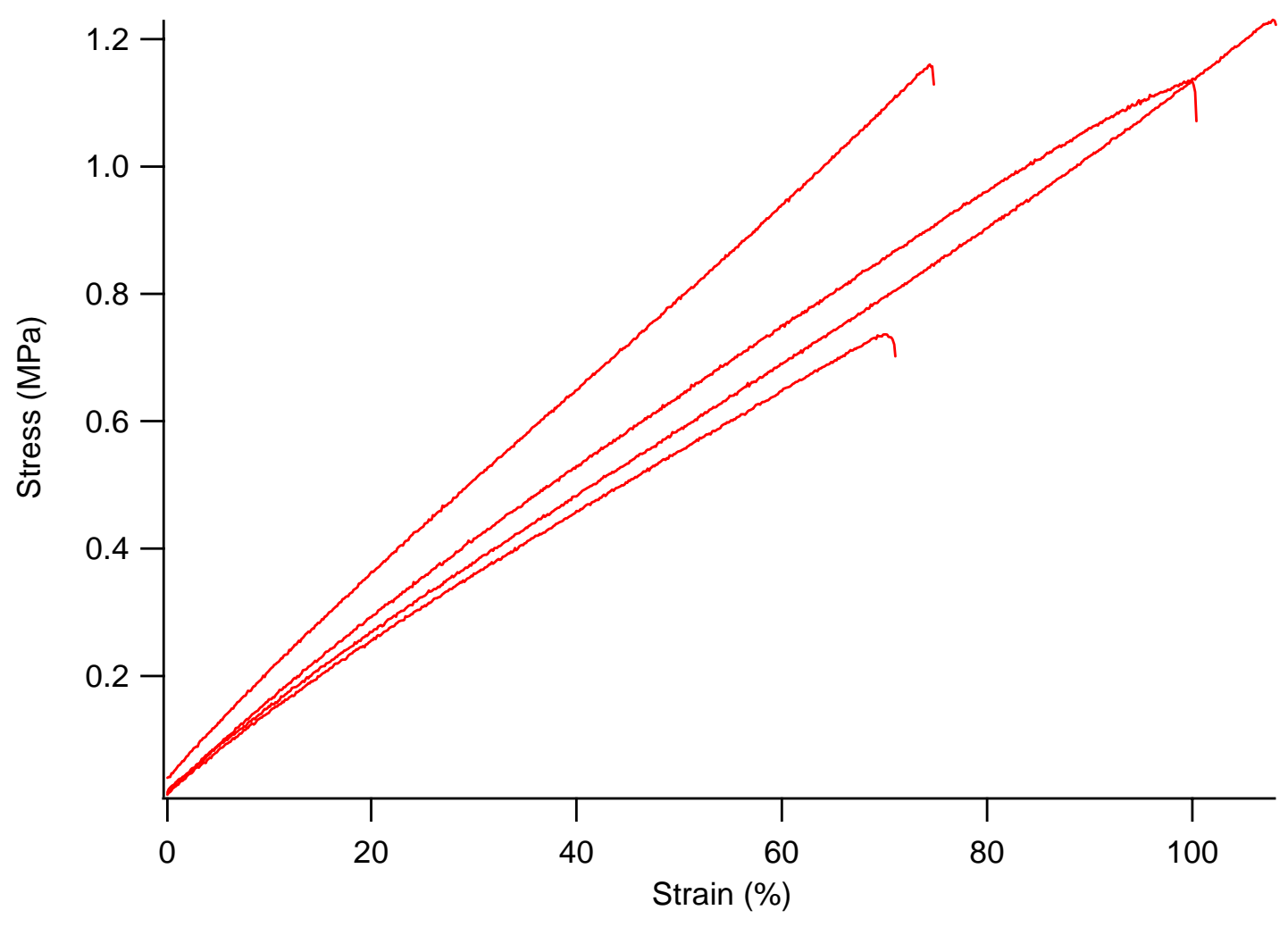

Figure 37. Representative Stress-Strain curves of PEGDMA-BMA-EGPEM networks.

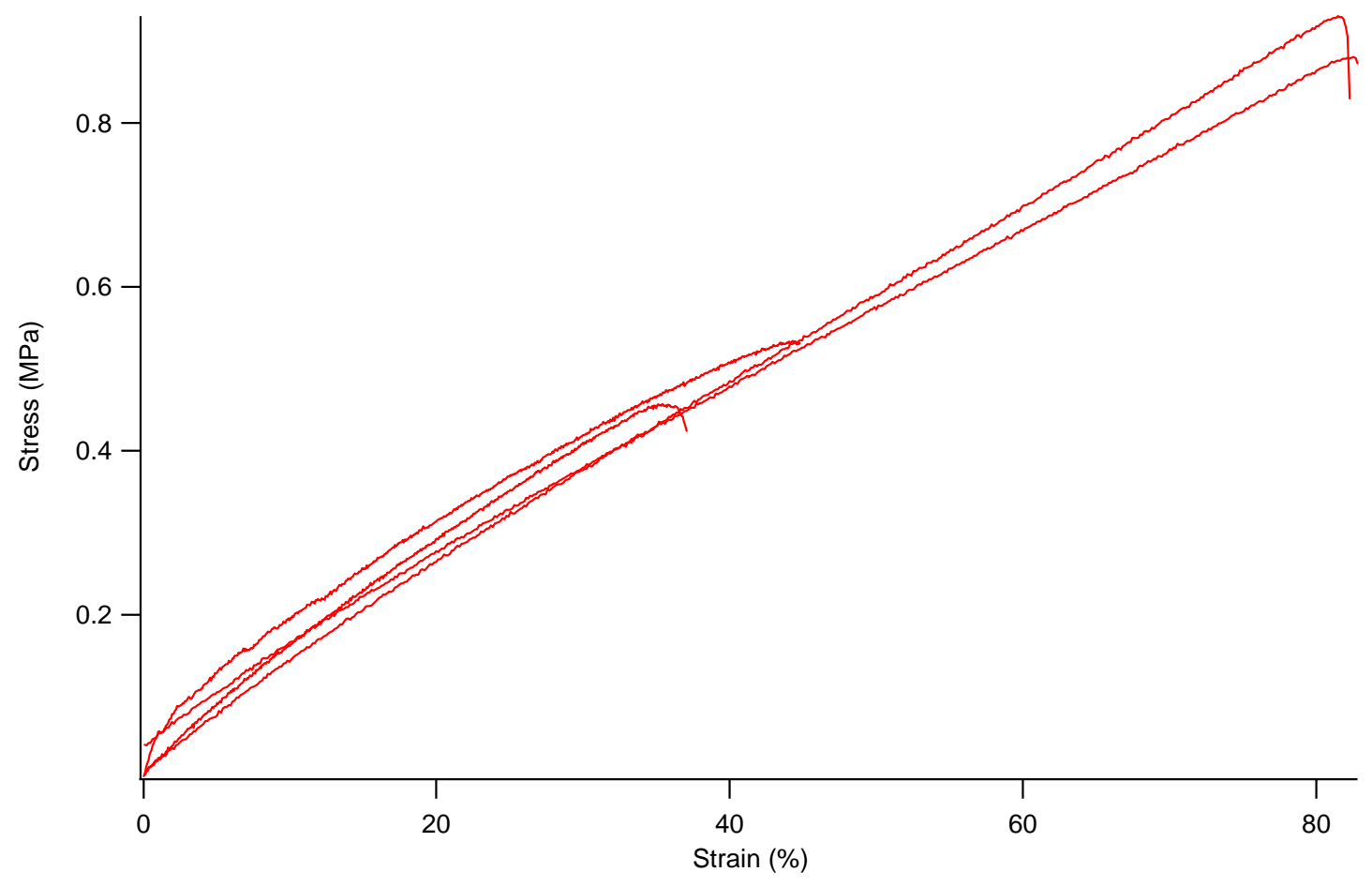

Figure 38. Representative Stress-Strain curves of PEGDMA-BMA-tBA networks. 


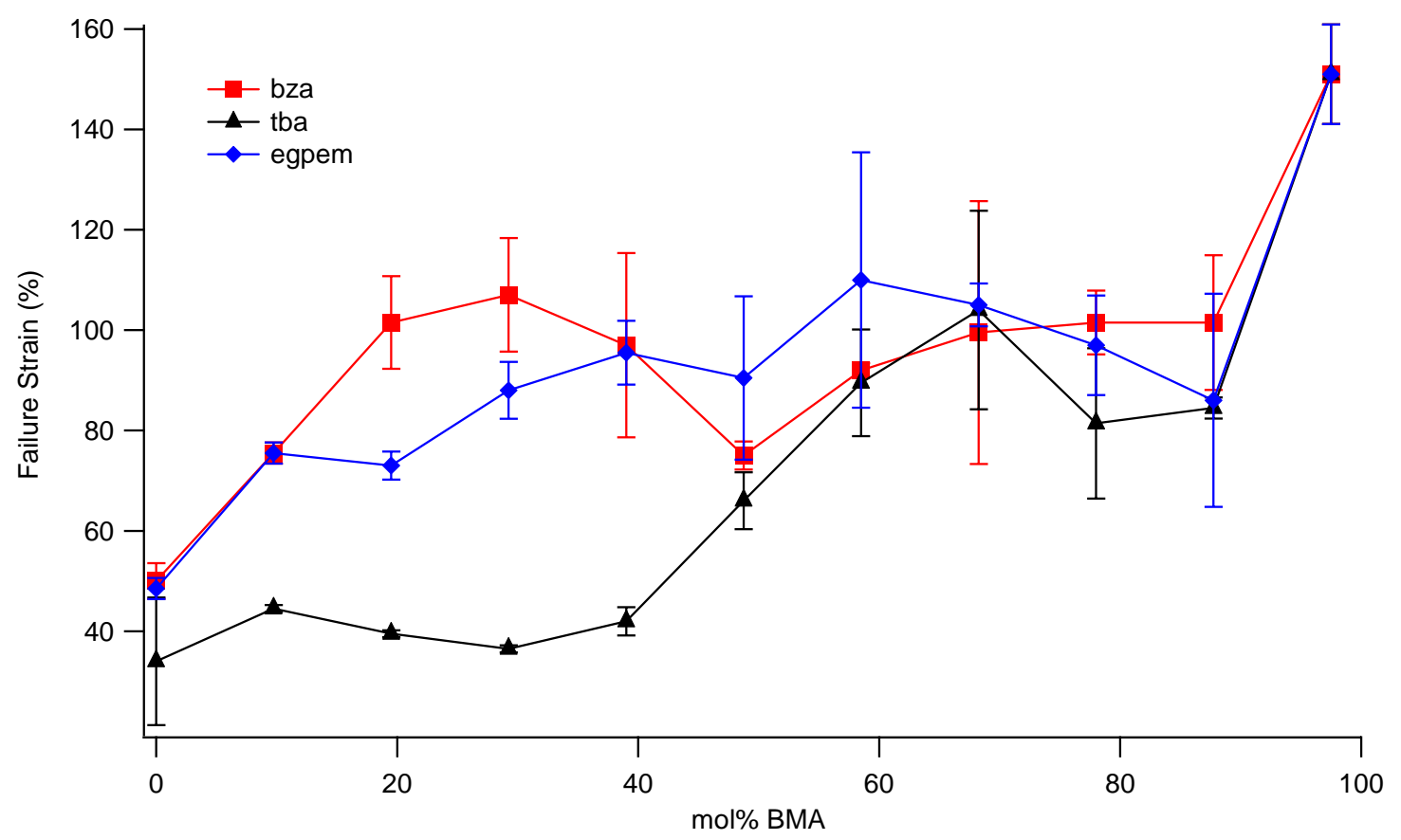

Figure 39. Failure strain as a function of mol \% BMA-co-3rd monomer.

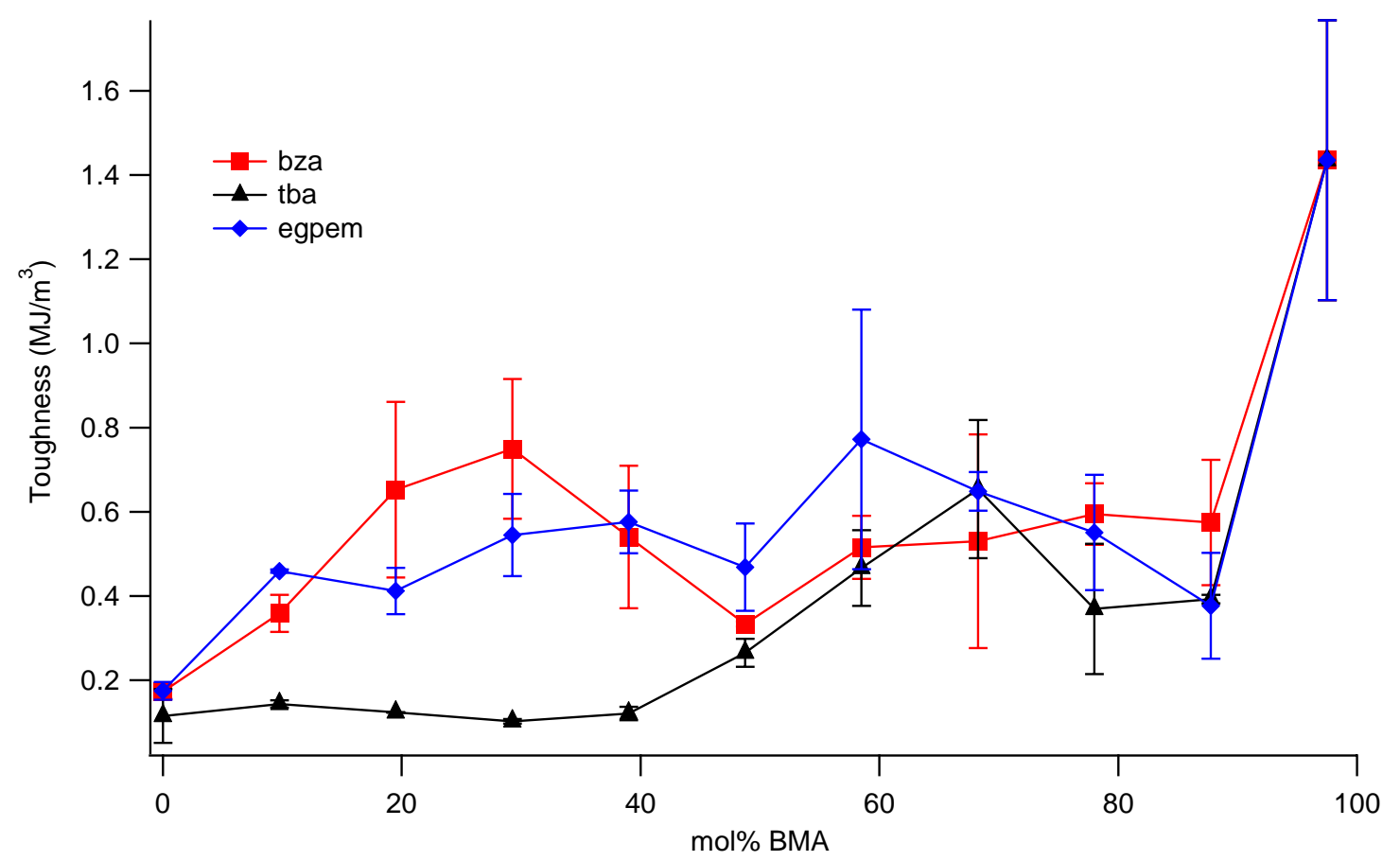

Figure 40. Toughness as a function of mol\% BMA-co-3rd monomer. 


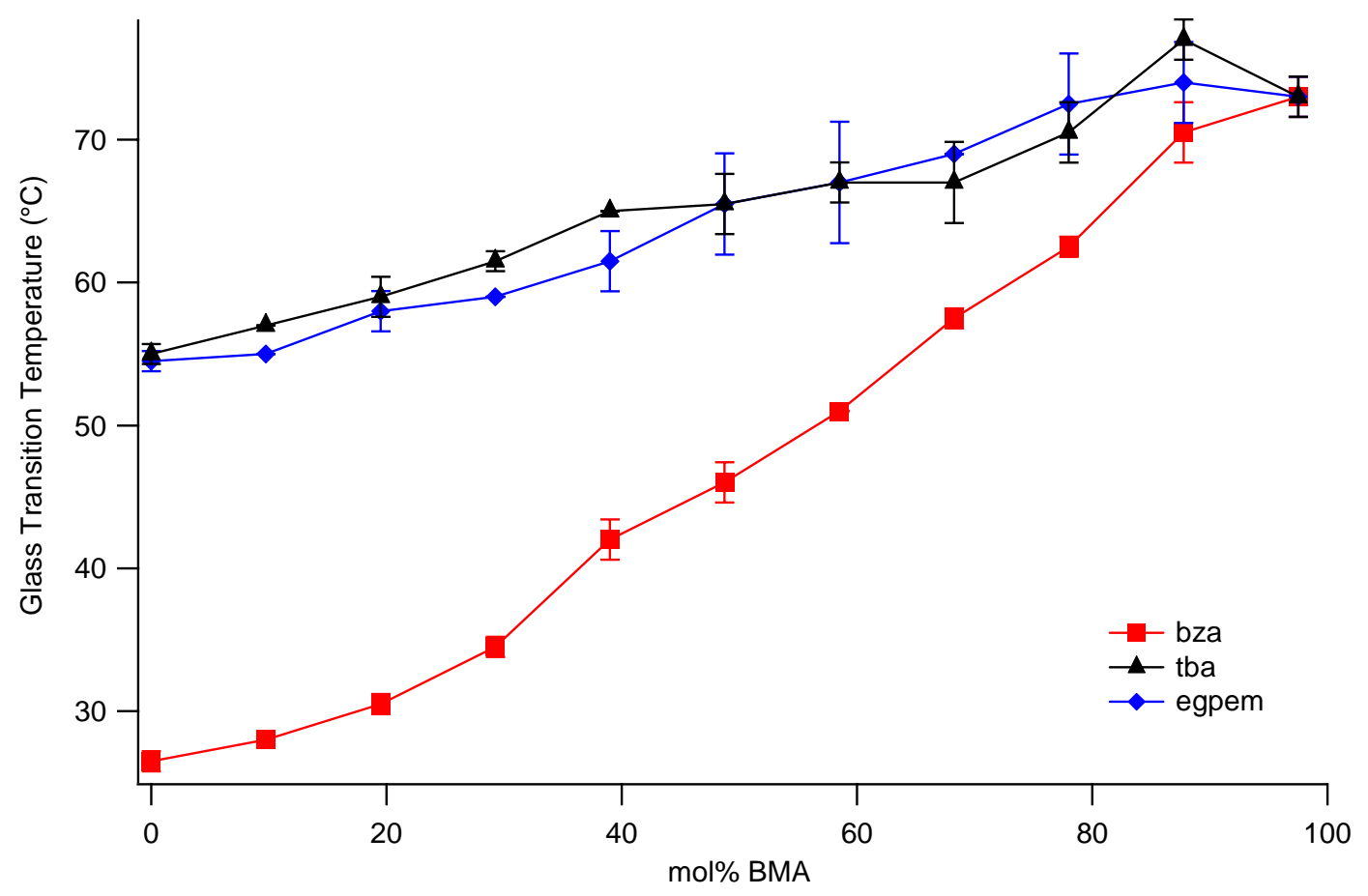

Figure 41. Glass Transition Temperature as a function of mol\% BMA-co-3rd monomer.

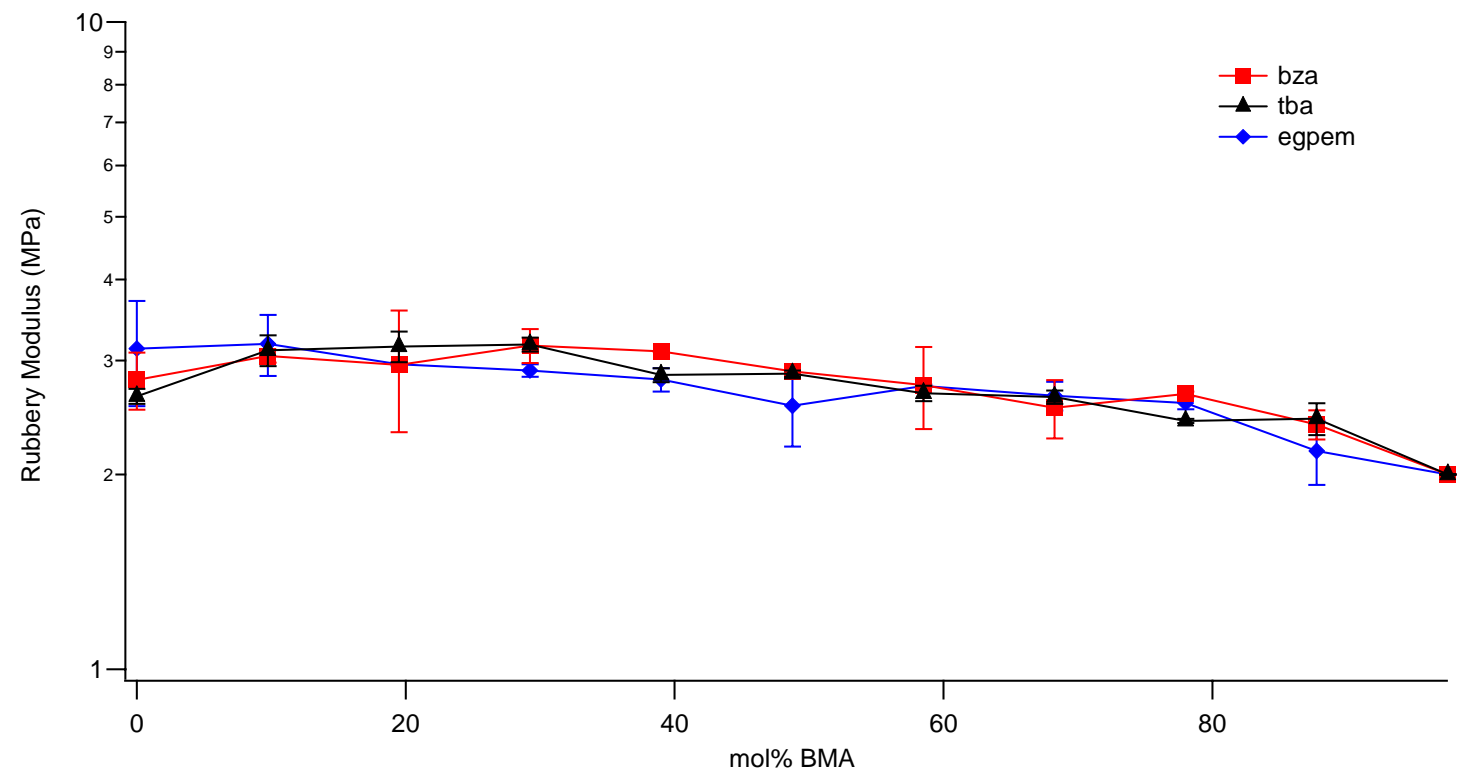

Figure 42. Rubbery Modulus as a function of mol\% BMA-co-3rd monomer. 


\section{CHAPTER 4}

\section{DISCUSSION}

Polymer networks based on (meth)acrylate monomers have the potential for a broad range of thermo-mechanical properties as demonstrated in prior work and were reproduced for the large set of materials herein. In order to understand the role of various component of these networks, mono-functional and multi-functional (meth)acrylates were used to synthesize a broad array of polymer networks. Structure-property relationships were determined in these networks by studying their thermo-mechanical transitions and stress-strain response for systematically varied monomer functionalities, concentrations, and chemistries.

By holding crosslinker concentration constant, the effect of the mono-functional (meth)acrylate chemistry on the networks properties was determined. Chain stiffness and cohesive energy are the main influences on $\mathrm{T}_{\mathrm{g}}$, but conformational motion, crosslinking, and other factors also participate ${ }^{[30]}$. The mono-functional (meth)acrylates with long sidegroups had the lowest $\mathrm{T}_{\mathrm{g}}$ as may be expected based on the reduction of steric hindrance due to the high flexibility of the methylene and ester groups ${ }^{[51]}$. As the sidegroup length decreased and $\alpha$-methyl side groups were added, the $\mathrm{T}_{\mathrm{g}}$ increased due primarily to local steric hindrance of segmental motion and increased cohesive energy between chains ${ }^{[52]}$. The effects are clear when combining the structures in Table A1 with the $\mathrm{T}_{\mathrm{g}}$ data from Table 8 . Even though these (meth)acrylates all have the same backbone, the sidegroup structure determines the $T_{g}$, and similar results in epoxies can be seen

where changing the chemical structure of the amine changes the $T_{\mathrm{g}}{ }^{[22],[53]}$. In summary, 
the combination of both $\alpha$-methyl groups and short, rigid pendant groups on each side of the chain's backbone increases the $\mathrm{T}_{\mathrm{g}}$ as can be seen in MMA and IMA.

In order to understand the effect of the crosslinker functionality on the networks, the mono-functional acrylate, tBA, was held constant and polymerized with various crosslinkers. By increasing the functionality of the network, the heterogeneity of the network increases as does the crosslinking density as measured by the rubbery modulus. This can be seen in Figure 8, where the spread of the $\tan \delta$ increases as the rubbery modulus increases. The most identifiable trend was the relationship between the crosslinkers' functionality and $\mathrm{E}_{\mathrm{r}}$. It is known that as the crosslinkers' functionality increases, the network crosslink density increases, thus increasing $\mathrm{E}_{\mathrm{r}}$. This trend can also be viewed in Figure 9, where the failure strain is plotted against the $\mathrm{E}_{\mathrm{r}}$. Driven by different crosslinking effectiveness, the 16 networks trade off failure strain and rubbery modulus. The majority of the networks with low $\mathrm{E}_{\mathrm{r}}$ had higher failure strains than the high $\mathrm{E}_{\mathrm{r}}$ networks. The materials with high $\mathrm{E}_{\mathrm{r}}$ due to higher functionality were relatively brittle due to high crosslink density.

Aside from basic thermo-mechanical properties, it is important for some applications, and for deeper fundamental understanding, to examine large strain behavior of the networks. Prior work has examined the effect of varying crosslinker length and concentration on the large strain behavior of acrylate networks ${ }^{[35]}$. Here we focus on the reciprocal problem of varying the type of mono-functional monomer with the same crosslinker added in varying concentrations. Five mono-functional monomers were chosen for differences in their transition temperatures, chemical structure, $\mathrm{C}_{\infty}$ and $\mathrm{CED}$ values. 
In order to determine an appropriate testing temperature and provide a rough measure of crosslink density, $T_{g}$ and $E_{r}$ were measured for all five materials across all crosslink densities. Representative data for the systems is presented in Figures 10, 11, 12, 13, and 14. As expected, the $\mathrm{E}_{\mathrm{r}}$ decreases as the concentration of the crosslinker decreases in all networks. Since the selected crosslinker has a relatively low $T_{g}$ value when homopolymerized, the addition of it to all linear monomers serves to reduce $T_{g}$ while increasing rubbery modulus. At $1 \mathrm{~mol} \%$ crosslinker, the networks had approached their final $\mathrm{T}_{\mathrm{g}}$, thus further characterization was not continued for the BZA and EGPEM systems. Also, below a 1 mol\% crosslinker concentration, the networks start to effectively transition to a thermoplastic, which is signified by a loss of their rubbery modulus plateau. The breadth of the transition from the glassy to rubbery state decreases as the concentration of crosslinker decreases, as is expected because highly crosslinked systems have increased heterogeneity. The results here are consistent with previous studies where concentration of crosslinker was varied in acrylates ${ }^{[35]}$. The results in Figures 15 and 17 demonstrate one of the advantages of commercially available (meth)acrylate systems; using combination of linear monomers and crosslinkers, one can independently tailor glass transition temperature and rubbery modulus.

The baseline thermo-mechanical experiments were necessary to assure that the selected test temperature is in the same proximity of an individual composition's $\mathrm{T}_{\mathrm{g}}$ and maintain equivalent states of molecular motion during large strain testing. Driven by their potential application, networks are often tested at room temperature, which can impair the development of structure-property relationships ${ }^{[48],[54],[55],[56],[57]}$. A key finding of the tensile test was the existence of a divergence point, seen in Figure 24 at a rubbery 
modulus of $10 \mathrm{MPa}$. Above $10 \mathrm{MPa}$, the crosslinking dominates the mechanical properties of the network and a relatively brittle response is observed. Although the choice of the mono-functional monomer has minimal impact on mechanical properties at these high crosslink densities, it will influence $\mathrm{T}_{\mathrm{g}}$ of the network and consequently impact mechanical properties at a constant testing temperature. As $\mathrm{E}_{\mathrm{r}}$ is decreased below $10 \mathrm{MPa}$, the large strain mechanical properties of the networks diverge and the capacity for strain and toughness depends on the choice of mono-functional monomer. Soon after entering the mono-functional monomer dominated region, the $T_{\mathrm{g}}$ of each network has reached close to a steady state value and thus there is no correlation between the $T_{g}$ of the network and the failure strain. This is evident in 2EEM and BZA having lower $\mathrm{T}_{\mathrm{g}}$ than tBA, but higher failure strains.

The stress-strain behavior at several rubbery moduli was examined to understand the divergence of the failure strain. In general, the networks transition from brittle to ductile behavior as the $\mathrm{E}_{\mathrm{r}}$ decreased as seen in Figure 25. An inherent trade-off between strength and strain is evident in most networks with exception to the BMA network which exhibited strain-hardening. This can be attributed to the reorientation of chains in the tensile direction ${ }^{[58]}$. Clearly, as $\mathrm{E}_{\mathrm{r}}$ decreases it becomes increasingly important to consider structural parameters of the monofunctional monomers. The failure strain results do not correlate inversely with $\mathrm{C}_{\infty}$ values as is common for thermoplastics. For example the $\mathrm{C}_{\infty}$ value for tBA is significantly lower than $\mathrm{C}_{\infty}$ for BMA although the latter has significantly higher failure strain at equivalent rubbery modulus. This observation implies that the capacity for network backbone chains to coil, as measured by $\mathrm{C}_{\infty}$, is incapable of predicting failure strain and toughness properties once these chains are 
moderately crosslinked. It seems that factors that toughen thermoplastics, such as coilability and high entanglement density are rendered less important due to chemical crosslinking $^{[38]}$. From Figure 28, it can be seen that the $\mathrm{E}_{\mathrm{r}}$ and $\mathrm{E}$ do not exactly match, but differ by a factor of 1.677 . Using the CED values calculated according to Van Krevelen and Fedors, E could be calculated using either Equation 13 or Equation 14 as seen in Table 10. These values of $\mathrm{E}$ are $10^{3}$ times higher than the values of $\mathrm{E}_{\mathrm{r}}$. This is expected because Equation 13 and Equation 14 apply to the polymer at temperatures below $\mathrm{T}_{\mathrm{g}}$. Modified equations need to be developed to predict CED from $\mathrm{E}$ or $\mathrm{E}_{\mathrm{r}}$ at temperatures near or above $\mathrm{T}_{\mathrm{g}}$, but must also take into account the crosslinking density of the network. On the other hand, the CED may be used for relative comparison to determine if a material will strain farther through enhanced network toughness, as seen by combining Table 7 and the trends from Figure 24. For example, networks with phenyl rings exhibit higher failure strains as the $\mathrm{E}_{\mathrm{r}}$ decreases due to the increasing CED. Thus, in networks, which have chemical crosslinks dominating deformability, strain to failure can be enhanced through improved toughness by increasing CED between chains.

Toughness was evaluated because of its importance for producing high recovery forces and high strains. Similar to failure strain, toughness diverges at $10 \mathrm{MPa}$, as seen in Figure 26. The toughness was near constant as $\mathrm{E}_{\mathrm{r}}$ varied below $10 \mathrm{MPa}$ due to the tradeoff between strength and strain. Due to the strain hardening that is observable in the stress strain behavior, BMA has the highest toughness within this region while the other linear monomers have the same lower amount of toughness. The parameter $\mathrm{C}_{\infty}$ further breaks down when examining network toughness. From Figure 27, BZA, EGPEM, and 2EEM have different calculated $\mathrm{C}_{\infty}$, but exhibit similar levels of toughness. Therefore, $\mathrm{C}_{\infty}$ is not 
applicable as a measure of toughness in (meth)acrylate networks, even at low crosslink densities.

In order to verify the inherently superior mechanical properties of BMA networks, the test temperature should be ruled out as a factor affecting mechanical properties. To assure test temperature was not a factor in comparison of the networks, PEGDMA550co-BMA and PEGDMA550-co-tBA at the same mol\% crosslinker, were tested over a wide temperature range. These two materials were chosen because their failure strains and test temperatures differed by $100 \%$ and by more than $10^{\circ} \mathrm{C}$, respectively. Considering a sweep of test temperatures, the PEGDMA550-co-BMA network has an inherent capacity for more deformation as seen in Figure 31 and Figure 32. Conclusive structure-property relationships were made using relative temperatures from $T_{g}$. The $T-T_{g}$ indicates the temperature at which the maximum failure strain will occur, not which network will strain farther. Thus, the choice of mono-functional monomer controls the strain capacity under identical conditions of crosslinking density and relative test temperature.

To ascertain the influence of different mono-functional monomers on mechanical properties, binary mixtures of mono-functional monomers with constant crosslinker concentration were formulated. With the BMA network as an upper bound of properties, the failure strain and toughness rise as BMA concentration increases, seen in Figure 39 and 40. The properties of the BMA-BZA mixtures increase as the concentration of the $\alpha$ methyl group increases, suggesting that the increased steric hindrance from the $\alpha$-methyl group affects the mechanical properties. Likewise, the properties of the BMA-EGPEM mixtures increase as the phenyl ring is moved closer to the backbone by the subtraction 
of flexible ethylene glycol groups. Given these two trends, the transition from 100\% tBA to $100 \%$ BMA is significant because both $\alpha$-methyl and phenyl ring groups are being added to the network with increased BMA concentration. tBA lacks substantial deformation capacity because the failure strain and toughness do not increase until the majority of the network is BMA. Selection of materials can be guided by combining the failure strain, toughness, and $T_{g}$ as a function of concentration, available in Figure 41 . BMA-EGPEM and BMA-tBA have different mechanical properties at low concentrations of BMA, but have similar $\mathrm{T}_{\mathrm{g}}$ throughout the systems. Therefore, the mechanical properties are governed by the monomer structure, not the $T_{g}$, at constant crosslinker concentration.

A method to theoretically predict (meth)acrylate network properties based upon the chemistry and structure has yet to be established. From this study, properties such as failure strain, toughness, $T_{g}$, and $E_{r}$ can be tailored by varying the components of the network. The macromolecular parameter $\mathrm{C}_{\infty}$ is incapable of predicting failure strain and toughness in moderately crosslinked networks while CED can be used with moderate success in acrylate networks. New predictive parameters need to be developed or previous ones augmented to take into account key characteristics of network structure. For instance, the monomer structure dominates the network in the glassy region and can be treated like a thermoplastic, while the crosslinked structure, not the individual monomer components, controls the properties of the material in the rubbery region. The viscoelastic region is of great importance because shape-memory polymers rely on approaching their $\mathrm{T}_{\mathrm{g}}$ for actuation. In this region, both the monomer and network structure play a role in the properties of the material ${ }^{[48]}$ as was demonstrated here. 


\section{CHAPTER 5}

\section{CONCLUSION}

The $\mathrm{T}_{\mathrm{g}}$ of (meth)acrylate networks increases by adding $\alpha$-methyl groups and moving bulky sidegroups close to the backbone. The crosslinking density rises as the functionality of crosslinkers increases, thus increasing the $\mathrm{E}_{\mathrm{r}}$ and lowering failure strain. By varying chemistry and crosslinking density, a divergence point is revealed, which delineates the crosslink-dominated region from the mono-functional monomer-dominated region. $\mathrm{C}_{\infty}$ was not an accurate predictor of network mechanical properties, particularly failure strain and toughness at equivalent crosslink density. However, CED provided relative estimates of network strain to failure and toughness. (Meth)acrylates with phenyl rings close to the backbone proved to have superior large-strain mechanical properties. This was confirmed across a range of temperatures and by ternary polymer systems. This study provides insight into relating structure-mechanical property relationships in (meth)acrylates, but an encompassing theory for the prediction of large-strain properties of networks of mono-functional and di-functional (meth)acrylates that incorporates chemical structure needs further study. 


\section{APPENDIX A}

CHEMICAL STRUCTURES, MOLECULAR WEIGHTS, AND CONVERSIONS

Table A1. Mono-functional Monomers

\begin{tabular}{|c|c|c|}
\hline Monomer & Structure & $\begin{array}{l}\text { Molecular } \\
\text { weight(g/mol) }\end{array}$ \\
\hline $\begin{array}{l}\text { Methyl acrylate } \\
\text { (MA) }\end{array}$ & 0 & 86.09 \\
\hline $\begin{array}{l}\text { Methyl } \\
\text { methacrylate(M } \\
\text { MA) }\end{array}$ & & 100.12 \\
\hline $\begin{array}{l}\text { Butyl } \\
\text { acrylate(BA) }\end{array}$ & & 128.17 \\
\hline $\begin{array}{l}\text { tert-Butyl } \\
\text { acrylate(tBA) }\end{array}$ & 0 & 128.17 \\
\hline $\begin{array}{l}\text { tert-Butyl } \\
\text { methacrylate(tB } \\
\text { MA) }\end{array}$ & 0 & 142.20 \\
\hline
\end{tabular}


Table A1. Continued

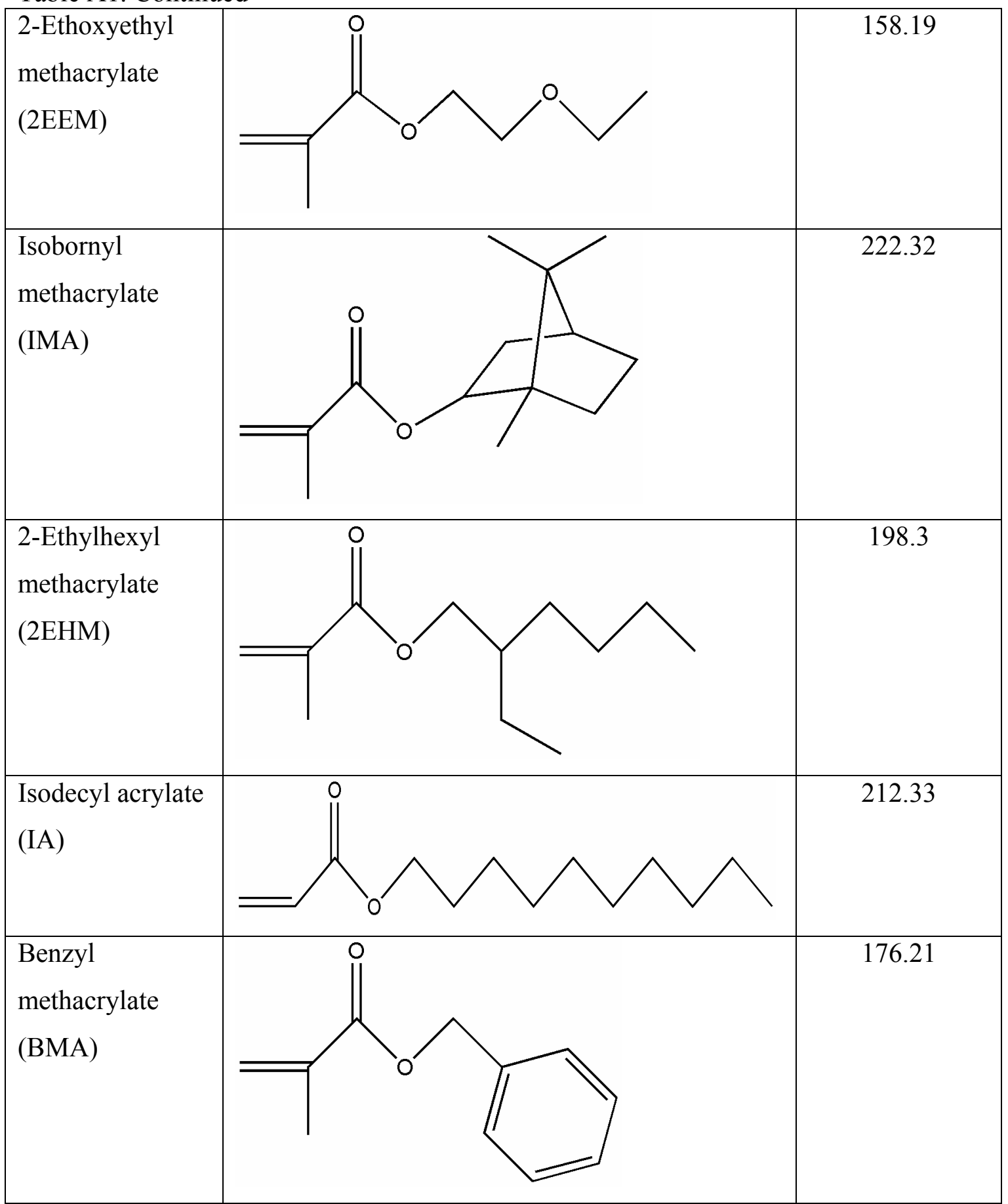


Table A1. Continued

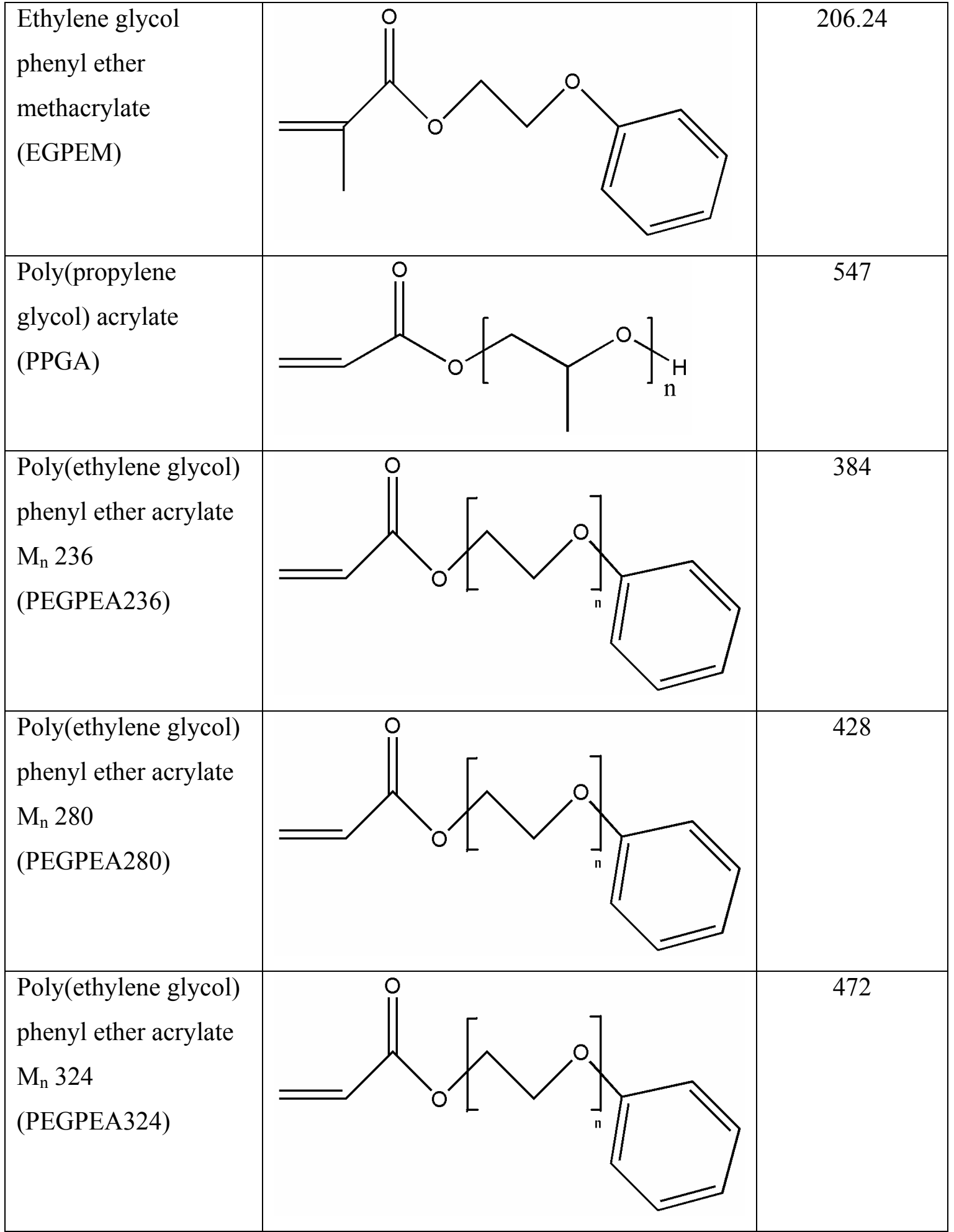


Table A1. Continued

\begin{tabular}{|l|l|l|}
\hline Benzyl acrylate \\
(BZA)
\end{tabular}

Table A2. Multi-functional Monomers

\begin{tabular}{|l|l|l|}
\hline Monomer & $\begin{array}{l}\text { Molecular } \\
\text { Weight }\end{array}$ \\
\hline $\begin{array}{l}\text { Bisphenol A } \\
\text { ethoxylate }\end{array}$ & \\
dimethacrylate \\
(BPA1700)
\end{tabular}


Table A2. Continued

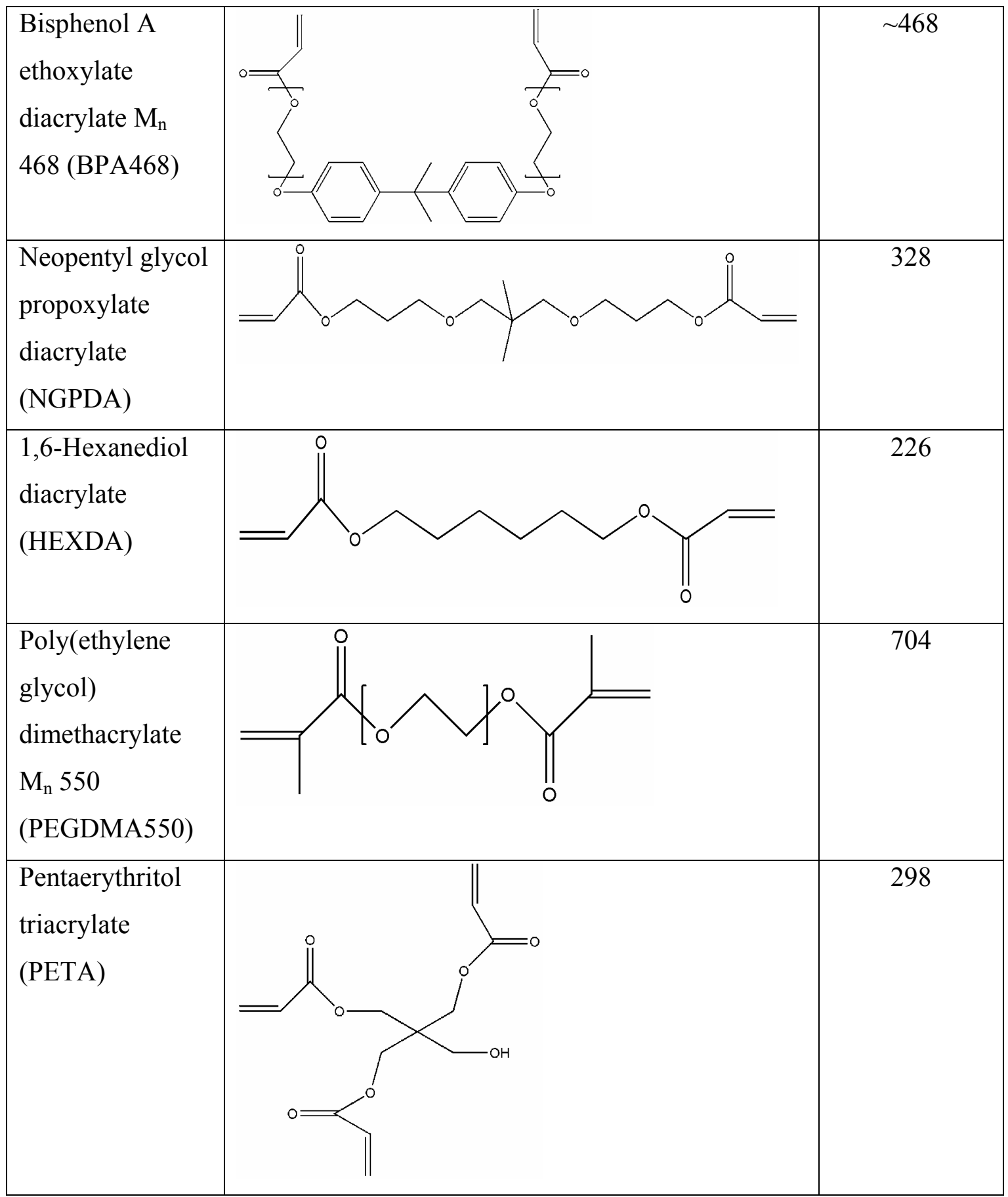


Table A2. Continued

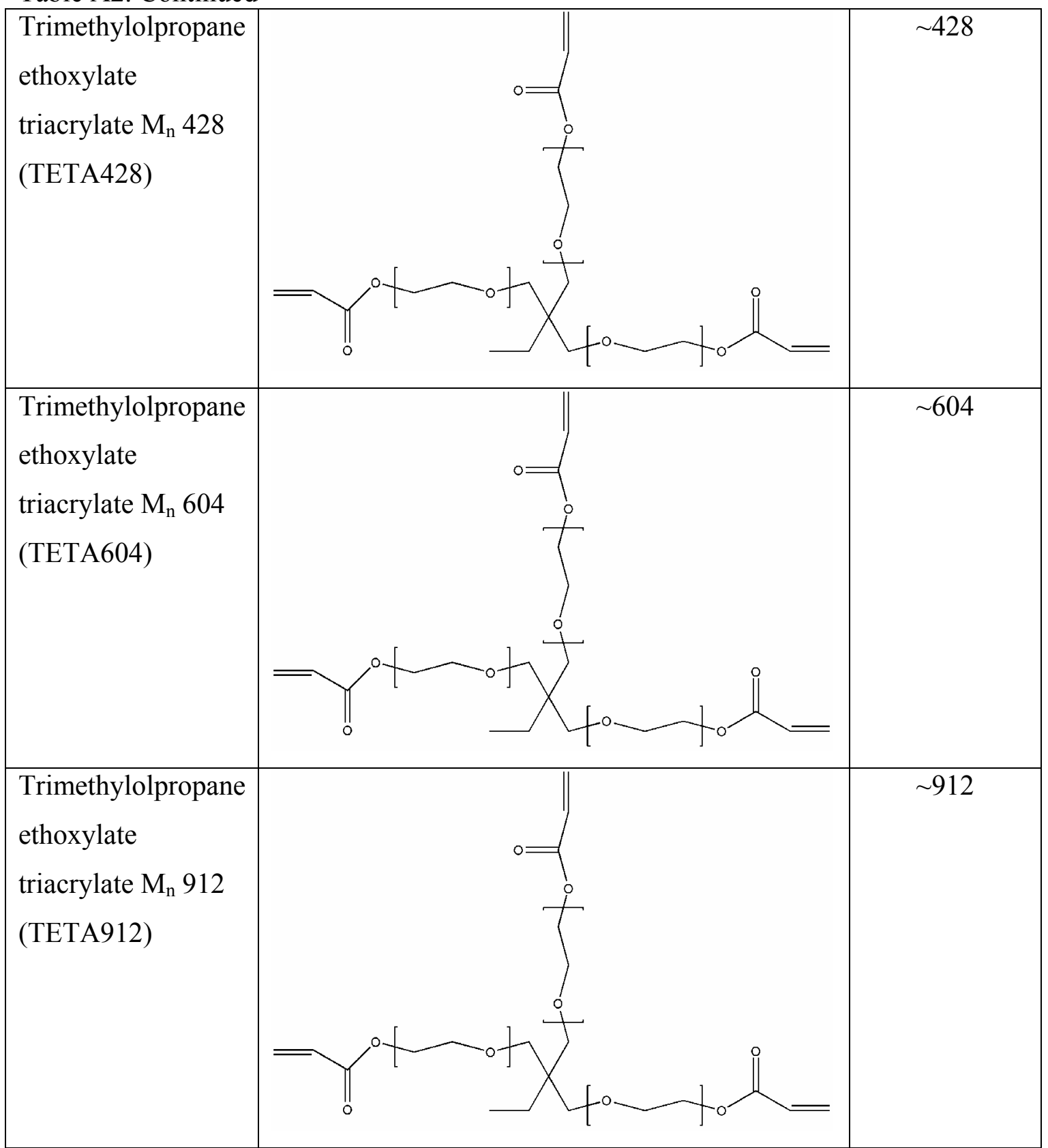


Table A2. Continued

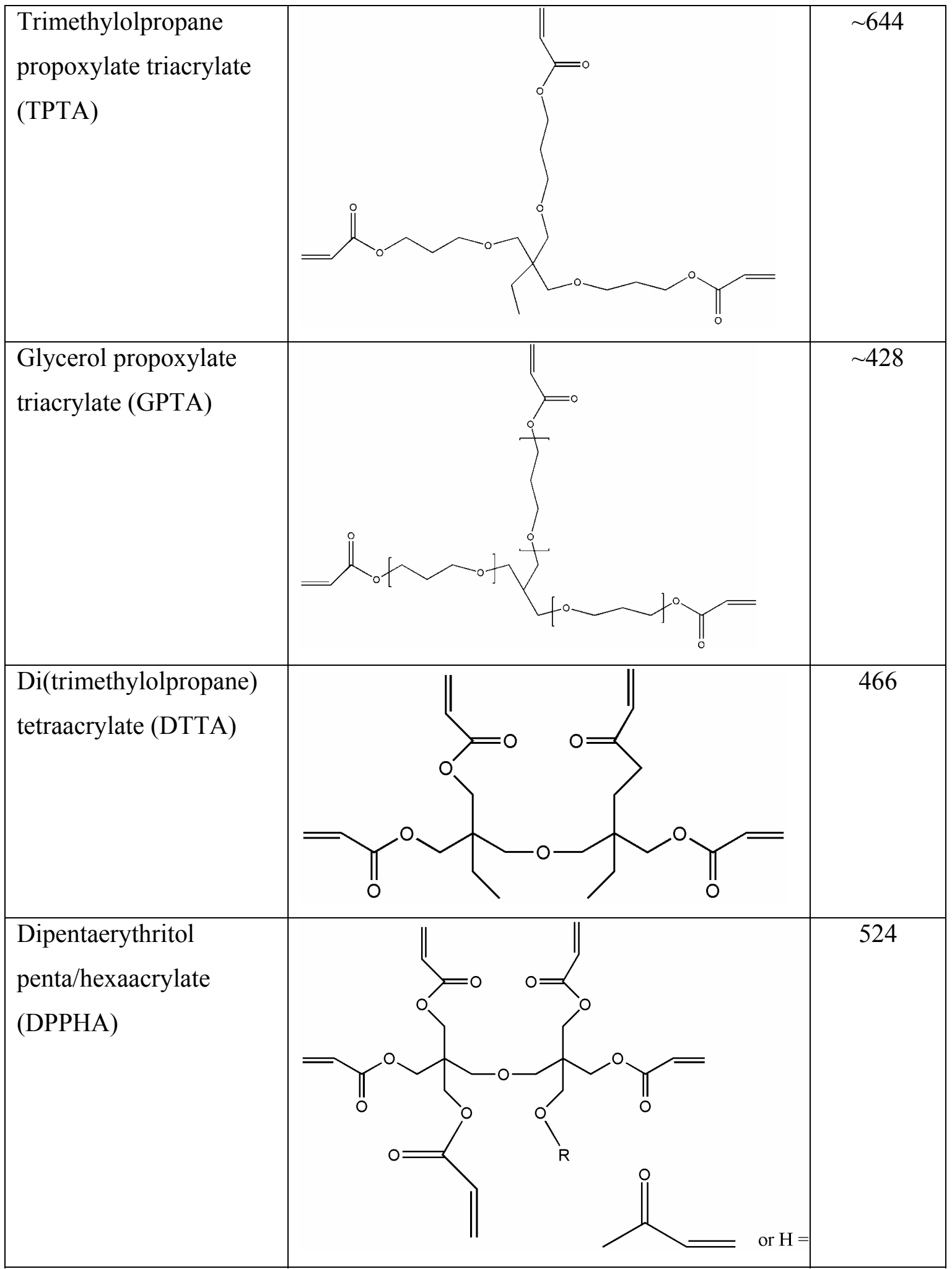


Table A3. Wt $\%$ Conversion of Ternary Networks of PEGDMA550-BMA-BZA

$\begin{array}{rrr}\text { Wt\% PEGDMA550 } & \text { Wt\% BMA } & \text { Wt\% BZA } \\ 0.094 & 0.822 & 0.084 \\ 0.094 & 0.736 & 0.169 \\ 0.095 & 0.649 & 0.256 \\ 0.096 & 0.560 & 0.344 \\ 0.096 & 0.471 & 0.433 \\ 0.097 & 0.379 & 0.524 \\ 0.098 & 0.287 & 0.616 \\ 0.099 & 0.193 & 0.709 \\ 0.099 & 0.097 & 0.804\end{array}$

Table A4. Wt $\%$ Conversion of Ternary Networks of PEGDMA-BMA-tBA

$\begin{array}{rrr}\text { Wt\% PEGDMA550 } & \text { Wt\% BMA } & \text { Wt } \% \text { tBA } \\ 0.095 & 0.837 & 0.068 \\ 0.098 & 0.763 & 0.139 \\ 0.100 & 0.686 & 0.214 \\ 0.103 & 0.604 & 0.293 \\ 0.106 & 0.518 & 0.376 \\ 0.109 & 0.426 & 0.465 \\ 0.112 & 0.329 & 0.559 \\ 0.116 & 0.226 & 0.658 \\ 0.120 & 0.117 & 0.764\end{array}$

Table A5. Wt $\%$ Conversion of Ternary Networks of PEGDMA-BMA-EGPEM

$\begin{array}{rrr}\text { Wt\% PEGDMA550 } & \text { Wt\% BMA } & \text { Wt\% EGPEM } \\ 0.092 & 0.804 & 0.105 \\ 0.090 & 0.704 & 0.206 \\ 0.089 & 0.607 & 0.304 \\ 0.088 & 0.513 & 0.400 \\ 0.086 & 0.421 & 0.493 \\ 0.085 & 0.332 & 0.583 \\ 0.084 & 0.246 & 0.671 \\ 0.083 & 0.161 & 0.756 \\ 0.082 & 0.080 & 0.839\end{array}$




\section{REFERENCES}

1. Maitland, D. J., et.al., Photothermal Properties of Shape Memory Polymer MicroActuators for Treating Stroke. Lasers in Surgery and Medicine, 2002. 30: p. 1-11.

2. Yakacki, C. M., et.al., Unconstrained recovery characterization of shape-memory polymer networks for cardiovascular applications. Biomaterials, 2007. 28: p. 2255-2263.

3. Sharp, A. A., et.al., Toward a self-deploying shape memory polymer neuronal electrode. Journal of Neural Engineering, 2006. 3: p. L-23-L30.

4. Flory, P. J., Principles of Polymer Chemistry. 1969, Ithaca: Cornell University Press.

5. Treloar, L. R. G., The Physics of Rubber Elasticity. 1958, Oxford: Clarendon Press.

6. Mohr, R., et.al., Initiation of shape-memory effect by inductive heating of magnetic nanoparticles in thermoplastic polymers. Proceedings of the National Academy of Sciences of the United States of America, 2006. 103(10): p. 3540.

7. Jiang, H., Kelch, S., Lendlein, A., Polymers Move in Response to Light. Advanced Materials, 2006. 18: p. 1471-1475.

8. Bowman, C. N., Peppas, N.A., A Kinetic Gelation Method for the Simulation of Free-Radical Polymerizations. Chemical Engineering Science, 1992. 47: p. 14111419.

9. Kannurpatti, A. R., Anseth, J.W., Bowman, C.N., A study of the evolution of mechanical properties and structural heterogeneity of polymer networks formed by photopolymerizations of mutlifunctional (meth)acrylates. Polymer, 1998. 39: p. 2507-2513.

10. Anseth, K. S., Wang, C.M., Bowman, C.N., Reaction behaviour and kinetic constants for photopolymerizations of multi(meth) acrylate monomers. Polymer, 1994. 35: p. 3243-3250.

11. Anseth, K. S., Bowman, C.N., Kinetic Gelation Model Predictions of Crosslinked Polymer Network Microstructure. Chemical Engineering Science, 1994. 49: p. 2207-2217. 
12. Bowman, C. N., et.al., Polymers for information storage systems III. Crosslinked structure of polydimethacrylates. Polymer, 1990. 31: p. 135-139.

13. Goodner, M. D., Bowman, C.N., Development of a comprehensive free radical photopolymerization model incorporating heat and mass transfer effects in thick films. Chemical Engineering Science, 2002. 57: p. 887-900.

14. Lovell, L. G., Bowman, C.N., The effect of kinetic chain length on the mechanical relaxation of crosslinked photopolymers. Polymer, 2003. 44: p. 39-47.

15. Anseth, K. S., Anderson, K.J., Bowman, C.N., Radical concentrations, environments, and reactivities during crosslinking polymerizations. Macromolecular Chemistry and Physics, 1996. 197: p. 833-848.

16. Matsumoto, A., Ando, H., Oiwa, M., Gelation in the Copolymerization of Methyl Methacrylate with Trimethylolpropane Trimethacrylate. European Polymer Journal, 1989. 25: p. 385-389.

17. Bastide, J., Leibler, L., Large-Scale Heterogeneities in Randomly Cross-Linked Networks. Macromolecules, 1988. 21: p. 2647-2649.

18. Parker, M. S., Krasnansky, V.J., Achhammer, B.G., Effects of Composition and Irradiation on the Glass Transition Temperature of Methyl Methacrylate-Styrene Copolymers. Journal of Applied Polymer Science, 1964. 8: p. 1825-1838.

19. Bellenger, V., Mortaigne, B., Verdu, J., Structure-Property Relationships for Styrene Crosslinked Polyesters.II.Glass Transition Temperature. Journal of Applied Polymer Science, 1992. 44: p. 653-661.

20. Gargallo, L., Russo, M., Effect of Structure on Glass Transition Temperatures of Poly(methacrylic ester)s with Bulky Side Groups. Die Makromolekulare Chemie, 1975. 176: p. 2735-2744.

21. Hayes, R. A., The Relationship Between Glass Temperature, Molar Cohesion, and Polymer Structure. Journal of Applied Polymer Science, 1961. 5: p. 318-321.

22. Lesser, A. J., Crawford, E., The Role of Network Architecture on the Glass Transition Temperature of Epoxy Resins. Journal of Applied Polymer Science, 1997. 66: p. 387-395.

23. Bicerano, J., Sammler, R.L., Carriere, C.J., Seitz, J.T., Correlation between Glass Transition Temperature and Chain Structure for Randomly Crosslinked High Polymers. Journal of Polymer Science Part B: Polymer Physics, 1996. 34: p. 2247-2259. 
24. Stutz, H., Illers, K.H., Mertes, J., A Generalized Theory for the Glass Transition Temperature of Crosslinked and Uncrosslinked Polymers. Journal of Polymer Science Part B: Polymer Physics, 1990. 28: p. 1483-1498.

25. Cook, W. D., Delatycki, O., Relaxations in the Transition Region of Crosslinked Polyesters. II. The Glass Transition. Journal of Polymer Science Part B: Polymer Physics, 1974. 12: p. 1925-1937.

26. Fox, T. G., Loshaek, S., Influence of Molecular Weight and Degree of Crosslinking on the Specific Volume and Glass Temperature of Polymers. Journal of Polymer Science, 1955. 15: p. 371-390.

27. Loshaek, S., Crosslinked Polymers, II. Glass Temperatures of Copolymers of Methyl Methacrylate and Glycol Dimethacrylates. Journal of Polymer Science, 1955. 15: p. 391-404.

28. Riande, E., et.al., ed. Polymer Viscoelasticity. 2000, Marcel Dekker: New York.

29. Rodriguez, F., et.al., Principles of Polymer Systems. 2003, New York: Taylor and Frances.

30. Bicerano, J., Prediction of Polymer Properties. 1996, New York: Marcel Dekker.

31. Yakacki, C. M., et.al., Strong, Tailored, Biocompatible Shape-Memory Polymer Networks. Submitted to Advanced Functional Materials, 2008.

32. Tobolsky, A. V., Katz, D., Thach, R., Schaffhauser, R. , Rubber Elasticity in a Highly Crosslinked System. Journal of Polymer Science, 1962. 62: p. S176-S177.

33. Gall, K., et.al., Thermomechanics of the shape memory effect in polymers for biomedical applications. Journal of Biomedical Materials Research Part A, 2005. 73A: p. 339-348.

34. Raab, M., Janacek, J. , Effect of Chemical Crosslinks on Ultimate Tensile Properties of Water Swollen Poly(2-Hydroxyethyl Methacrylate) Gels. International Journal of Polymeric Materials, 1972. 1: p. 147-158.

35. Ortega, A. M., et.al., Structure-Property Relationships in Photopolymerizable Polymer Networks: Composition and crosslinking effects on the structure and thermomechanical properties of a model (meth)acrylate system. In Review. 2008.

36. Flory, P. J., Statistical Mechanics of Chain Molecules. 1969, New York: Interscience.

37. Wu, S., Predicting Chain Conformation and Entanglement of Polymers from Chemical Structure. Polymer Engineering and Science, 1992. 32: p. 823-830. 
38. Wu, S., Control of Intrinsic Brittleness and Toughness of Polymers and Blends by Chemical Structure: A Review. Polymer International 1992. 29: p. 229-247.

39. Wu, S., Secondary Relaxation, Brittle-Ductile Transition Temperature, and Chain Structure. Journal of Applied Polymer Science 1992. 46: p. 619-624.

40. Xu, Z., Hadjichristidis, N., Fetters, L.J., Mays, J.W., Structure/Chain-Flexibility Relationships of Polymers, in Advances in Polymer Science. 1995, Spring-Verlag: Berlin.

41. Van Krevelen, D. W., Properties of Polymers. 1972, Amsterdam: Elsevier.

42. Ahmad, H., Yaseen, M., Application of Chemical Group Contribution Technique for Calculating Solubility Parameters of Polymers. Polymer Engineering and Science, 1979. 19: p. 858-863.

43. Bicerano, J., ed. Computational Modeling of Polymers. 1992, Marcel Dekker: New York.

44. Zellers, E. T., Anna, D.H., Sulewski, R., Wei, X., Improved Methods for the Determination of Hansen's Solubility Parameters and the Estimation of Solvent Uptake for Lightly Crosslinked Polymers. Journal of Applied Polymer Science, 1996. 62: p. 2081-2096.

45. Zellers, E. T., Anna, D.H., Sulewski, R., Wei, X., Critical Analysis of the Graphical Determination of Hansen's Solubility Parameters for Lightly Crosslinked Polymers. Journal of Applied Polymer Science, 1996. 62: p. 20692080 .

46. Bellenger, V., Kaltenecker-Commercon, J., Verdu, J., Interactions of solvents with poly(methyl methacrylate). Polymer, 1997. 38: p. 4175-4184.

47. Fedors, R. F., A Method for Estimating Both the Solubility Parameters and the Molar Volumes of Liquids. Polymer Engineering and Science, 1974. 14: p. 147154.

48. Pascault, J., Sautereau, H., Verdu, J., Williams, R.J.J., Thermosetting Polymers. 2002, New York: Marcel Dekker.

49. Lee, C. J., Correlations of elastic modulus, cohesive energy density, and heat capacity jump of glassy polymers. Polymer Engineering and Science, 1987. 27: p. 1015-1017.

50. Lesser, A. J., Calzia, K.J., Molecular Parameters Governing the Yield Response of Epoxy-Based Glassy Networks. Journal of Polymer Science: Part B: Polymers Physics, 2004. 42: p. 2050-2056. 
51. Gallardo, A., San Roman, J., Effect of Large Polar Side Groups on the Glass Transition Temperature of Acrylic Copolymers. Macromolecules, 1993. 26: p. 3681-3686.

52. Seymour, R. B., Carraher, C.E., Structure-Property Relationships in Polymers. 1984, New York: Plenum Press.

53. Crawford, E., Lesser, A.J,, The Effect of Network Architecture on the Thermal and Mechanical Behavior of Epoxy Resins. Journal of Polymer Science: Part B: Polymers Physics, 1998. 36: p. 1371-1382.

54. Lou, X., Van Coppenhagen, C., Mechanical characteristics of poly(2hydroxyethyl methacrylate) hydrogels crosslinked with various difunctional compounds. Polymer International, 2001. 50: p. 319-325.

55. Kong, H. J., Wong, E. , Mooney, D.J., Independent control of rigidity and toughness of polymeric hydrogels. Macromolecules, 2003. 36(12): p. 4582-4588.

56. Senyurt, A. F., et.al., Ternary Thiol-Ene/Acrylate Photopolymers: Effect of Acrylate Structure on Mechanical Properties. Macromolecules, 2007. 40(14): p. 4901-4909.

57. Timmer, M. D., Ambrose, C.G., Mikos, A.G., Evaluation of thermal- and photocrosslinked biodegradable poly(propylene fumarate)-based networks. Journal of Biomedical Materials Research Part A, 2003. 66A: p. 811-818.

58. Ward, I. M., Mechanical Properties of Solid Polymers. 1971, New York: WileyInterscience. 